\title{
Photovoltaic Translation Equations: A New Approach \\ Final Subcontract Report
}

A. J. Anderson

Sunset Technology

Highlands Ranch, Colorado

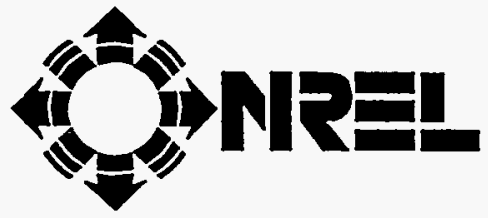

National Renewable Energy Laboratory 1617 Cole Boulevard

Golden, Colorado 80401-3393

A national laboratory of the U.S. Department of Energy Managed by Midwest Research Institute for the U.S. Department of Energy under Contract No. DE-AC36-83CH10093 



\section{Photovoltaic Translation Equations: A New Approach}

\section{Final Subcontract Report}

A. J. Anderson

Sunset Technology

Highlands Ranch, Colorado

NREL technical monitor: L. Mrig

National Renewable Energy Laboratory 1617 Cole Boulevard Golden, Colorado 80401-3393

A national laboratory of the U.S. Department of Energy Managed by Midwest Research Institute for the U.S. Department of Energy under contract No. DE-AC36-83CH10093

Prepared under Subcontract No. TAD-4-14166-01

January 1996 
This publication was reproduced from the best available camera-ready copy submitted by the subcontractor and received no editorial review at NREL.

\section{NOTICE}

This report was prepared as an account of work sponsored by an agency of the United States government. Neither the United States government nor any agency thereof, nor any of their employees, makes any warranty, express or implied, or assumes any legal liability or responsibility for the accuracy, completeness, or usefulness of any information, apparatus, product, or process disclosed, or represents that its use would not infringe privately owned rights. Reference herein to any specific commercial product, process, or service by trade name, trademark, manufacturer, or otherwise does not necessarily constitute or imply its endorsement, recommendation, or favoring by the United States govemment or any agency thereof. The views and opinions of authors expressed herein do not necessarily state or reflect those of the United States government or any agency thereof.

Available to DOE and DOE contractors from:

Office of Scientific and Technical Information (OSTI)

P.O. Box 62

Oak Ridge, TN 37831

Prices available by calling (615) $576-8401$

Available to the public from:

National Technical Information Service (NTIS)

U.S. Department of Commerce

5285 Port Royal Road

Springfield, VA 22161

(703) $487-4650$ 


\section{INTRODUCTION}

The author is grateful for the guidance provided by Richard DeBlasio and Laxmi Mrig, managers for the National Renewable Energy Laboratory. In addition, the author wishes to thank Ben Kroposki, Keith Emery, and Carl Osterwald of the NREL technical staff for their assistance in gathering test data and for providing many helpful suggestions. 
The equations and methodology presented in this report are intended to improve the accuracy and to simplify the translating of PV performance values from one set of temperature and irradiance conditions to any other set of conditions. It should be noted that many such methods are available, all varying in the degree of mathematical and physical sophistication and difficulty. The equations presented herein are intended to provide engineers and analysts with a simple yet accurate means of performing the calculations with an ordinary handheld calculator. The introduction of dimensionless temperature and irradiance coefficients further simplifies matters because these coefficients are the same (or nearly so) for a cell, module, panel, or large complex array, and in many cases are very similar for PV products of different manufacturers. 


\section{INTRODUCTION}

This work was performed under NREL Subcontract No. TAD-4-14166-01. It resulted from a need to develop a better method for predicting the performance of photovoltaic devices over a wide range of temperature and irradiance conditions. Frequently such performance is only known at one condition, and the need to extrapolate these results to some other set of conditions is essential. The most commonly used method of translating PV performance from one condition to another was difficult to use and was found to produce poor results at low irradiance levels. Because the most frequently occurring irradiance conditions are either very high (900 to 1000 $\mathrm{W} / \mathrm{m}^{2}$ ) or very low $\left(200 \text { to } 300 \mathrm{~W} / \mathrm{m}^{2}\right)^{\star}$, the translation equations need to be valid over a wide range of conditions to be useful.

Some initial work on this subject was performed in collaboration with NREL personnel participating on the IEEE-SCC 21 PV standards committee. During this work, a test program was conducted that revealed the inaccuracies of the then-current methods. This, in turn, led to the support of this new method by NREL. It should be mentioned that work is continuing on the development of new, improved equations. These will be even simpler to use, they will account for changes in fill factor, and they will be expanded to include equations for the current and voltage at the maximum power point $\left(I_{\max }\right.$ and $\left.V_{\max }\right)$.

\footnotetext{
* Low irradiance occurs very frequently as a result of overcast conditions, intermittent cloud passage, and every day at sunrise and sunset.
} 


\section{Clause}

1 SUMMARY

$2 \quad$ HISTORY

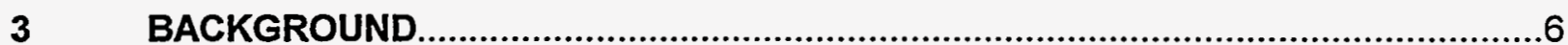

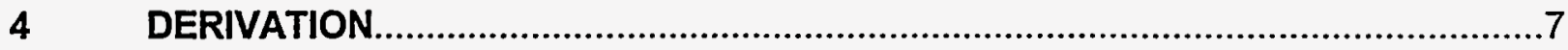

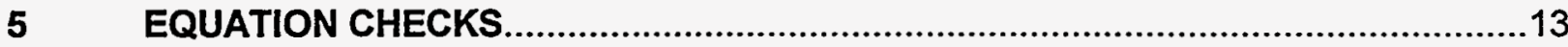

$6 \quad$ PROCESS

Appendixes

$1 \quad$ APPENDIX A

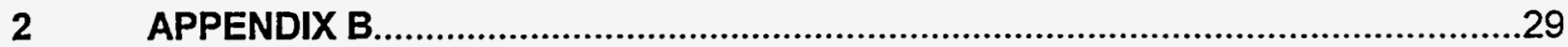

$3 \quad$ APPENDIX C 


\section{PHOTOVOLTAIC TRANSLATION EQUATIONS A NEW APPROACH}

\section{Summary}

New equations were developed for the purpose of evaluating the performance of photovoltaic cells, modules, panels, and arrays. These equations enable the performance values determined at one condition of temperature and irradiance to be translated to any other condition of temperature and irradiance. The equations were developed to satisfy the following goals:

- The equations should more accurately translate the short-circuit current, $I_{s c}$ and the open-circuit voltage, $V_{o c}$. In particular, the influence of irradiance on $V_{o c}$ should be more accurately treated.

- The equations should more accurately and more simply translate the I-V curve data point pairs, $I_{i}$ and $V_{i}$.

- The equations should be based on the use of dimensionless coefficients such that $\alpha$ and $\beta$ have units of ${ }^{\circ} \mathrm{C}^{-1}$, and not, for example, amps $/{ }^{\circ} \mathrm{C}$ or volts ${ }^{\circ} \mathrm{C}$.

- An equation should be developed for translating the maximum power without involving the translation of $I_{\mathrm{sc}}, \mathrm{V}_{\mathrm{oc}}$, or any I-V data pairs.

All of these goals were successfully met. The data which is presented in this report shows good agreement between the analytical predictions made with the new equations versus actual test measurements, and superior performance when compared to the current translation equations. The agreement is usually within $5 \%$, which is very good considering that the data used undoubtedly contain some measurement errors, and that the translations were made over an extremely wide range of temperature and irradiance conditions:

- For device temperatures from $25^{\circ} \mathrm{C}$ to $75^{\circ} \mathrm{C}$

- For irradiance levels from 100 to $1000 \mathrm{~W} / \mathrm{m}^{2}$

In spite of the success of this program, further evaluation of these equations is necessary. Additional checks need to be made for other PV technologies, for larger modules, and for modules that have less-than-perfect performance characteristics, such as shunts. Also, some improvements to the equations themselves are possible. The equations presented are a compromise between simplicity, accuracy, and convenience.

A comparison between the currently used equations and the new equations is presented on Table 1. 


\section{Table 1}

COMPARISON OF THE ORIGINAL (JPL) TRANSLATION EQUATIONS AND THE NEW EQUATIONS

\begin{tabular}{|c|c|}
\hline OLD EQUATIONS & NEW EQUATIONS \\
\hline 1). $\begin{aligned} \quad I_{\mathrm{sc} 2} & =I_{\mathrm{sc} 1}+I_{\mathrm{sc} 1} \cdot\left(\frac{E_{2}}{E_{1}}-1\right)+\alpha \cdot\left(T_{2} \cdot T_{1}\right) \\
\Delta I_{\mathrm{sc}} & =I_{\mathrm{sc} 2}-I_{\mathrm{sc} 1}\end{aligned}$ & 1). $\quad I_{S C 2}=\frac{I_{S C 1}}{\left[1+\alpha \cdot\left(T_{1}-T_{2}\right)\right] \cdot\left[E_{1} / E_{2}\right]}$ \\
\hline No equation available for direct computation of $V_{\text {oc2 }}$ & 2). $V_{O C 2}=\frac{V_{O C 1}}{\left[1+\beta \cdot\left(T_{1}-T_{2}\right)\right] \cdot\left[1+\delta \cdot \ln \left(E_{1} / E_{2}\right)\right]}$ \\
\hline $\begin{array}{l}\text { 3). I-V Data Pair Translation: } \\
\text { A. } V_{2}=V_{1}-\beta \cdot\left(T_{2}-T_{1}\right)-\Delta I_{s c} \cdot R_{s}-k \cdot\left(T_{2}-T_{1}\right) \cdot I_{2} \\
\text { B. } \quad I_{2}=I_{1}+\Delta I_{s c}\end{array}$ & $\begin{array}{l}\text { 3). I-V Data Pair Translation: } \\
\qquad \begin{array}{l}\text { A. } V_{2}=V_{1} \cdot\left(\frac{V_{O C 2}}{V_{O C 1}}\right) \\
\text { B. } \quad I_{2}=I_{1} \cdot\left(\frac{I_{\mathrm{sc} 2}}{I_{s c 1}}\right)\end{array}\end{array}$ \\
\hline 4). $\quad P_{2}=I_{2} \cdot V_{2}$ & 4). $\quad P_{2}=I_{2} \cdot V_{2}$ \\
\hline 5). No equations available for $P_{\max }$ & 5). $\begin{aligned} P_{\text {MAX } 2} & =P_{\text {MAX } 1} \cdot\left(\frac{I_{S C 2}}{I_{S C 1}}\right) \cdot\left(\frac{V_{O C 2}}{V_{O C 1}}\right) \text {, or } \\
P_{\text {MAX } 2} & =\frac{P_{\text {MAX1 } 1} \cdot\left(E_{2} / E_{1}\right)}{\left[1+\gamma \cdot\left(T_{1}-T_{2}\right)\right] \cdot\left[1+\delta \cdot \ln \left(E_{1} / E_{2}\right)\right]}\end{aligned}$ \\
\hline
\end{tabular}




\section{History}

The history of the translation equations currently used throughout the world dates back to an IEEE paper ${ }^{1}$ by J. D. Sandstrom of the Jet Propulsion Laboratory (JPL) published in 1967. This work was performed in conjunction with Mars and Venus space mission analysis. The paper presents some very good correlative results between experimental measurements and the resultant analytical predictions over a cell temperature range from $20{ }^{\circ} \mathrm{C}$ to $130{ }^{\circ} \mathrm{C}$, and over an irradiance range of $500 \mathrm{~W} / \mathrm{m}^{2}$ to $3000 \mathrm{~W} / \mathrm{m}^{2}$. The equations presented in this 1967 paper are the same as those used today:
1) $\Delta \mathrm{l}_{\mathrm{SC}}=\mathrm{I}_{\mathrm{SC} 1} \cdot\left(\frac{\mathrm{E}_{2}}{\mathrm{E}_{1}}-1\right)+\alpha \cdot\left(\mathrm{T}_{2} \cdot \mathrm{T}_{1}\right)$
2) $I_{2}=I_{1}+\Delta I_{s c}$
3) $V_{2}=V_{1}-\beta \cdot\left(T_{2}-T_{1}\right)-\Delta I_{s c} \cdot R_{s}-k \cdot\left(T_{2}-T_{1}\right) \cdot I_{2}$
4) $P_{2}=I_{2} \cdot V_{2}$
where $E=$ irradiance, $\mathrm{W} / \mathrm{m}^{2}$
$1=$ current, amps
$I_{\text {sc }}=$ short circuit current, amps
$\mathrm{V}=$ voltage, volts
$\mathrm{T}=$ cell temperature, ${ }^{\circ} \mathrm{C}$
$\alpha=$ current coefficient, amps $/{ }^{\circ} \mathrm{C}$
$\beta=$ voltage coefficient, volts $/{ }^{\circ} \mathrm{C}$
$\mathrm{R}_{\mathrm{s}}=$ module series resistance ohms
$P=$ power, watts
$k=$ curve correction factor

1 and $2=$ conditions at a specific irradiance level and cell temperature.

These equations have been in widespread use for nearly 30 years and are employed in ASTM Standard E1036 and in IEC Standard 891. Almost all of the field performance measurements, all system sizings, and all of the PV manufacturer's factory data analysis are based on these equations.

\footnotetext{
I"A Method for Predicting Solar Cell Current-Voltage Curve Characteristics as a Function of Incident Solar Intensity and Cell Temperature", J. D. Sandstrom, JPL, Conference Record of the Sixth Photovoltaic Specialist Conference, IEEE, Cocoa Beach, Florida March 1967.
} 


\section{Background}

Interest in translation equations arose at an IEEE SCC21 meeting in San Ramon, California, on January 16, 1991. This IEEE group was working on some new versions of the Sandstrom equations using dimensionless coefficients (actually ${ }^{\circ} \mathrm{C}^{-1}$ units) for $\alpha$ and $\beta$. Module testing was conducted to check on the correctness of these new equations.

To perform this equation check, a matrix of I-V curve data was generated for a wide variety of irradiance levels, module temperatures, and PV technologies. It was found that the proposed equations did not check well with the test data. More importantly, it was found that the original Sandstrom equations did not check well with the test data either.

- The form of the equations for $\Delta \mathrm{l}_{\mathrm{sc}}$ and $\mathrm{l}_{2}$ suggests that the temperature effect on current is independent of irradiance; i.e., the term $\alpha \cdot\left(T_{2}-T_{1}\right)$ gives the same number of milliamps of change at $100 \mathrm{~W} / \mathrm{m}^{2}$ as it would at $1000 \mathrm{~W} / \mathrm{m}^{2}$ irradiance. This is incorrect; the effect is actually proportional to irradiance. Sandstrom noted this by stating that $\alpha$ is not a constant, but varies with irradiance. However, in today's usage of these equations, $\alpha$ is treated as a constant. So, the original equation of Sandstrom is correct, but the usage of it is erroneous. The problem is easily solved by modifying the current equation as follows:

$$
\text { 5). } \Delta \mathrm{I}_{\mathrm{SC}}=\mathrm{I}_{\mathrm{SC} 1} \cdot\left(\frac{\mathrm{E}_{2}}{\mathrm{E}_{1}}-1\right)+\alpha \cdot\left(\mathrm{T}_{2} \cdot \mathrm{T}_{1}\right) \cdot\left(\frac{\mathrm{E}_{2}}{\mathrm{E}_{1}}\right)
$$

- The irradiance effect on $V_{o c}$ is accounted for by the term $\Delta l_{S C} \cdot R_{S}$, and for his data (single cell with $R_{S}=0.5 \mathrm{ohm}$ ) Sandstrom found a good correlation. However, if one visualizes an experiment wherein a variable series resistor is built into a PV module and then $V_{o c}$ is measured at two different irradiance levels, it will be found that the $V_{o c}$ values measured at these two light levels are the same no matter how much the series resistance is changed. In fact, for the data presented herein, the polycrystalline module has a series resistance of $6.1 \mathrm{ohms}$, and the single crystalline module has a series resistance of $1.2 \mathrm{ohms}$, and yet they have nearly identical voltage - irradiance characteristics (neither of which matches the $\Delta \mathrm{I}_{S C} \cdot \mathrm{R}_{\mathrm{S}}$ equation). However, the $V_{\text {oc }} \mathrm{s}$ do match the following equation:

$$
\text { 6). } V_{\mathrm{OC} 2}=\frac{V_{\mathrm{OC} 1}}{\left[1+\delta \cdot \ln \left(E_{1} / E_{2}\right)\right]}
$$

Note that this equation is also completely independent of the module series resistance.

The accuracy of the Sandstrom equations can, therefore, be improved by making the two corrections discussed above. However, even better equations can be derived. 


\section{Derivations}

The modified Sandstrom equations still rely on $\alpha$ and $\beta$ coefficients that carry dimensions, amps $/{ }^{\circ} \mathrm{C}$ and volts $/{ }^{\circ} \mathrm{C}$. This means that anytime a manufacturer "rearranges" the circuit by changing cell size, changing the number of cells in a module, or by changing the series-parallel cell arrangement in a module, these coefficients change. Also, if a user has more than one module, the coefficients are different depending on whether he connects the modules in series, in parallel, or in a combination series-parallel arrangement. It was found that much of the time the wrong coefficients were being used. So, modified Sandstrom equations were developed based on "neutered" coefficients because these are independent of the configuration. When used this was they are constants.

When the $\alpha$ and $\beta$ coefficients have dimensions of amps $/{ }^{\circ} \mathrm{C}$ and volts ${ }^{\circ} \mathrm{C}$, they are defined as:

$$
\begin{aligned}
& \text { 7). } \alpha=\frac{I_{S C 2}-I_{S C 1}}{T_{2}-T_{1}} \\
& \text { 8). } \quad \beta=\frac{V_{O C 2}-V_{O C 1}}{T_{2}-T_{1}}
\end{aligned}
$$

Transposing these and solving for $I_{\mathrm{sc} 2}$ and $V_{\mathrm{oc} 2}$ gives the following:

9). $\quad \mathrm{ISC} 2_{\mathrm{SC} 1}=\mathrm{I}_{\mathrm{SC}}+\alpha \cdot\left(\mathrm{T}_{2}-\mathrm{T}_{1}\right)$

10). $V_{O C 2}=V_{O C 1}+\beta \cdot\left(T_{2}-T_{1}\right)$

But when the coefficients are "neutered", they are defined as follows:

$$
\begin{aligned}
& \text { 11). } \quad \alpha=\frac{\left(I_{\mathrm{SC}_{2}}-I_{\mathrm{SC} 1}\right)}{\mathrm{ISC2}_{\mathrm{SC}} \cdot\left(\mathrm{T}_{2}-\mathrm{T}_{1}\right)} \\
& \text { 12). } \quad \beta=\frac{\left(\mathrm{V}_{\mathrm{OC} 2}-\mathrm{V}_{\mathrm{OC} 1}\right)}{\mathrm{V}_{\mathrm{OC} 2} \cdot\left(\mathrm{T}_{2}-\mathrm{T}_{1}\right)}
\end{aligned}
$$

These equations transpose to the following:

13).

$$
I_{S C 2}=\frac{I_{S C 1}}{\left[1+\alpha \cdot\left(T_{1}-T_{2}\right)\right]}
$$

14). $\quad V_{O C 2}=\frac{V_{O C 1}}{\left[1+\beta \cdot\left(T_{1}-T_{2}\right)\right]}$ 
And, if we now account for any irradiance changes, these equations become:

15).

$$
I_{S C 2}=\frac{I_{S C 1}}{\left[1+\alpha \cdot\left(T_{1}-T_{2}\right)\right] \cdot\left[E_{1} / E_{2}\right]}
$$

16).

$$
V_{O C 2}=\frac{V_{O C 1}}{\left[1+\beta \cdot\left(T_{1}-T_{2}\right)\right] \cdot\left[1+\delta \cdot \ln \left(E_{1} / E_{2}\right)\right]}
$$

These are the new equations for $\mathrm{I}_{\mathrm{sc}}$ and $\mathrm{V}_{\mathrm{oc}}$ that are being presented and evaluated. These equations incorporate the following features and characteristics:

- The form of the $I_{s c}$ equation has been changed such that the irradiance level "magnifies" or "shrinks" the temperature correction effect.

- A $V_{o c}$ equation has been derived that accounts for the irradiance using a logarithmic term rather than as a series resistance effect.

- The coefficients $\alpha$ and $\beta$ have been "neutered," and the equation form has been altered to account for this new definition of $\alpha$ and $\beta$.

The next major goal pursued was developing a better method for translating I-V curve data points. The Sandstrom equations were lengthy and difficult to use and relied upon the knowledge of the module (or panel, or array) series resistance and on another mysterious constant, $k$, known as the curve correction factor. Another bothersome point was the unusual translation of points; $I_{s c 1}$ did not translate to $I_{s c 2}$ and $V_{o c 1}$ did not translate to $V_{o c 2}$. A new idea was tried based on translating I-V data from condition 1 to condition 2 along lines of constant load resistance. This would result in $I_{\mathrm{sc} 1}$ translating to $I_{\mathrm{sc} 2}$ along the line $R=0$ ohms, and, $V_{\text {oc1 }}$ would translate to $V_{o c 2}$ along the line $R=\infty$. The $1-V$ point pairs in between would similarly translate along lines of constant resistance with values of $R=V_{i} / I_{i}$.

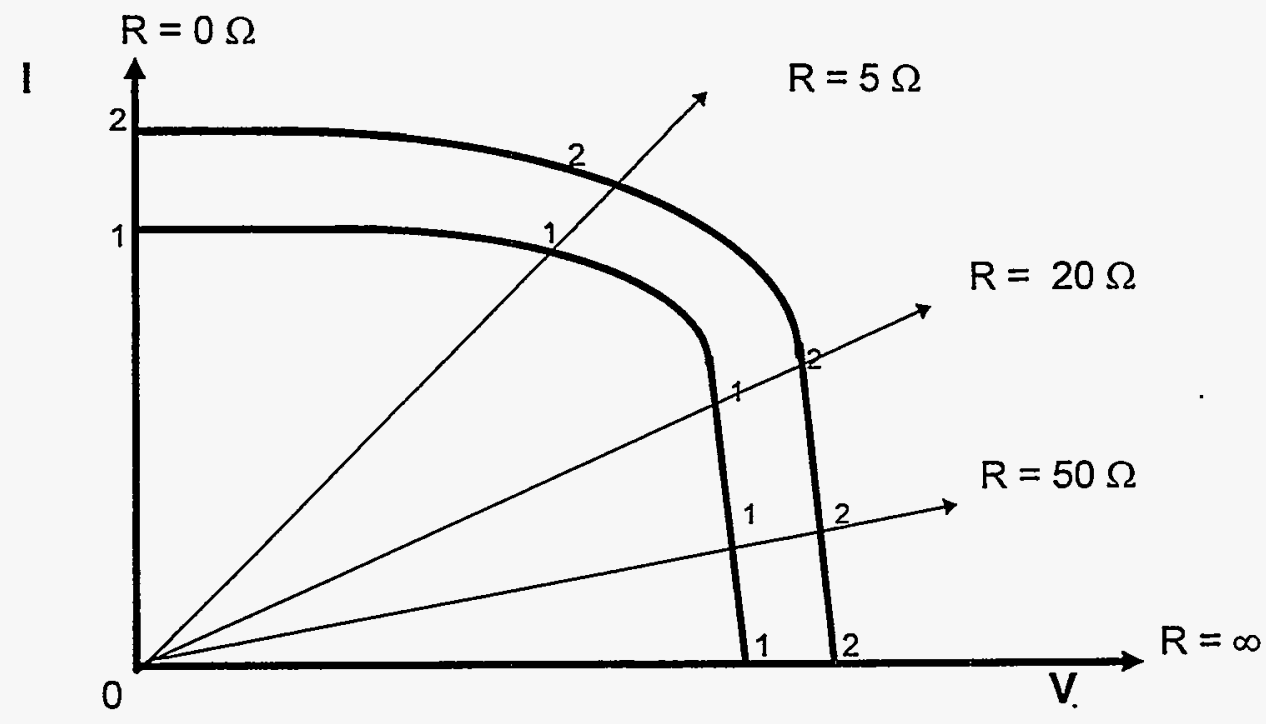


This idea remained dormant until July 4, 1993 when the analysis was resumed. The idea of translating along lines of constant load resistance was studied, but was never perfected. In the midst of a very lengthy derivation of the constant load resistance translation equations, a new concept evolved. A set of equations that satisfied the goal that $I_{S c 1}$ would translate to $I_{s c 2}$, and $V_{o c 1}$ would translate to $V_{o c 2}$ was simply to multiply each current point by the Isc ratio, and to multiply each voltage point by the $V_{O C}$ ratio :

17). $\mathrm{I}_{2}=\mathrm{l}_{1} \cdot\left(\frac{\mathrm{ISC}_{\mathrm{SC}}}{\mathrm{ISC}_{\mathrm{SC}}}\right)$
18). $\quad \mathrm{V}_{2}=\mathrm{V}_{1} \cdot\left(\frac{\mathrm{V}_{\mathrm{OC2} 2}}{\mathrm{~V}_{\mathrm{OC} 1}}\right)$

19). $\quad P_{2}=I_{2} \cdot V_{2}$

These equations were given a preliminary check by translating approximately ten I-V curve data sets, and then checking these against actual test data. The translations were nearly perfect.

With equations 15), 16), 17), and 18) verified, it was now a simple matter to theorize a new translation equation for the maximum power, $P_{\max }$. Because each of the $I_{1} \times V_{1}$ and $I_{2} \times V_{2}$ products represents a power point, if equations 17) and 18) are multiplied together, a very simple equation for translating any power point (including $P_{\max }$ ) is obtained:

$$
\text { 20). } \quad P_{M A X 2}=P_{M A X 1} \cdot\left(\frac{I_{S C 2}}{I_{S C 1}}\right) \cdot\left(\frac{V_{O C 2}}{V_{O C 1}}\right)
$$

Frequently, $I_{s c}$ and $V_{\text {oc }}$ values are not known (such as would occur with an inverter operating at maximum power). Therefore, a power translation equation based on temperature and irradiance measurements is also desirable. Substituting 15) and 16) into 20) gives:

21).

$$
P_{2}=\frac{P_{1} \cdot\left(E_{2} / E_{1}\right)}{\left[1+\alpha \cdot\left(T_{1}-T_{2}\right)\right]\left[1+\beta\left(T_{1}-T_{2}\right)\right]\left[1+\delta \cdot \ln \left(E_{1} / E_{2}\right)\right]}
$$

To keep things simple, assume for the moment that $T_{1}=T_{2}$, so 21) becomes:

$$
\text { 22). } \quad P_{2}=\frac{P_{1} \cdot\left(E_{2} / E_{1}\right)}{\left[1+\delta \cdot \ln \left(E_{1} / E_{2}\right)\right]}
$$


One might be tempted to simplify this by assuming that $\delta \cdot \ln \left(E_{1} / E_{2}\right) \approx 0$. However, this will cause significant errors. This term is very important, and it helps explain several puzzles:

- For small changes in irradiance (at any irradiance level, low or high), the maximum power seems to be directly proportional to irradiance. The reason is that the term In $\left(E_{1} / E_{2}\right)$ is small when $\left(E_{1} / E_{2}\right) \approx 1$ because $\ln (1)=0$ and the term $\left[1+\delta \cdot \ln \left(E_{1} / E_{2}\right)\right] \approx 1$. Therefore, $P_{2} \approx P_{1} \cdot\left(E_{1} / E_{2}\right)$.

- A plot of maximum power versus irradiance $\left(P_{\max }\right.$ vs $E$ ) is usually very linear, but does not appear to pass through the 0,0 point on the plot as it should. The reason for this is because the term $\left[1+\delta \cdot \ln \left(E_{1} / E_{2}\right)\right]$ is normally small until $E_{2}$ gets very close to 0 . Then, as $E_{2} \rightarrow 0,\left[1+\delta \cdot \ln \left(E_{1} / E_{2}\right)\right] \rightarrow \infty$ and $P_{2} \rightarrow 0$.

Finally, between equations 21) and 22) it was assumed that $T_{1}=T_{2}$ to simplify the derivation of 24). We now need to re-insert the temperature effect. This is best accomplished by introducing a new power-temperature coefficient, $\gamma$, which is defined as follows:

$$
\text { 23). } \quad \gamma=\frac{P_{\text {MAX2 }}-P_{\text {MAX1 }}}{P_{\text {MAX2 }}\left(T_{2}-T_{1}\right)}
$$

When this is transposed and combined with equation 22), the final equation for $P_{\max }$ is obtained:

$$
\text { 24). } \quad \mathrm{P}_{\mathrm{MAX} 2}=\frac{\mathrm{P}_{\mathrm{MAX} 1} \cdot\left(\mathrm{E}_{2} / \mathrm{E}_{1}\right)}{\left[1+\gamma \cdot\left(\mathrm{T}_{1}-\mathrm{T}_{2}\right)\right] \cdot\left[1+\delta \cdot \ln \left(\mathrm{E}_{1} / \mathrm{E}_{2}\right)\right]}
$$

Equations for the maximum power point current and voltage, $I_{\max }$ and $V_{\max }$ translation are also being developed, but have not been adequately checked against test data at this point. However, equations for fill factor $\left(F F_{1}\right.$ and $\left.F F_{2}\right)$ can be stated by definition:

$$
\begin{aligned}
& \text { 25). } \quad \mathrm{FF}_{1}=\frac{\mathrm{P}_{\mathrm{MAX} 1}}{\mathrm{I}_{\mathrm{SC} 1} \cdot \mathrm{V}_{\mathrm{OC} 1}} \\
& \text { 26). } \quad \mathrm{FF}_{2}=\frac{\mathrm{P}_{\mathrm{MAX} 2}}{\mathrm{I}_{\mathrm{SC} 2} \cdot \mathrm{V}_{\mathrm{OC} 2}}
\end{aligned}
$$


One final point needs to be discussed. The astute reader has probably noticed that when the coefficients $\alpha, \beta, \gamma$, and $\delta$ were non-dimensionalized, the neutering denominator was selected as the condition 2 value; e.g., see equations 11 ), 12) and 23). It might be logically asked: "Why was this done, and what would have happened if condition 1 had been selected as the neutering denominator?" To answer this question, consider the following derivation using $V_{o c}$ as the example.

Because the data correction is normally made from some hot field condition $\left(V_{\text {oc1 }}, T_{1}\right)$ to the standard condition $\left(\mathrm{V}_{\mathrm{oc} 2}, \mathrm{~T}_{2}=25^{\circ} \mathrm{C}\right)$, the "neutering denominator" could logically be the STC value which in this case is $V_{\text {oc2 }}$. Hence, the "neutered $\beta^{\prime \prime}$ is defined as:

$$
\text { 27). } \quad \beta=\frac{\mathrm{V}_{\mathrm{OC2}}-\mathrm{V}_{\mathrm{OC} 1}}{\mathrm{~V}_{\mathrm{OC2} 2} \cdot\left(\mathrm{T}_{2}-\mathrm{T}_{1}\right)}
$$

Rearranging this equation results in the equation for voltage using the "neutered $\beta$ ":

$$
\text { 28). } \quad V_{O C 2}=\frac{V_{O C 1}}{\left[1+\beta\left(T_{1}-T_{2}\right)\right]}
$$

Now, one might argue that this equation is good for correcting hot field test data back to STC, but what if the translation were made the other way, from STC ( $I_{s c 1}, V_{\text {oc1 } 1}, P_{\max 1}$ $\left., T_{1}, E_{1}\right)$ to the hot field condition $\left(I_{s c 2}, V_{o c 2}, P_{\max 2}, T_{2}, E_{2}\right)$. In this case, wouldn't a different equation 28) evolve? Because the "neutering denominator" used to calculate $\beta$ was $V_{o c}$ at $25^{\circ} \mathrm{C}$, this would now be called $V_{o c 1}$ as a result of the reverse translation:

$$
\text { 29). } \quad \beta=\frac{V_{O C 2}-V_{O C 1}}{V_{O C 1}\left(T_{2}-T_{1}\right)}
$$

Rearranging and solving for $\mathrm{V}_{\mathrm{OC} 2}$ gives what appears to be a different equation:

30). $\quad V_{o c 2}=V_{o c 1} \cdot\left[1+\beta \cdot\left(T_{2}-T_{1}\right)\right]$

So, one might think that the basic equation 28 ) is only valid for a one-way translation, and equation 30 ) is needed for translating the other way but, it will now be shown that equations 28) and 30 ) are nearly identical. Consider an example wherein $\beta=-0.004$ ${ }^{\circ} \mathrm{C}^{-1}, \mathrm{~V}_{\mathrm{oc1}}=20.0$ volts, $\mathrm{T}_{1}=25^{\circ} \mathrm{C}$ and $\mathrm{T}_{2}=50^{\circ} \mathrm{C}$ :

$$
\text { 28). } \begin{aligned}
\quad V_{O C 2} & =\frac{V_{O C 1}}{\left[1+\beta\left(T_{1}-T_{2}\right)\right]} \\
V_{O C 2} & =\frac{20}{1-0.004(25-50)}=18.18 \text { volts }
\end{aligned}
$$




$$
\text { 30). } \begin{aligned}
\quad V_{o c 2} & =V_{o c 1} \cdot\left[1+\beta \cdot\left(T_{2}-T_{1}\right)\right] \\
V_{o c 2} & =20[1-0.004(50-25)]=18.00 \text { volts }
\end{aligned}
$$

So, the error is very small (1\%), and the same equation can be used for correcting either from STC or to STC, or actually, between any two points. The bottom line is that the neutered coefficients and the resultant equations are not exact (they may in fact not be as accurate as their non-neutered counterparts), but they do give a very good approximation, and they offer one outstanding benefit .... the neutered coefficients are constant .... they do not change (significantly) for a cell, a series module, a seriesparallel module, a panel, or an array.

The remaining question is: "which numerical value of $V_{o c}$ should be used to "neuter" the voltage versus temperature slope?" Because this equation is for general use between any two conditions (and STC may not be one of them) the best choice is probably a mid-range value of $V_{o c}$ for the irradiance and temperature range of interest. 


\section{Equation Check}

A matrix of data was obtained on three modules: a Siemens single-crystal silicon module, a Siemens amorphous thin-film silicon module, and a Solarex polycrystalline silicon module. This matrix was obtained by warming the module to the desired temperature and maintaining it at that temperature by means of a flat, heater blanket located under the module. The entire module and heater assembly was installed in a solar simulator. When the desired temperature was reached, I-V curves were taken with various porous filters covering the module. For the test series described in this report, very thin paper tissues were employed for filtration. These are actually full of small openings, so the light that penetrates was not spectrally altered. For each of the six temperature conditions $\left(25,35,45,55,65\right.$ and $\left.75^{\circ} \mathrm{C}\right)$, a total of ten different filter layers were used $(0,1,2 \ldots .9$ layers). So, a $6 \times 10$ matrix (temperature $x$ number of filters) was obtained. The filter layers were selected to give irradiance levels from approximately $100 \mathrm{~W} / \mathrm{m}^{2}$ to $1000 \mathrm{~W} / \mathrm{m}^{2}$.

Although it may seem like a complex task to obtain the required $60 \mathrm{I}-\mathrm{V}$ curves for each module, it was actually very simple and was easily accomplished in about 3-4 hours for each of the 3 modules. Tables 1,2 , and 3 (see Appendix A) present a summary of this matrix data $\left(\mathrm{I}_{\mathrm{sc}}, \mathrm{V}_{\mathrm{oc}}\right.$, and $\left.\mathrm{P}_{\max }\right)$.

Using the summary data from Tables 1,2 , and 3 , the coefficients $\alpha, \beta, \gamma$, and $\delta$ were determined as follows for the three different $P V$ technologies.

$\begin{array}{llll}\begin{array}{c}\text { Equation } \\ \text { Coefficient }\end{array} & \begin{array}{l}\text { Single- } \\ \text { Crystal }\end{array} & \begin{array}{c}\text { Poly- } \\ \text { Crystalline }\end{array} & \begin{array}{c}\text { Thin-Film } \\ \text { Silicon }\end{array} \\ \alpha,{ }^{\circ} \mathrm{C}^{-1} & 0.00095 & 0.00090 & 0.00036 \\ \beta,{ }^{\circ} \mathrm{C}^{-1} & -0.0031 & -0.0040 & -0.0028 \\ \gamma,{ }^{\circ} \mathrm{C}^{-1} & -0.0033 & -0.0047 & -0.0020 \\ \delta & 0.085 & 0.110 & 0.063\end{array}$

Note that the coefficient, $\delta$, is inherently dimensionless because of the logarithmic nature of the equation in which it is used. 
The equations in which these coefficients are used are reiterated as follows:

$$
\begin{aligned}
& I_{S C 2}=\frac{I_{S C 1}}{\left[1+\alpha \cdot\left(T_{1}-T_{2}\right)\right] \cdot\left[\left(E_{1} / E_{2}\right)\right]} \\
& V_{O C 2}=\frac{V_{O C 1}}{\left[1+\beta \cdot\left(T_{1}-T_{2}\right)\right] \cdot\left[1+\delta \cdot \lambda n\left(E_{1} / E_{2}\right)\right]} \\
& P_{M A X 2}=P_{M A X 1} \cdot\left(\frac{I_{S C 2}}{I_{S C 1}}\right) \cdot\left(\frac{V_{O C 2}}{V_{O C 1}}\right), \text { or } \\
& P_{M A X 2}=\frac{P_{M A X 1} \cdot\left(E_{2} / E_{1}\right)}{\left[1+\gamma \cdot\left(T_{1}-T_{2}\right)\right] \cdot\left[1+\delta \cdot \ln \left(E_{1} / E_{2}\right)\right]} \\
& F F_{2}=\frac{P_{M A X 2}}{I_{S C 2} \cdot V_{O C 2}}
\end{aligned}
$$

These equations translate $I_{s c}, V_{O c}$, and $P_{\text {MAX }}$ from the measured value at an irradiance level of $E_{1}$, and a module temperature of $T_{1}$, to a new value at an irradiance level of $E_{2}$, and a module temperature of $T_{2}$. The equations are valid for translation between any two conditions.

To check on the validity of the equations, analytical calculations were performed using these coefficients and equations to predict each of the 60 matrix entries using the single STC value as a starting point. Tables 4,5 , and 6 present these analytically derived matrices (see Appendix A). In other words, using a single STC value for $I_{\mathrm{sc}}, V_{\mathrm{OC}}$, and $\mathrm{P}_{\mathrm{MAX}}$, the other 59 entries in each matrix were analytically predicted. The comparison between these analytical predictions and actual measurements can be made by comparing Tables 1, 2, and 3 (actual) to Tables 4, 5, and 6 (predicted). It will be noted that good agreement exists between the analytical predictions and the actual measurements for all three PV technologies.

These table-to-table comparisons are provided on the following pages (with the actual vs predicted values shown on the same sheet). 
After translating $I_{s c}$ and $V_{o c}$ using the above equations, the complete I-V curve can next be translated by using the following equations for each I-V pair.

$$
\begin{aligned}
& I_{2}=I_{1} \cdot\left(\frac{I_{S C 2}}{I_{S C 1}}\right) \quad \text { for each current point on the I-V curve, and } \\
& V_{2}=V_{1} \cdot\left(\frac{V_{O C 2}}{V_{O C 1}}\right) \quad \text { for each corresponding voltage point }
\end{aligned}
$$

A total of $114 \mathrm{I}-\mathrm{V}$ curves were translated and were then plotted on the actual measured I-V curve plots for this translated condition. These comparative plots are presented in Appendix B. In these examples, a reverse translation is demonstrated: the I-V curves at STC are translated to various non-standard temperature and irradiance conditions.

The Appendix B results show that these new translation equations demonstrate good agreement for thin film silicon, polycrystalline, and single-crystal modules.

The new equations were next checked against the ASTM E1036 standard equations. A total of $54 \mathrm{I}-\mathrm{V}$ curves were translated using the ASTM E1036 standard equations, 18 each for singlecrystal, polycrystalline, and thin-film silicon modules. Within the group of 18 translations for each technology were a matrix of $\mathrm{I}-\mathrm{V}$ curve data for three modules temperatures $(25,45$ and 65 ${ }^{\circ} \mathrm{C}$ ) and six irradiance levels (approximately $1000,650,450,350,225$, and $125 \mathrm{~W} / \mathrm{m}^{2}$ ). For each technology, 13-14 I-V data pairs were chosen from the STC I-V curve, and then a reverse translation was performed, wherein each data pair was translated to a non-standard temperature and irradiance data pair. The new equations were also used to make comparative translations. With the new equations, no modification or algebraic manipulation was necessary to accomplish the reverse translation; i.e., the equations work properly between any two conditions because "dimensionless" coefficients (actually, units of ${ }^{\circ} \mathrm{C}^{-1}$ ) are used. For the ASTM E1036 reverse translation, modified equations had to be derived because even though the current coefficient, $\alpha$, is "dimensionless," the voltage coefficient, $\beta$, is not and carries units of volts $/{ }^{\circ} \mathrm{C}$. 
Appendix $\mathrm{C}$ presents the graphical results for the $54 \mathrm{I}-\mathrm{V}$ curves that were translated using both the new equations and the standard ASTM E1036 equations. These analytical results are shown plotted against the actual test I-V curve traces. The following conclusions can be drawn from these plots and the analytical operations:

- At $1000 \mathrm{~W} / \mathrm{m}^{2}$ irradiance, the ASTM standard equations and the new equations give nearly identical I-V curve translations. Agreement with the actual measured I-V curves is excellent for all of the module temperatures and for all three technologies.

- As irradiance is reduced, the ASTM E1036 equations become increasingly erroneous. For example, the voltage error for the three technologies and the three module temperatures averages about $6 \%$ at $450 \mathrm{~W} / \mathrm{m}^{2}$, and about $15 \%$ at $125 \mathrm{~W} / \mathrm{m}^{2}$.

- As irradiance is reduced, the new equations remain very accurate. For example, the voltage error for the three technologies and the three module temperatures averages about $2 \%$ at $450 \mathrm{~W} / \mathrm{m}^{2}$, and about $5 \%$ at $125 \mathrm{~W} / \mathrm{m}^{2}$.

- The ASTM E1036 standard erroneously treats irradiance and temperature effects on current as additive effects, whereas they are actually multiplicative effects. This results in an erroneous translation of $\mathrm{I}_{\mathrm{SC}}$, but the error is small.

- The ASTM E1036 standard equations contain at least three typographical equation errors, and possibly six sign errors. The obvious typographical errors were corrected before the comparative analysis was performed. The remaining sign errors (if they are in fact actually errors) are believed to have only a small effect on the results, and were not corrected.

- The ASTM E1036 standard equations are very complex and difficult to use, particularly when hand calculation methods are employed.

- The new equations are very easy to use, and are well-suited to hand calculation methods.

- The new equations can be used to translate between any two conditions; STC need not be one of these conditions.

- The new equations are based on neutered coefficients, and hence, the same coefficients and equations can be used for single cells, series-connected modules, parallel-connected modules, series/parallel-connected modules, panels, and even entire arrays with the modules connected in any manner. 


\section{Process}

The complete process for gathering data, evaluating it, computing coefficients, and, finally, actually using the coefficients, is summarized as follows:

STEP 1: A matrix of data is first derived. This matrix is obtained by warming the module to the desired temperature and maintaining it at that temperature by means of a heater blanket located under the module. The entire module and heater assembly are installed in a solar simulator. When the desired temperature is reached, I-V curves are taken with various porous filters covering the module. Screens or thin paper tissues can be employed as filters. These have many small openings, so the light that penetrates will not be spectrally altered. For each temperature condition $\left(25,45\right.$ and $65^{\circ} \mathrm{C}$ as a minimum), at least three different filter layers should used. These filters should give four irradiance levels from approximately $250 \mathrm{~W} / \mathrm{m}^{2}$ to $1000 \mathrm{~W} / \mathrm{m}^{2}(0,1,2$ and 3 layers). So, a minimum $3 \times 4$ matrix (temperature $x$ number of filters) will be obtained resulting in 12 data sets for the module.

Although it may seem like a complex task to obtain the required $12 \mathrm{I}-\mathrm{V}$ curves for each module, it is actually very simple, and can be easily accomplished in about 3-4 hours for a module.

STEP 2: The I-V curve summary data is next transferred to data sheets that tabulate $I_{\text {sc }}$ , $V_{O C}$ and $P_{\max }$ as a function of module temperature and irradiance. An examination of these tabulations will sometimes reveal erroneous data that can then be discarded or corrected by re-test.

STEP 3: The irradiance for each filter set is computed using the measured values of $I_{s c}$, and assuming that the $I_{s c}$ value measured with no-filter equates to an irradiance level of $1000 \mathrm{~W} / \mathrm{m}^{2}$.

STEP 4: A plot of $V_{o c}$ vs module temperature is made, and a best-fit line (least squares fit or eyeball) is made through the data points. Because $V_{o c}$ is (nearly always) linear with temperature, discrepancies between the data points and the line can be used to deduce the "true" module temperature. Again, an examination of this plot will sometimes reveal erroneous data, which can then be discarded or corrected by re-test.

Repeat this process for $I_{s c}$ and $P_{\max }$ vs module temperature.

STEP 5: Determine the slope of $I_{s c}, V_{o c}$, and $P_{\max }$ versus temperature for each irradiance level (actually for each filter set).

STEP 6: For each irradiance level, determine the slope of $V_{\text {oc }}$ versus the natural logarithm of irradiance (In E) for each module temperature.

STEP 7: The coefficients $\alpha, \beta, \gamma$, and $\delta$ are next computed. Use the average value of the slopes obtained for a given variable. For example, for each irradiance level a slope of $V_{o c}$ vs temperature was determined. These should be averaged. For the "neutering denominator," use the average or mid-range value of the dependent variable (for example, use the $V_{o c}$ at $45^{\circ} \mathrm{C}$ and $600 \mathrm{~W} / \mathrm{m}^{2}$ for neutering the average of the $V_{o c} v s$ temperature slopes to compute $\beta$ ). 
STEP 8: Now the equations with the coefficients are ready to use for any combination of module temperature and irradiance.

STEP 9: To translate an I-V curve from a field test condition to STC, use the equations and constants wherein:

Subscript 1 = field test condition

Subscript $2=$ STC

To translate an I-V curve from STC to some field condition, use the same equations and constants, but use:

Subscript $1=$ STC

Subscript 2 = field condition

STEP 10: The complete I-V curve (actually the I-V data point pairs) is very easy to translate, and can be quickly accomplished using a hand-held calculator:

a). Translate $I_{\mathrm{Sc} 1}$ to $I_{\mathrm{Sc} 2}$ using the $I_{\mathrm{sc}}$ translation equation.

b). Translate $V_{o c 1}$ to $V_{o c 2}$ using the $V_{o c}$ translation equation.

c). Translate each I-V current data point by multiplying by the $I_{\mathrm{sc} 2} / I_{\mathrm{sc} 1}$ ratio.

d). Translate each $\mathrm{I}-\mathrm{V}$ voltage data point by multiplying by the $\mathrm{V}_{\mathrm{Oc} 2} N_{\mathrm{oc} 1}$ ratio.

STEP 11: Translate $P_{\max }$ using one of the two equations provided. One is a "standalone" equation that does not require any $I_{s c}, V_{o c}$ or $I-V$ data pair translations. The other equation is based on the $I_{S C}$ and $V_{O C}$ translation ratios, and is very simple to use.

In summary, all of the goals have been successfully met. The data that is presented in this report shows good agreement between the analytical predictions made with the new equations versus actual test measurement and superior performance when compared to the current translation equations. In spite of the success of this program, further evaluation of these equations is necessary. Additional checks need to be made for other PV technologies, for larger modules, and for modules that have less-than-perfect performance characteristics, such as shunts. Also, some improvements to the equations themselves are possible. 


\section{APPENDIX A}

COMPARATIVE VALUES FOR $\mathrm{I}_{\mathrm{SC}}, \mathrm{V}_{\mathrm{OC}}, \mathrm{P}_{\mathrm{mAX}}$ ACTUAL MEASUREMENTS VS ANALYTICAL PREDICTIONS

TABLES 1 - 6 

TABLE 1

ACTUAL MEASUREMENTS - MATRIX DATA SUMMARY - SINGLE CRYSTAL SILICON

\begin{tabular}{|c|c|c|c|c|c|c|c|c|c|c|c|c|c|}
\hline NUMBER OF FILTERS $\rightarrow$ & 0 & 1 & 2 & 3 & 4 & 5 & 6 & 7 & 8 & 9 & 0 & & \\
\hline $\begin{array}{l}\text { Isc } @ 25^{\circ} \mathrm{C} \\
\\
@ 35^{\circ} \mathrm{C}\end{array}$ & $\begin{array}{r}.910 \\
.922 \\
\end{array}$ & $\begin{array}{r}.578 \\
.601\end{array}$ & $\begin{array}{r}.418 \\
.434\end{array}$ & $\begin{array}{r}315 \\
-333 \\
\end{array}$ & $\begin{array}{r}.260 \\
.265 \\
\end{array}$ & $\begin{array}{r}.212 \\
.218 \\
\end{array}$ & $\begin{array}{r}.176 \\
.185 \\
\end{array}$ & $\begin{array}{l}.151 \\
.157 \\
\end{array}$ & $\begin{array}{r}.133 \\
.133 \\
\end{array}$ & $\begin{array}{l}.114 \\
.115 \\
\end{array}$ & $\begin{array}{l}.911 \\
.923\end{array}$ & & \\
\hline & .931 & .602 & .433 & .333 & .264 & .218 & .185 & .158 & .134 & .117 & .938 & & \\
\hline @ $55^{\circ} \mathrm{C}$ & .938 & .599 & .434 & .336 & .271 & .217 & .181 & .159 & .136 & .119 & .938 & & \\
\hline$@ 65^{\circ} \mathrm{C}$ & .942 & .614 & .440 & .335 & .270 & .224 & .185 & .159 & .134 & .117 & .940 & & \\
\hline$@ 75^{\circ} \mathrm{C}$ & .953 & .606 & .440 & .343 & .273 & .224 & .190 & .161 & .138 & 1122 & .955 & & \\
\hline & & & & & & & & & 1 & & & & \\
\hline & & & & & & & . & & & & & & \\
\hline & & & & & & & & & & & & & \\
\hline Voc @25 C & 20,31 & 19.80 & 19.37 & 19.02 & 18.73 & 18,43 & 18.18 & 17,92 & 17.69 & 17,41 & 20.26 & & \\
\hline @ $35^{\circ} \mathrm{C}$ & 19.69 & 19.19 & 18.77 & 18,43 & 18,12 & 17.82 & 17.58 & 12,29 & 17.03 & 16,77 & 19.6 .5 & & \\
\hline$@ 45^{\circ} \mathrm{C}$ & 19,12 & 18.63 & 18.21 & 17.85 & 17.53 & 17.24 & 16.94 & 16.70 & 16.43 & 16.19 & 19.07 & & \\
\hline Q $55^{\circ} \mathrm{C}$ & 18.58 & 18.04 & 17.63 & 17.27 & 16,89 & 16.58 & 16,28 & 16,04 & 15,78 & 15.58 & 18.46 & & \\
\hline$@ 65^{\circ} \mathrm{C}$ & 18,14 & 17.63 & 17.21 & 16,83 & 16.50 & 16.21 & 15,89 & 15,62 & 15.36 & 15,11 & 18.04 & & \\
\hline$@ 75^{\circ} \mathrm{C}$ & 17,47 & 16,97 & 16155 & 16.20 & 15.87 & 15,53 & 15.25 & 14,97 & 14,70 & 14.45 & 17.39 & & \\
\hline & & & & & & & & & & & & & \\
\hline & & & & & & & & & & & & & \\
\hline & & & & & & & & & & & & & \\
\hline$P_{\max } @ 25^{\circ} \mathrm{C}$ & 12.64 & 7.93 & 5,54 & 4,08 & 3.25 & 2.57 & 2.09 & 1.73 & 1,48 & 1,23 & 12.60 & & \\
\hline @ $35^{\circ} \mathrm{C}$ & 12.23 & 7.90 & 5,49 & 4.09 & 3,16 & 2,52 & 2.09 & 1,71 & 1.41 & 1.18 & 12.19 & & \\
\hline Q $45^{\circ} \mathrm{C}$ & 11.83 & 7.58 & 5.30 & 3,93 & 3.04 & 2.44 & 1.99 & 1,65 & 1.36 & 1.17 & 11.86 & & \\
\hline @ $55^{\circ} \mathrm{C}$ & 11,42 & 7.21 & 5.07 & 3.81 & 2.95 & 2,31 & 1.87 & 1.54 & 1.32 & 1.13 & 11.25 & & \\
\hline @65 ${ }^{\circ} \mathrm{C}$ & 11.07 & 7.17 & 4,99 & 3.69 & 2.87 & 2.32 & 1.84 & 1.53 & 1,26 & 1.06 & 10.96 & & \\
\hline$@ 75^{\circ} \mathrm{C}$ & 10,57 & 6.73 & 4.75 & 3.58 & 2.78 & 2.18 & 1.78 & 1,47 & 1.22 & 1.04 & 10,49 & & \\
\hline & & & & & & & & & & & & & \\
\hline & & & & & & & & & & & & & \\
\hline Irradiance, $\mathrm{W} / \mathrm{m}^{2}$ & 1000 & 635 & 459 & 346 & 286 & 233 & 193 & 166 & 146 & 125 & 1001 & & \\
\hline & & & & & & & & & & & & & \\
\hline & & & & & & & & & & & & & \\
\hline & & & & & & & & & & & & & \\
\hline & & & & & & & & & & & & & \\
\hline
\end{tabular}


TABLE 2

ACTUAL MEASUREMENTS - MATRIX DATA SUMMARY - POLYCRYSTALLINE SILICON

\begin{tabular}{|c|c|c|c|c|c|c|c|c|c|c|c|c|c|}
\hline NUMBER OF FILTERS $\rightarrow$ & 0 & 1 & 2 & 3 & 4 & 5 & 6 & 7 & 8 & 9 & 0 & & \\
\hline & & & & & & & & & & & & & \\
\hline Isc @25 $92 \mathrm{C}$ & .319 & .205 & .148 & .112 & .091 & .073 & 061 & .050 & .043 & .037 & .318 & & \\
\hline$@ 35^{\circ} \mathrm{C}$ & .323 & .209 & .152 & .116 & .091 & .074 & .062 & .052 & 1042 & .034 & .322 & & \\
\hline @ $45^{\circ} \mathrm{C}$ & .324 & .212 & .149 & .115 & .091 & .075 & .062 & .052 & .045 & .032 & .323 & & \\
\hline$@ 55{ }^{\circ} \mathrm{C}$ & .323 & .210 & .152 & .111 & .092 & .072 & .062 & .052 & .044 & .032 & .324 & & \\
\hline$@ 65^{\circ} \mathrm{C}$ & .327 & .210 & .151 & .116 & .088 & .075 & .059 & .053 & .045 & .031 & .324 & & \\
\hline Q75 ${ }^{\circ} \mathrm{C}$ & .331 & .215 & .157 & .119 & .085 & .076 & .062 & .053 & .045 & .029 & .331 & & \\
\hline & & & & & & & & & & & & & \\
\hline & & & & & & & & & & & & & \\
\hline $\mathrm{V}_{O C} @ 25^{\circ} \mathrm{C}$ & 20.46 & 19.90 & 19.41 & 18.98 & 18.65 & 18,29 & 17,96 & 17,60 & 17,30 & 16,99 & 20.45 & & \\
\hline$@ 35^{\circ} \mathrm{C}$ & 19.75 & 19.14 & 18.69 & 18.25 & 17.86 & 17,50 & $17 \cdot 16$ & 16.83 & 16.50 & 16.19 & 19.70 & & \\
\hline$@ 45^{\circ} \mathrm{C}$ & 19,07 & 18.48 & 17.97 & 17,53 & 17.14 & 16.75 & 16.39 & 16.17 & 15.81 & 15.45 & 18,99 & & \\
\hline (a) $55^{\circ} \mathrm{C}$ & 18.33 & 17.77 & 17.32 & 16,22 & 16.47 & 16.06 & 15.70 & 15,33 & 15.01 & 14.70 & 18,30 & & \\
\hline$@ 65^{\circ} \mathrm{C}$ & 17,77 & 17.14 & 16.58 & 16.15 & 15,72 & 15,32 & 14,86 & 14,75 & 14,37 & 14,04 & 17.63 & & \\
\hline @ $75{ }^{\circ} \mathrm{C}$ & 17.07 & 16.44 & 15,92 & 15.45 & 15,03 & 14.64 & 14,23 & 13.95 & 13,55 & 13,21 & 17.02 & & \\
\hline & & & & & & & & & & & & & \\
\hline & & & & & & & & & & & & & \\
\hline & & & & & & & & & & & & & \\
\hline$P_{\max } @ 25^{\circ} \mathrm{C}$ & 4.54 & 2.78 & 1,90 & 1.38 & 1.07 & .83 & .67 & .53 & .44 & .36 & 4.51 & & \\
\hline @ $35^{\circ} \mathrm{C}$ & 4.35 & 2,69 & 1,87 & 1.35 & 1.02 & .79 & .63 & .51 & .42 & .34 & 4,32 & & \\
\hline$@ 45^{\circ} \mathrm{C}$ & 4.19 & 2,61 & 1.75 & 1.27 & 0.97 & .75 & .60 & .49 & .45 & $\times 32$ & 4.15 & & \\
\hline$@ 55^{\circ} \mathrm{C}$ & 4,01 & 2.46 & 1.70 & 1.18 & 0.93 & .72 & .57 & .45 & .38 & -3.2 & 3,97 & & \\
\hline Q $65^{\circ} \mathrm{C}$ & 3,88 & 2.36 & 1,60 & 1.16 & 0.88 & 162 & .50 & .44 & .36 & .30 & 3,82 & & \\
\hline Q $75^{\circ} \mathrm{C}$ & 3,70 & 2.27 & 1.52 & 1.12 & 0.85 & .66 & .51 & .43 & 133 & .27 & 3.6 .2 & .... & \\
\hline & & & & & & & & & & & & & \\
\hline & & & & & & & & & & & & & \\
\hline & & & & & & & & & & & & & \\
\hline Irradiance- $w-m^{2}$ & 1000 & 643 & 464 & 351 & 285 & 229 & 191 & 157 & 135 & 116 & 997 & & \\
\hline & & & & & & & & & & & & & \\
\hline & & & & & & & & & & & & & \\
\hline & & & & & & & & & & & & & \\
\hline & & & & & & & & & & & & & \\
\hline
\end{tabular}


TABLE 3

ACTUAL MEASUREMENTS - MATRIX DATA SUMMARY - AMORPHOUS THIN-FILM SILICON

\begin{tabular}{|c|c|c|c|c|c|c|c|c|c|c|c|c|c|}
\hline NUMBER OF FILTERS $\rightarrow$ & 0 & 1 & 2 & 3 & 4 & 5 & 6 & 7 & 8 & 9 & 0 & & \\
\hline & & & & & & & & & & & & & \\
\hline Isc @25 ${ }^{\circ} \mathrm{C}$ & .421 & .270 & .191 & 143 & .111 & .090 & .074 & .061 & .051 & .043 & .428 & & \\
\hline$@ 35^{\circ} \mathrm{C}$ & .424 & .264 & .187 & .142 & .112 & .091 & .074 & .062 & .050 & .043 & .426 & & \\
\hline$@ 45^{\circ} \mathrm{C}$ & .427 & .272 & .191 & .144 & .113 & .091 & .073 & .063 & .052 & .044 & .429 & & \\
\hline$@ 55^{\circ} \mathrm{C}$ & .431 & 1267 & .190 & .143 & .113 & 1090 & .074 & .062 & .052 & .044 & .431 & & \\
\hline @ $65^{\circ} \mathrm{C}$ & .435 & .272 & .191 & .144 & .113. & .091 & .075 & .062 & .052 & .044 & .440 & & \\
\hline$@ 75^{\circ} \mathrm{C}$ & .438 & .274 & .191 & .145 & .113 & .091 & 1075 & .064 & .051 & .044 & 1437 & & \\
\hline & & & & & & & & & & & & & \\
\hline & & & & & & & & & & & & & \\
\hline$V_{O C} @ 25^{\circ} \mathrm{C}$ & & & & & 20,68 & & 20.24 & 20,04 & 19,85 & 19,68 & 22.09 & & \\
\hline @ $35^{\circ} \mathrm{C}$ & $\frac{22.12}{21.55}$ & $\frac{21.62}{21.02}$ & 20.65 & $\frac{20,94}{20,34}$ & $\begin{array}{l}20,68 \\
20,07\end{array}$ & $\frac{20,43}{19,85}$ & $\frac{20.24}{19,63}$ & $\frac{2,04}{19,42}$ & 19.21 & 19.03 & $\frac{22104}{21,48}$ & & \\
\hline (a) $45^{\circ} \mathrm{C}$ & 20.98 & 20.48 & 20.09 & 19,78 & 19.51 & 19,24 & 19,02 & 18.82 & 18.63 & 18.43 & 20.95 & & \\
\hline @ $55^{\circ} \mathrm{C}$ & 20.48 & 19.93 & 19.54 & 19.21 & 18.92 & 18,68 & 18.43 & 18.21 & 17.99 & 17,80 & 20.39 & & \\
\hline @ $65^{\circ} \mathrm{C}$ & 19,95 & 19.41 & 18.99 & 18.68 & 18.38 & 18.12 & 17,90 & 17,65 & 12.43 & 17,24 & 19.89 & & \\
\hline$@ 75^{\circ} \mathrm{C}$ & 19,42 & 18.87 & 18,46 & $18 i 12$ & 12.80 & 17,54 & 17.29 & 17.07 & 16.82 & 16,60 & 19,34 & & \\
\hline & & & & & & & & & & & & & \\
\hline & & & & & & & & & & & & & \\
\hline $\mathrm{P}_{\max } @ 25^{\circ} \mathrm{C}$ & 6.28 & 3.99 & 2.79 & 2,05 & 1.59 & 1,26 & 1.02 & .83 & .69 & .56 & 6,28 & & \\
\hline @ $35^{\circ} \mathrm{C}$ & 6,20 & 3.83 & 2,68 & 1,99 & 1.53 & 1.23 & 0.99 & .82 & .66 & .026 & 6.16 & & \\
\hline$@ 45^{\circ} \mathrm{C}$ & 6,11 & 3,86 & 2,67 & 1.97 & 1.51 & 1.20 & 0,97 & .79 & .65 & .53 & 6.11 & & \\
\hline @ $55^{\circ} \mathrm{C}$ & 6,02 & 3.69 & 2.60 & 1.91 & 1.47 & 1.16 & 0.93 & .75 & .62 & .51 & 6.01 & & \\
\hline (1) $65^{\circ} \mathrm{C}$ & 5.90 & 3,65 & 2.51 & 1,85 & 1.44 & 1.12 & 0,91 & .74 & .60 & .50 & 5,96 & & \\
\hline$@ 75^{\circ} \mathrm{C}$ & 5,77 & 3.58 & 2,44 & 1.79 & 1.37 & 1,08 & 0.87 & .72 & .58 & .48 & 5.74 & & \\
\hline & & & & & & & & & & & & & \\
\hline & & & & & & & & & & & & & \\
\hline & & & & & & & & & & & & & \\
\hline & 1000 & 641 & 454 & 340 & 264 & 214 & 176 & 145 & 121 & 102 & 1016 & & \\
\hline Irradiance, $W+m^{2}$ & & & & & & & & & & & & & \\
\hline & & & & & & & & & & & & & \\
\hline & & & & & & & & & & & & & \\
\hline & & & & & & & & & & & & & \\
\hline
\end{tabular}


TABLEE 4

ANALYTICAL PREDICTIONS - MATRIX DATA SUMMARY - SINGLE CRYSTAL SILICON

\begin{tabular}{|c|c|c|c|c|c|c|c|c|c|c|c|c|c|}
\hline NUMBER OF FILTERS $\rightarrow$ & $\mathbf{0}$ & 1 & 2 & 3 & 4 & 5 & 6 & 7 & 8 & 9 & 0 & & \\
\hline & & & & & & & & & & & & & \\
\hline Isc @ $250^{\circ} \mathrm{C}$ & .910 & .578 & .418 & . 315 & 1260 & +212 & 476 & .151 & .133 & .114 & .911 & & \\
\hline @ $35^{\circ} \mathrm{C}$ & .919 & 1584 & .422 & .318 & .263 & .214 & .178 & .152 & .134 & .115 & .920 & & \\
\hline @ $45^{\circ} \mathrm{C}$ & .928 & 1589 & .426 & .321 & .265 & .216 & .179 & .154 & .136 & 1117 & .929 & & \\
\hline$@ 55^{\circ} \mathrm{C}$ & .937 & .595 & .430 & 324 & .267 & .218 & 1181 & .155 & .137 & .1117 & 938 & & \\
\hline$@ 65^{\circ} \mathrm{C}$ & .946 & .601 & .435 & 1327 & 1270 & 1220 & .183 & .157 & 1138 & .119 & .947 & & \\
\hline$@ 75^{\circ} \mathrm{C}$ & 1955 & .607 & .439 & .331 & .273 & .222 & .185 & .158 & .140 & .120 & .956 & & \\
\hline & & & & & & & & & $\ldots$ & & & & \\
\hline & & & & & & & & & & & & & \\
\hline & & & & & & & & & & & & & \\
\hline$V_{o c} @ 25^{\circ} \mathrm{C}$ & 20.31 & 19.56 & 19,05 & 18,63 & 18.36 & 18.07 & 17.82 & 17.62 & 17.46 & 17.26 & 20,31 & & \\
\hline @ $35^{\circ} \mathrm{C}$ & 19.70 & 18.97 & 18.48 & 18.07 & 17.81 & 17.53 & 17,28 & 17.09 & 16.94 & 16,74 & 19,70 & & \\
\hline$@ 45^{\circ} \mathrm{C}$ & 19.12 & 18.41 & 17,93 & 17,54 & 17.28 & 17.01 & 16.78 & 16,59 & 16.44 & 16.25 & 19.12 & & \\
\hline$@ 55^{\circ} \mathrm{C}$ & 18.58 & 17.89 & 17.43 & 17.04 & 16,80 & 16.53 & 16.30 & 16,12 & 15.98 & 15.79 & 18,58 & & \\
\hline$@ 65^{\circ} \mathrm{C}$ & 18.07 & 17.40 & 16,95 & 16,58 & 16,34 & 16,08 & 15.85 & 15.68 & 15.53 & 15,36 & 18.07 & & \\
\hline$@ 75^{\circ} \mathrm{C}$ & 17,58 & 16.93 & 16.49 & 16.13 & 15,89 & 15.64 & 15,42 & 15,25 & 15.11 & 14,94 & 17,58 & & \\
\hline & & & & & & & & & & & & & \\
\hline & & & & & & & & & & & & & \\
\hline $\bar{P}_{\max } @ 25^{\circ} \mathrm{C}$ & 12,64 & 7.73 & 5.46 & 4.01 & 3.26 & 2.62 & 2,14 & 1.82 & 1.59 & 1.35 & 12,65 & & \\
\hline$@ 35^{\circ} \mathrm{C}$ & 12.24 & 7.49 & 5,27 & 3.89 & 3.16 & 2.54 & 2.08 & 1.76 & 1.54 & 1.30 & 12.25 & & \\
\hline$@ 45^{\circ} \mathrm{C}$ & 11,86 & 7.25 & 5.11 & 3,77 & 3.06 & 2.46 & 2.01 & 1.71 & 1,49 & 1.26 & 11.87 & & \\
\hline$@ 55^{\circ} \mathrm{C}$ & 11.50 & 7.03 & 4.95 & 3,65 & 2.97 & 2,38 & 1.95 & 1,66 & 1.44 & 1.22 & 11,51 & & \\
\hline @ $65^{\circ} \mathrm{C}$ & 11.17 & 6,83 & 4.81 & 3.55 & 2.89 & 2.32 & 1.90 & 1.61 & 1.40 & 1.19 & 11.18 & & \\
\hline @ $75^{\circ} \mathrm{C}$ & 10.85 & 6.64 & 4.67 & 3,45 & 2.80 & 2.25 & 1.84 & 1.56 & 1.36 & 1.16 & 10.86 & & \\
\hline & & & & & & & & & & & & & \\
\hline & & & & & & & & & & & & & \\
\hline & 1000 & 635 & 459 & 346 & 286 & 233 & 193 & 166 & 146 & 125 & 1001 & & \\
\hline Irradiance, $-\mathrm{W}-\mathrm{m}^{2}$ & & & & & & & & & & & & & \\
\hline & & & & & & & & & & & & & \\
\hline & & & & & & & & & & & & & \\
\hline & & & & & & & & & & & & & \\
\hline
\end{tabular}


TABLE 5

ANALYTICAL PREDICTIONS - MATRIX DATA SUMMARY - POLYCRYSTALLINE SILICON

\begin{tabular}{|c|c|c|c|c|c|c|c|c|c|c|c|c|c|}
\hline NUMBER OF FILTERS $\rightarrow$ & 0 & 1 & 2 & 3 & 4 & 5 & 6 & 7 & 8 & 9 & $\mathbf{0}$ & & \\
\hline $\mathrm{Isc}_{\mathrm{sc}} @ 25^{\circ} \mathrm{C}$ & .319 & .205 & 148 & .112 & .091 & 073 & 061 & & & & 319 & & \\
\hline @ $35^{\circ} \mathrm{C}$ & .322 & .207 & .149 & .113 & .092 & .074 & $\begin{array}{l}.061 \\
.062 \\
\end{array}$ & $\begin{array}{l}.050 \\
.050\end{array}$ & $\begin{array}{l}.043 \\
.043\end{array}$ & $\frac{.037}{.037}$ & $.3 / 8$ & & \\
\hline$@ 45^{\circ} \mathrm{C}$ & .325 & .209 & .151 & .114 & .093 & .074 & .062 & .051 & .044 & 1038 & .324 & & \\
\hline @5 $55^{\circ} \mathrm{C}$ & .328 & .211 & .152 & .115 & .094 & .075 & .063 & .051 & .044 & .038 & .327 & & \\
\hline$@ 65^{\circ} \mathrm{C}$ & .331 & .213 & .154 & .116 & .094 & .076 & .063 & .052 & .045 & .038 & .330 & & \\
\hline (C) $75^{\circ} \mathrm{C}$ & .334 & .215 & .155 & .117 & .095 & .076 & .064 & .052 & .045 & .039 & .333 & & \\
\hline & & & & & & & & & & & & & \\
\hline & & & & & & & & & & & & & \\
\hline Voc@25-C & 20.46 & 1.9 .51 & 10.87 & 18.35 & 17.98 & 17.61 & 17.31 & 17.00 & 16.77 & 16,54 & 20.45 & & \\
\hline (a) 350 & 19.67 & 18.76 & 18.14 & 17,64 & 17,28 & 16.93 & 16.64 & 16.34 & 16.12 & 15.90 & 19,66 & & \\
\hline (a) 450 & 18.94 & 18.06 & 17.46 & 16.98 & 16.64 & 16.30 & 16.02 & 15.74 & 15.52 & 15,31 & 18,94 & & \\
\hline (a) $65^{\circ} \mathrm{C}$ & 18.27 & 17.42 & 16.85 & 16.38 & 16,05 & 15,72 & 15.46 & 15.18 & 14.97 & $14: 77$ & 18,26 & & \\
\hline (क) $750^{\circ} \mathrm{C}$ & 17,64 & 16.82 & 16.27 & 15.82 & 15.50 & 15.18 & 14.92 & 14.66 & 14.46 & 14,26 & 17.63 & & \\
\hline & 17.05 & 16.26 & 15.72 & 15,29 & 14.98 & 14.67 & 14.42 & 14.17 & 13.97 & 13.78 & 17,04 & & \\
\hline & & & & & & & & & & & & & \\
\hline & & & & & & & & & & & & & \\
\hline$P_{\max } @ 25^{\circ} \mathrm{C}$ & 4.54 & 2.78 & 1.94 & 1,43 & 1.14 & 0.89 & 0.73 & 0.59 & 0.50 & 0.43 & 4.52 & & \\
\hline @ $35^{\circ} \mathrm{C}$ & 4.34 & 2.66 & 1,85 & 1.37 & 1.09 & 0.85 & 0.70 & 0,56 & 0.48 & 0.41 & 4,32 & & \\
\hline$@ 45^{\circ} \mathrm{C}$ & 4.15 & 2,54 & 1,77 & 1,31 & 1.04 & 0.81 & 0.67 & 0.54 & 0.46 & 0.39 & 4,13 & & \\
\hline$@ 55^{\circ} \mathrm{C}$ & 3.98 & 2.44 & 1.70 & 1.25 & 1.00 & 0,78 & 0.64 & 0.52 & 0.44 & 10,38 & 3.96 & & \\
\hline$@ 65^{\circ} \mathrm{C}$ & 3.82 & 2,34 & 1.63 & 1.20 & 0,96 & 0.75 & 0.61 & 0.50 & 0.42 & 0.36 & 3,80 & & \\
\hline @ $75^{\circ} \mathrm{C}$ & 3.68 & 2.25 & 1.57 & 1.16 & 0.92 & 0.72 & 0.59 & 0.48 & 0.41 & 0.35 & 3,66 & & \\
\hline & & & & & & & & & & & & & \\
\hline & & & & & & & & & & & & & \\
\hline Irradiance, $\mathrm{W} / \mathrm{m}^{2}$ & 1000 & 643 & 464 & 351 & 285 & 229 & 191 & 157 & 135 & 116 & 997 & & \\
\hline & & & & & & & & & & & & & \\
\hline & & & & & & & & & & & & & \\
\hline & & & & & & & & & & & & & \\
\hline
\end{tabular}


TABLE 6

ANALYTICAL PREDICTIONS - MATRIX DATA SUMMARY - AMORPHOUS THIN-FILM SILICON

\begin{tabular}{|c|c|c|c|c|c|c|c|c|c|c|c|c|c|}
\hline NUMBER OF FILTERS $\rightarrow$ & 0 & 1 & 2 & 3 & 4 & 5 & 6 & 7 & 8 & 9 & 0 & & \\
\hline \multirow[b]{3}{*}{ @ $35^{\circ} \mathrm{C}$} & & & & & & & & & & & & & \\
\hline & .421 & 1270 & 191 & 143 & .111 & .090 & .074 & .061 & .051 & .043 & .428 & & \\
\hline & .423 & .271 & .190 & .143 & 1111 & .090 & 1074 & .061 & .051 & 1043 & 1430 & & \\
\hline (a) $45^{\circ} \mathrm{C}$ & .424 & .272 & .192 & .144 & .112 & .091 & .075 & .061 & .051 & .043 & 1431 & & \\
\hline$@ 55^{\circ} \mathrm{C}$ & .426 & +273 & .193 & .145 & .112 & .091 & .075 & .062 & .052 & .043 & 1433 & & \\
\hline$@ 65^{\circ} \mathrm{C}$ & 427 & .274 & .194 & 145 & 1113 & .091 & .075 & .062 & 1052 & .044 & .434 & & \\
\hline \multirow[t]{2}{*}{$@ 75^{\circ} \mathrm{C}$} & .429 &, 275 & 195 & .146 & .113 & .092 & .075 & .062 & .052 & .044 & .436 & & \\
\hline & & & & & & & & & & & & & \\
\hline & & & & & & & & & & & & & \\
\hline \multirow{2}{*}{$V_{o c} @ 25^{\circ} \mathrm{C}$} & & & & & & & & & & & & & \\
\hline & 22.12 & 21.52 & 21.07 & 20.71 & 20,41 & 20,16 & 19.94 & 19,72 & 19,52 & 19.34 & 22,14 & & \\
\hline (d) $35^{\circ} \mathrm{C}$ & 21.52 & 20.94 & 20,50 & 20.15 & 19.85 & 19.61 & 19.40 & 19.19 & 18.99 & 18.82 & 21,54 & & \\
\hline (a) $45^{\circ} \mathrm{C}$ & 20,95 & 20,38 & 19,96 & 19,62 & 19,33 & 19.10 & 18.88 & 18.68 & 18,49 & 18.32 & 20.97 & & \\
\hline$@ 55^{\circ} \mathrm{C}$ & 20.41 & 19,86 & 19.44 & 19.11 & 18.83 & 18,60 & 18.40 & 18.20 & 18,01 & 17,84 & 21,43 & & \\
\hline$@ 65^{\circ} \mathrm{C}$ & 19.89 & 19.35 & 18.95 & 18.62 & 18.35 & 18.13 & 17.93 & 17,73 & 17,55 & 17.39 & 19,91 & & \\
\hline @75으 & 19.40 & 18,87 & 18.48 & 18.17 & 17,90 & 17,68 & 17.49 & 17.30 & 17.12 & 16,96 & 19.42 & & \\
\hline . & & & & & & & & & & & & & \\
\hline \multirow[t]{2}{*}{ 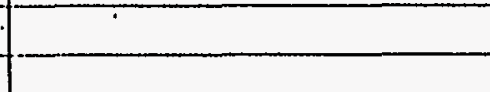 } & & & & & & & & & & & & & \\
\hline & & & & & & & & & & & & & \\
\hline$P_{\max } @ 25^{\circ} \mathrm{C}$ & 6,28 & 3,92 & 2,72 & 2.00 & 1,53 & 1.22 & 1,00 & 0.81 & 0.67 & 0.56 & 6.39 & & \\
\hline @ $35^{\circ} \mathrm{C}$ & 6.16 & 3.84 & 2.66 & 1.96 & 1,50 & 1.20 & 0.98 & 0.80 & 0.66 & 0.55 & 6.26 & & \\
\hline$@ 45^{\circ} \mathrm{C}$ & 6.04 & 3,77 & 2.61 & 1.92 & 1.47 & 1,18 & 0,96 & 0.78 & 0.64 & 0.54 & 6.14 & & \\
\hline \multirow{4}{*}{$\begin{array}{r}@ 55^{\circ} \mathrm{C} \\
@ 65^{\circ} \mathrm{C} \\
@ 75^{\circ} \mathrm{C}\end{array}$} & 5,92 & 3,69 & 2.56 & 1,88 & 1,44 & 1.15 & 0,94 & 0.77 & 0,63 & 0.53 & 6,02 & & \\
\hline & 5,81 & 3.62 & 2,51 & 1,85 & 1.42 & 1.13 & 0.92 & 0,75 & 0,62 & 0.52 & 5.91 & & \\
\hline & 5,71 & 3,56 & 2.47 & 1,82 & 1,39 & 1.11 & 0,91 & 0.74 & 0.61 & 0.51 & 5.81 & & \\
\hline & & & & & & & & & & & & & \\
\hline & & & & & & & & & & & & & \\
\hline & 1000 & 641 & 454 & 340 & 264 & 214 & 176 & 145 & 121 & 102 & 1016 & & \\
\hline Irradiance, $\mathrm{W} / \mathrm{m}^{2}$ & & & & & & $\alpha 17$ & & & & & 1016 & & \\
\hline \multirow{2}{*}{ 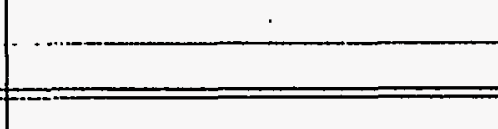 } & & & & & & & & & & & & & \\
\hline & & & & & & & & & & & & & \\
\hline 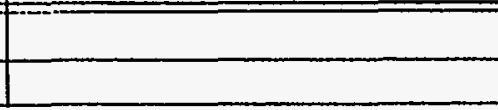 & & & & & & & & & & & & & \\
\hline
\end{tabular}




\section{APPENDIX B}

A COMPARISON OF ANALYTICAL I-V CURVE

TRANSLATIONS VS ACTUAL I-V CHARACTERISTICS 



\section{I-V TRANSLATION EQUATION CHECK FOR}

SINGLE CRYSTAL SILICON MODULE 


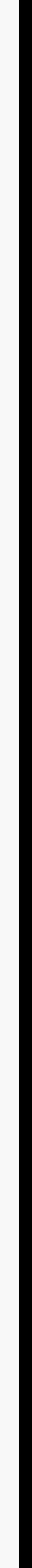



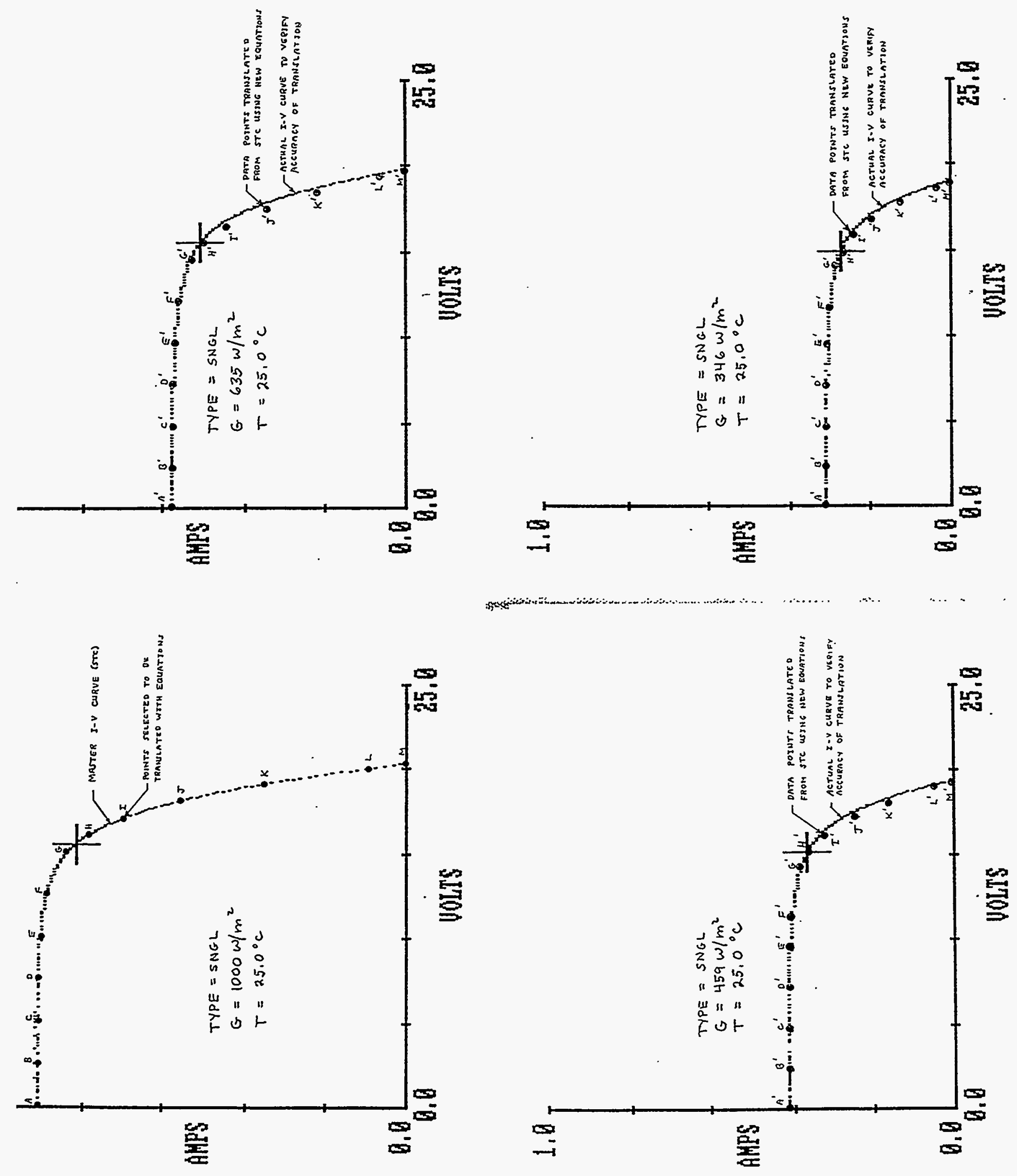

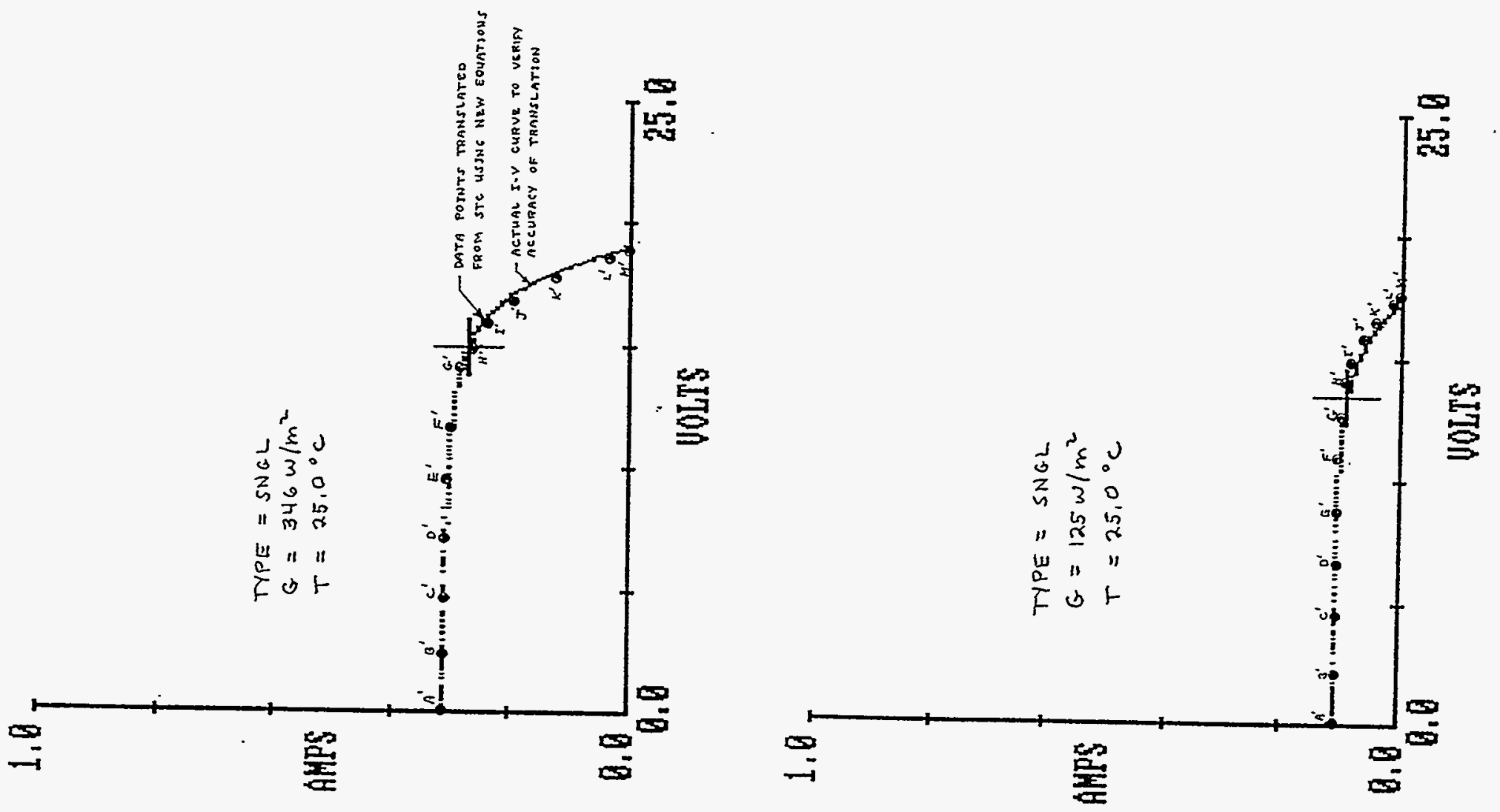

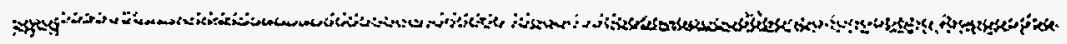
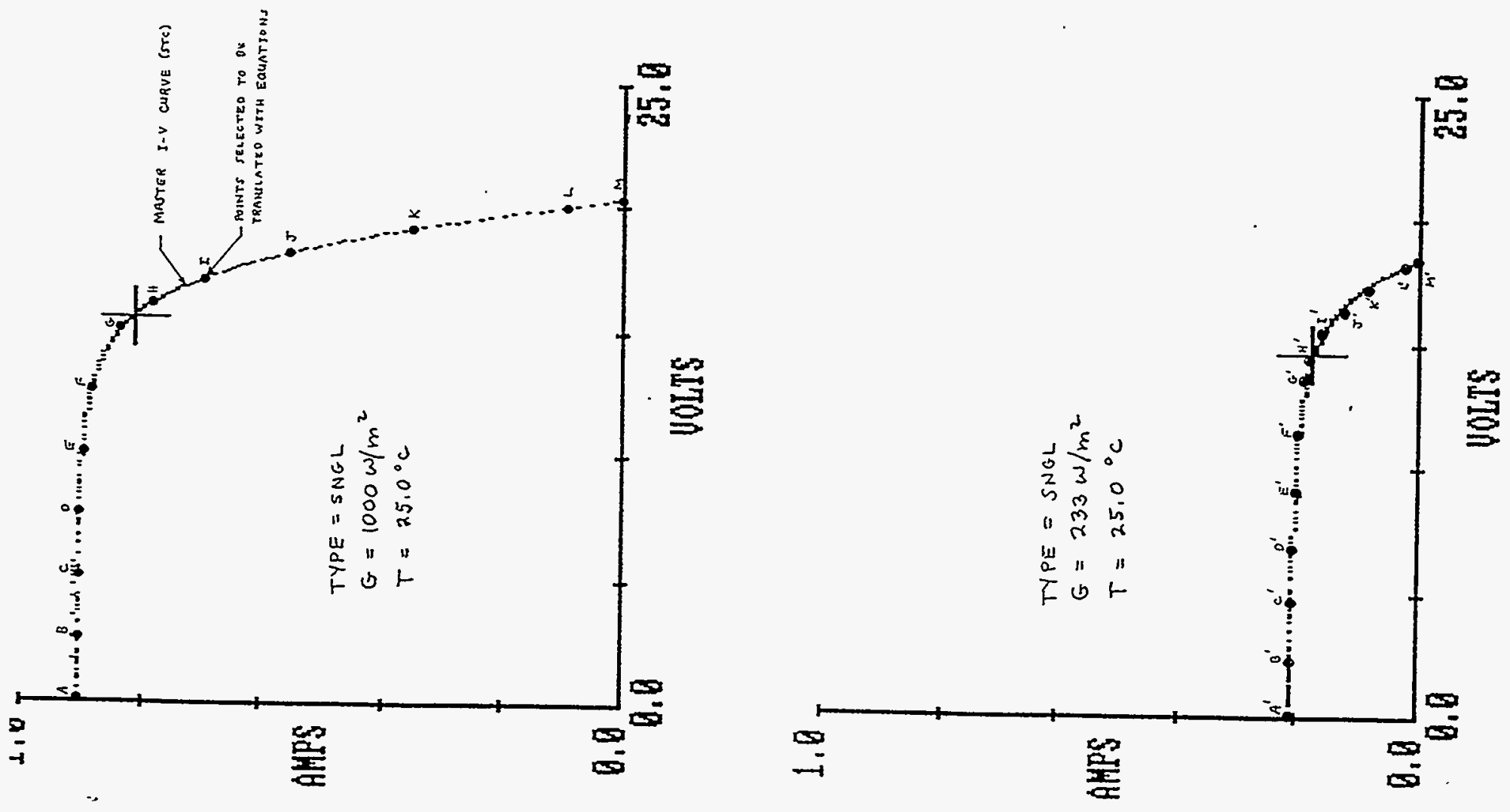

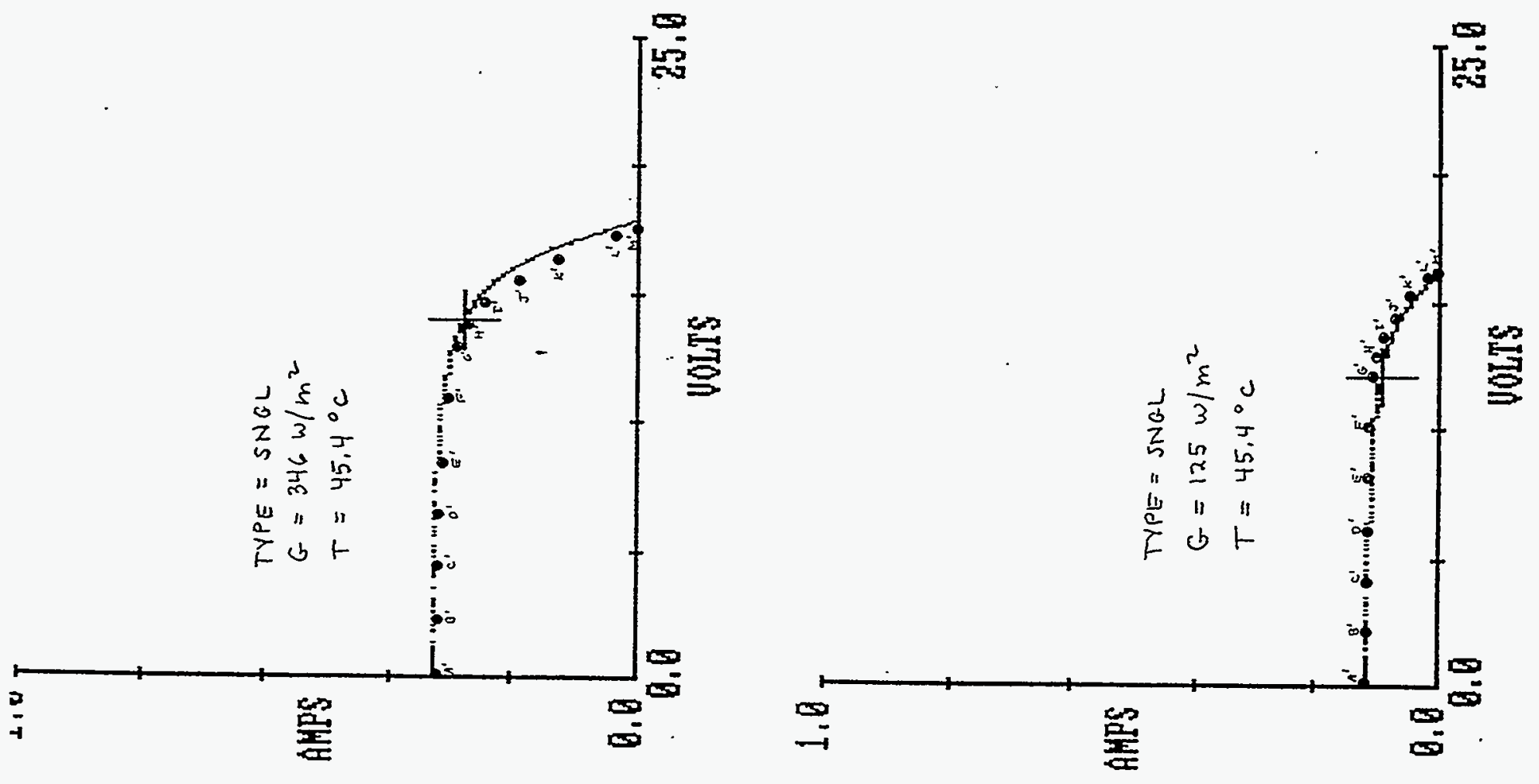

\$24
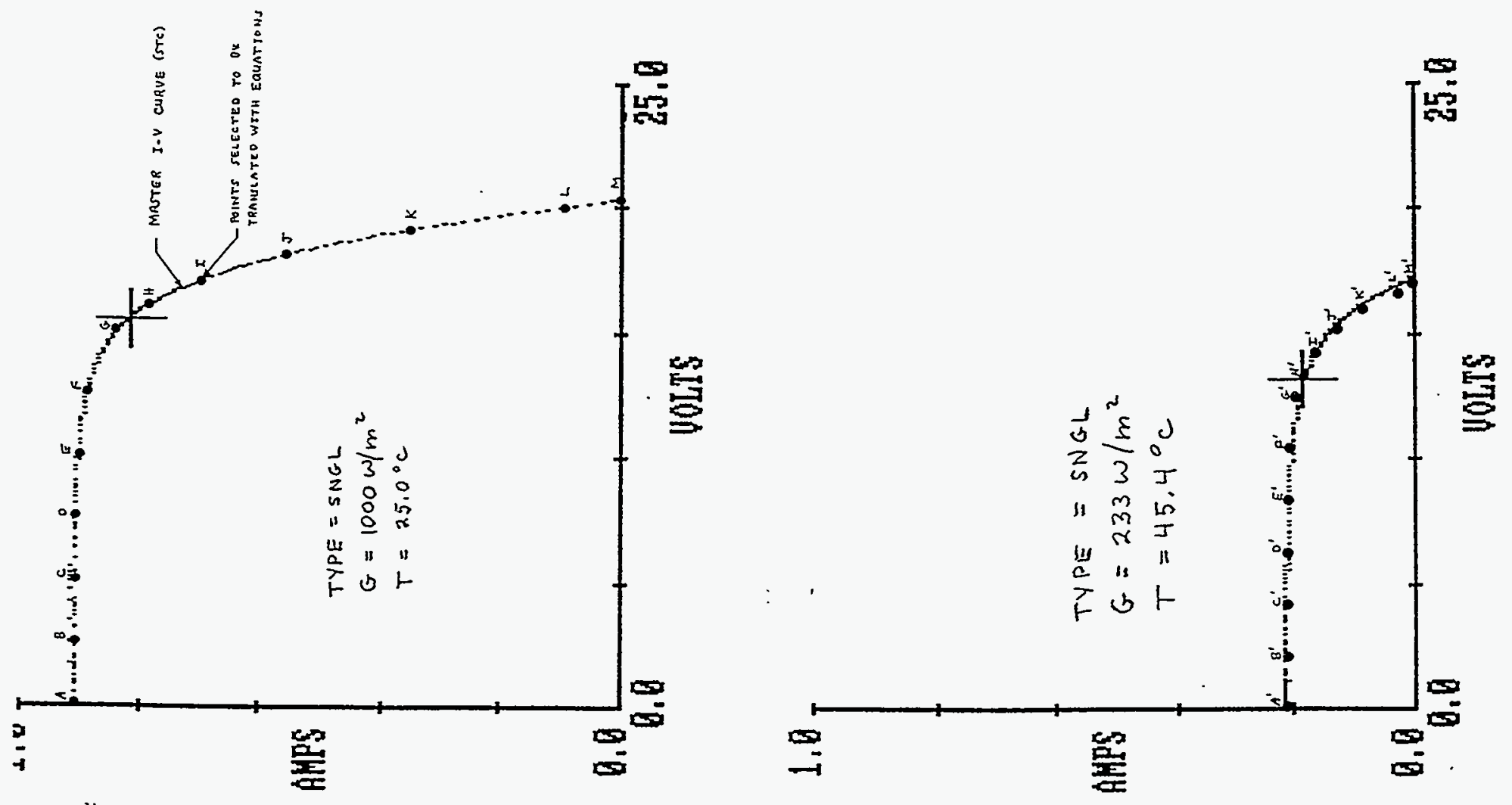

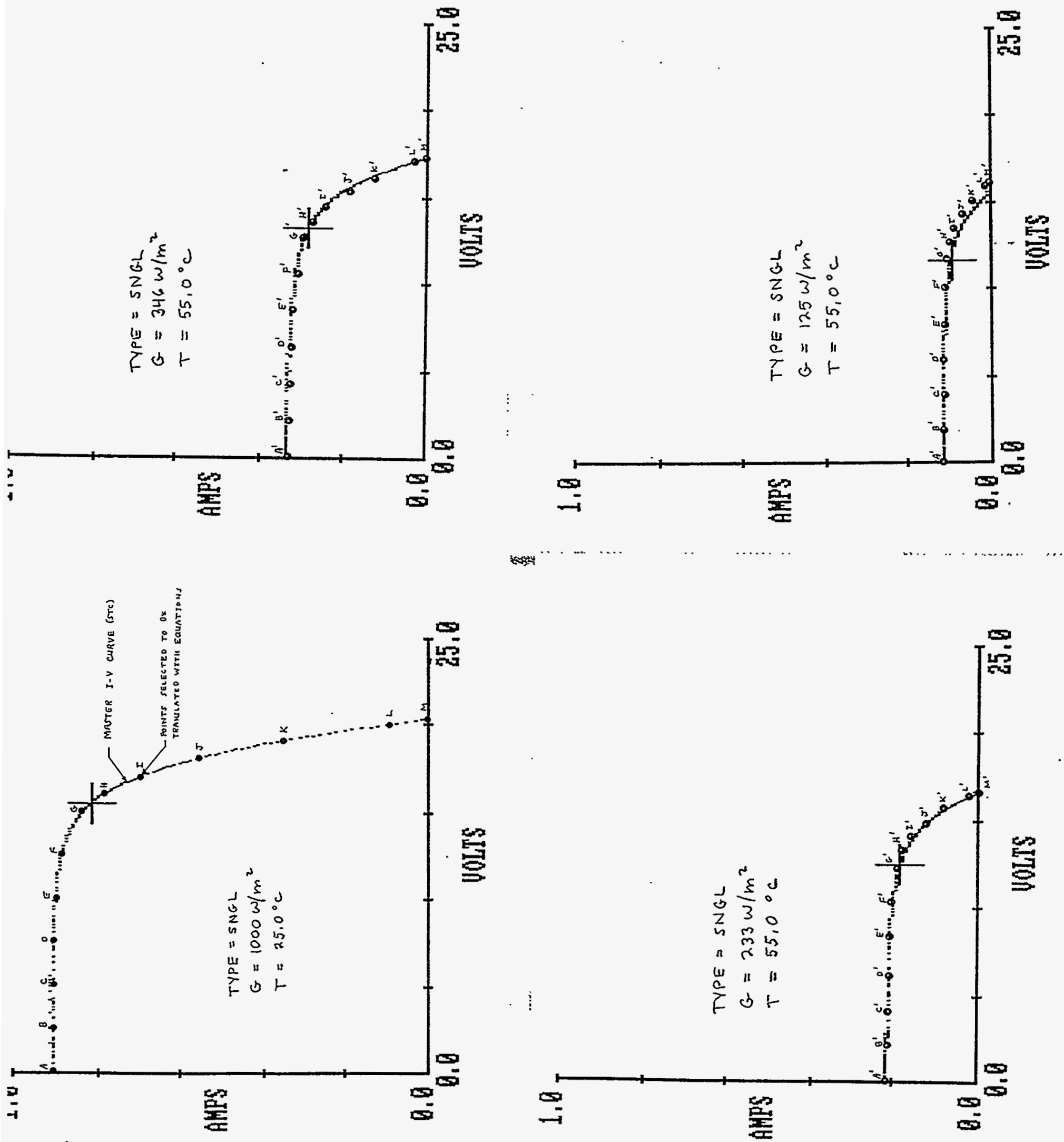

(5)

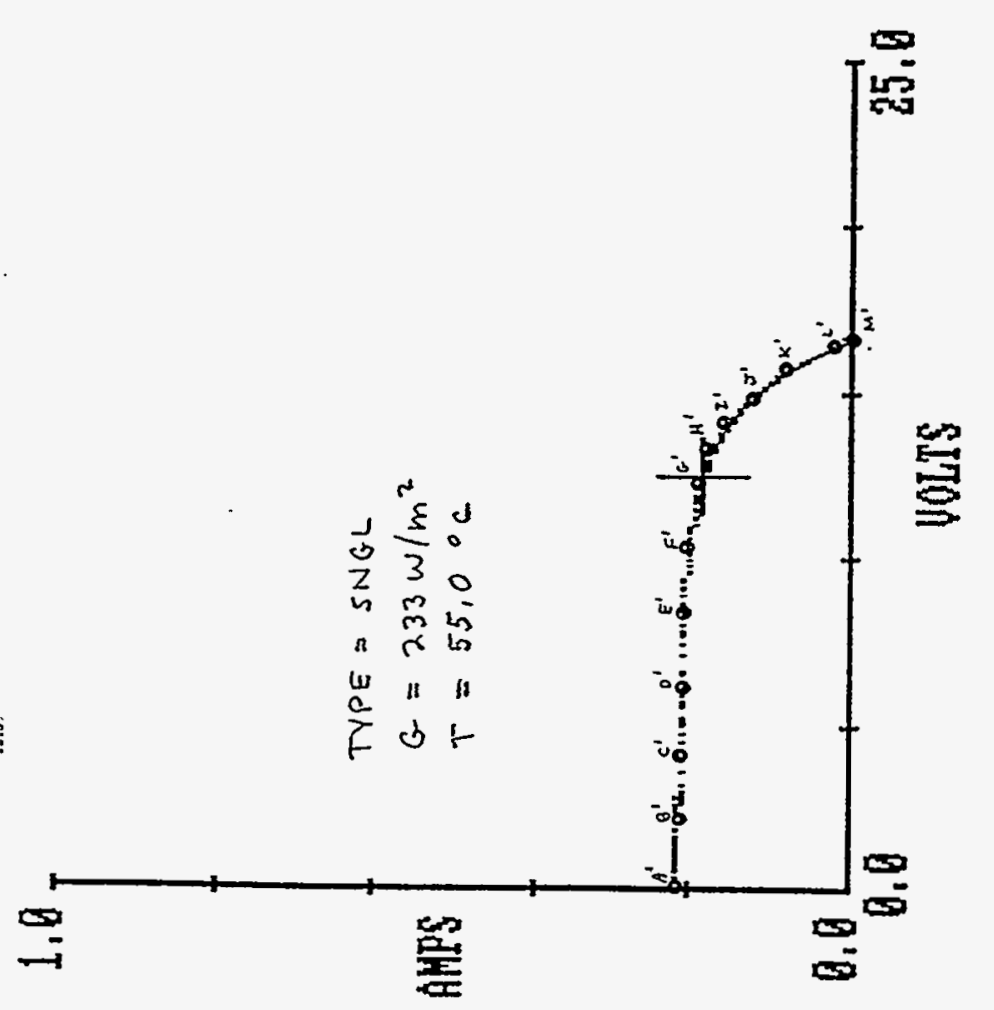



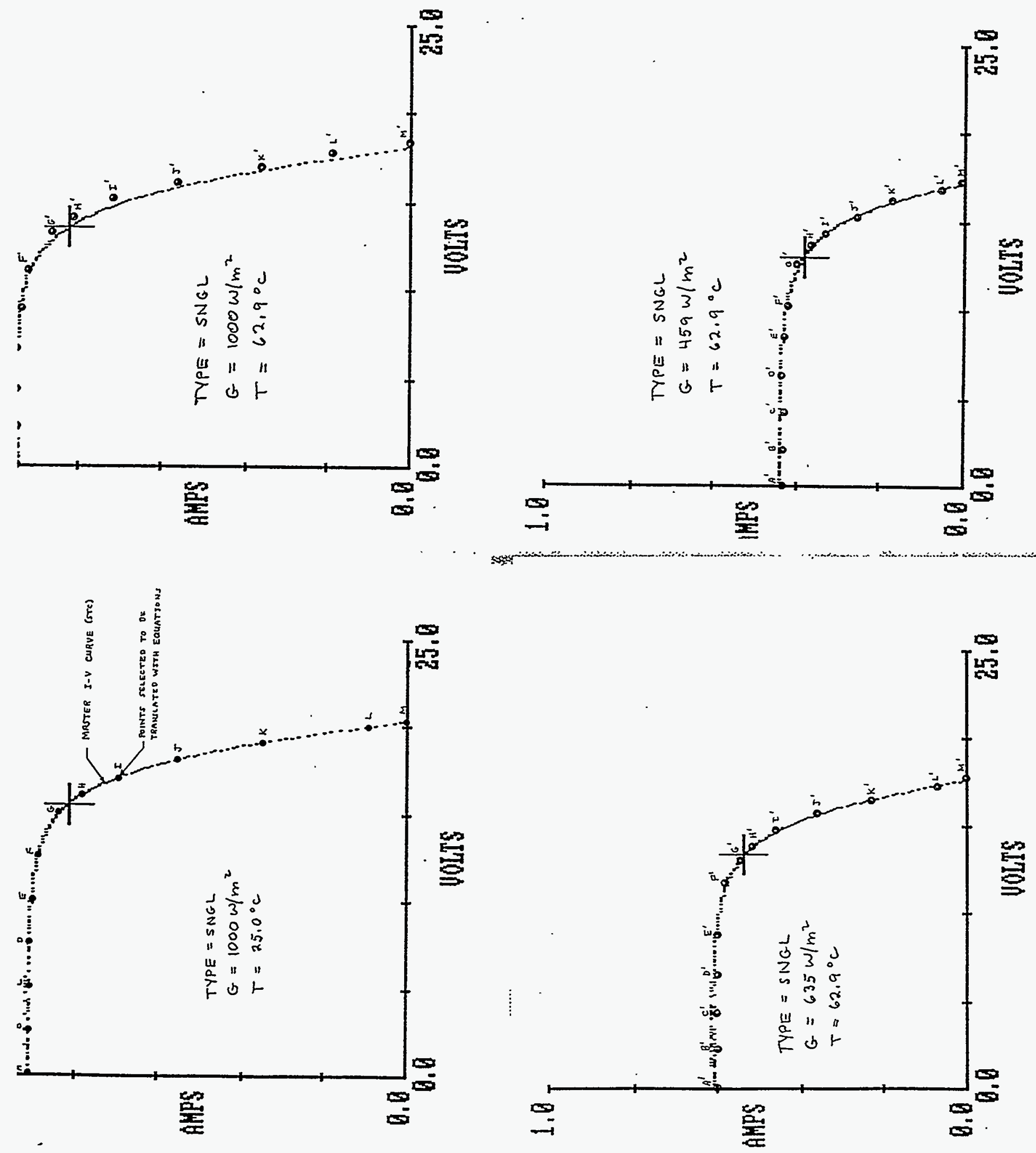

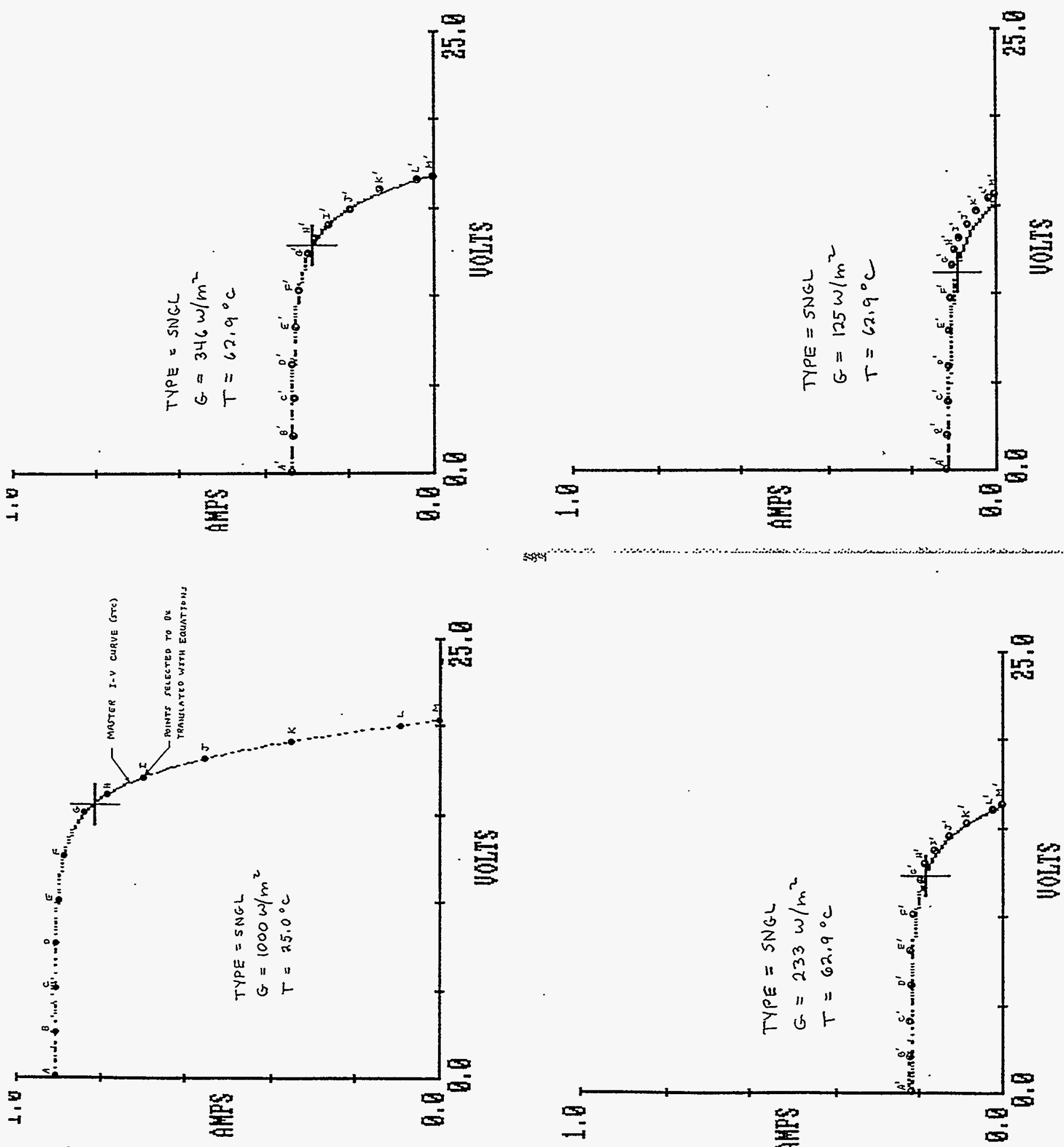

sकy

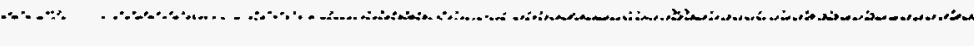



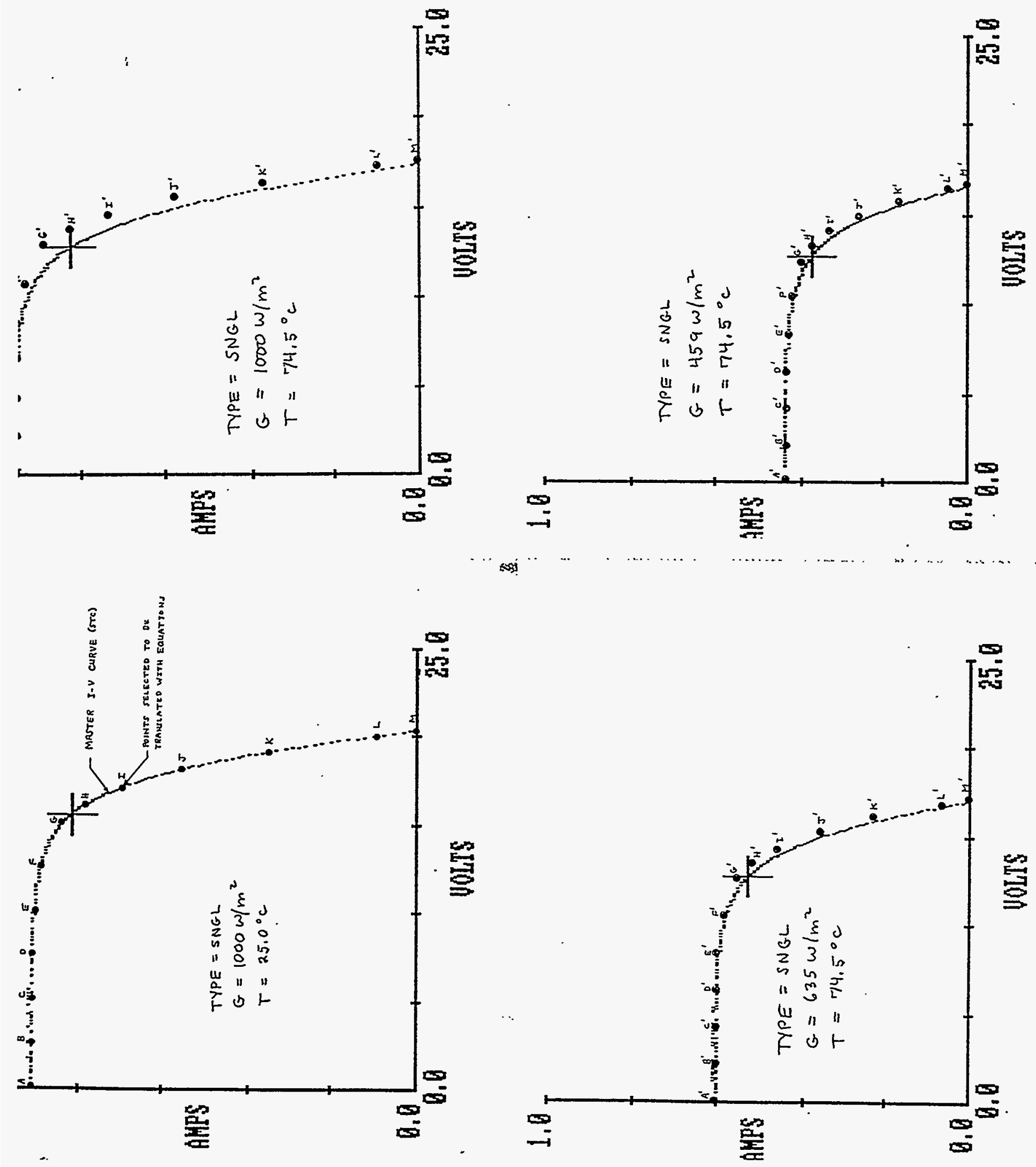

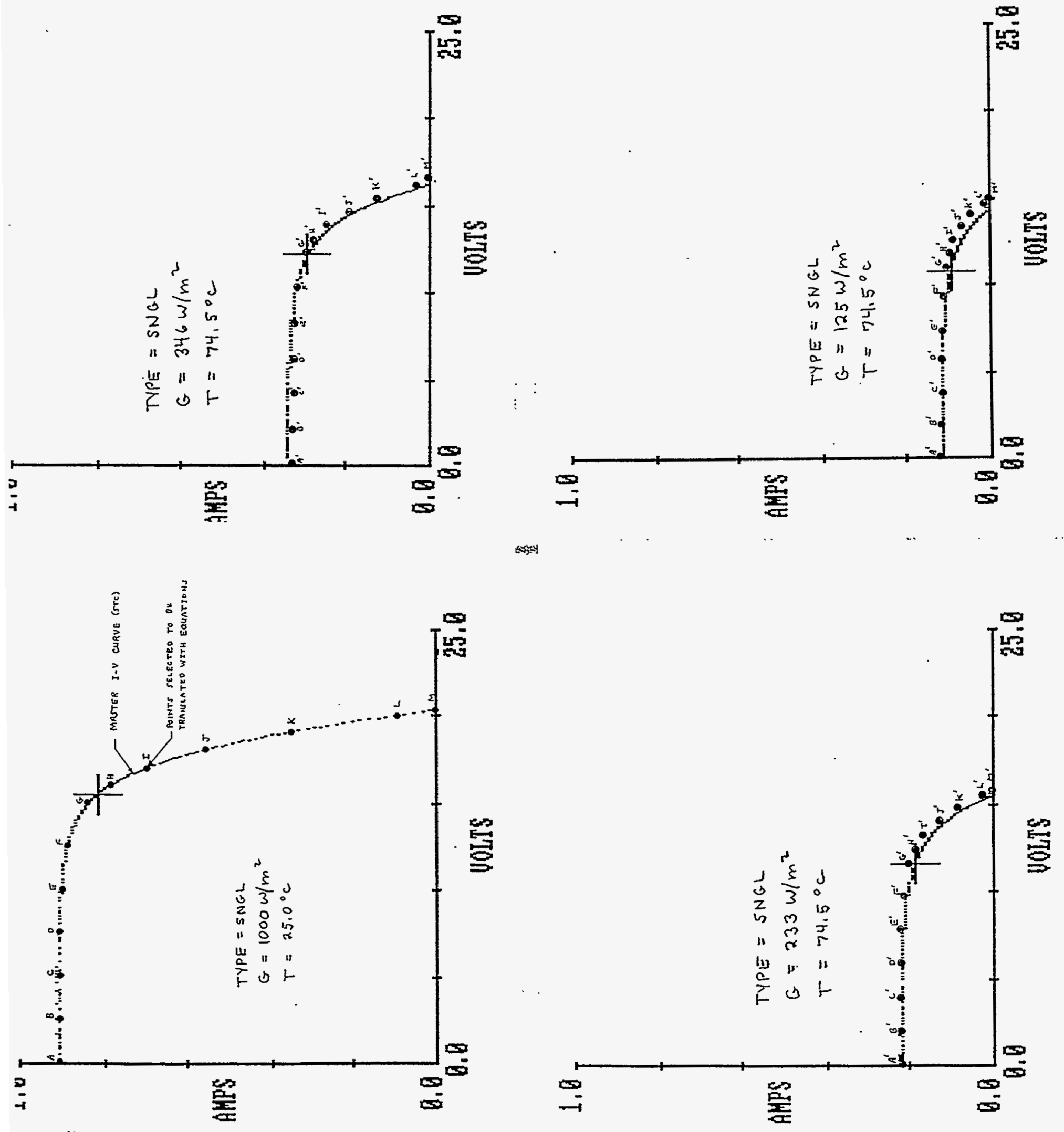
I-V TRANSLATION EQUATION CHECK FOR POLYCRYSTALLINE SILICON MODULE 


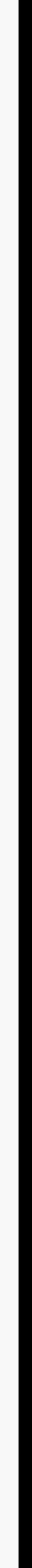



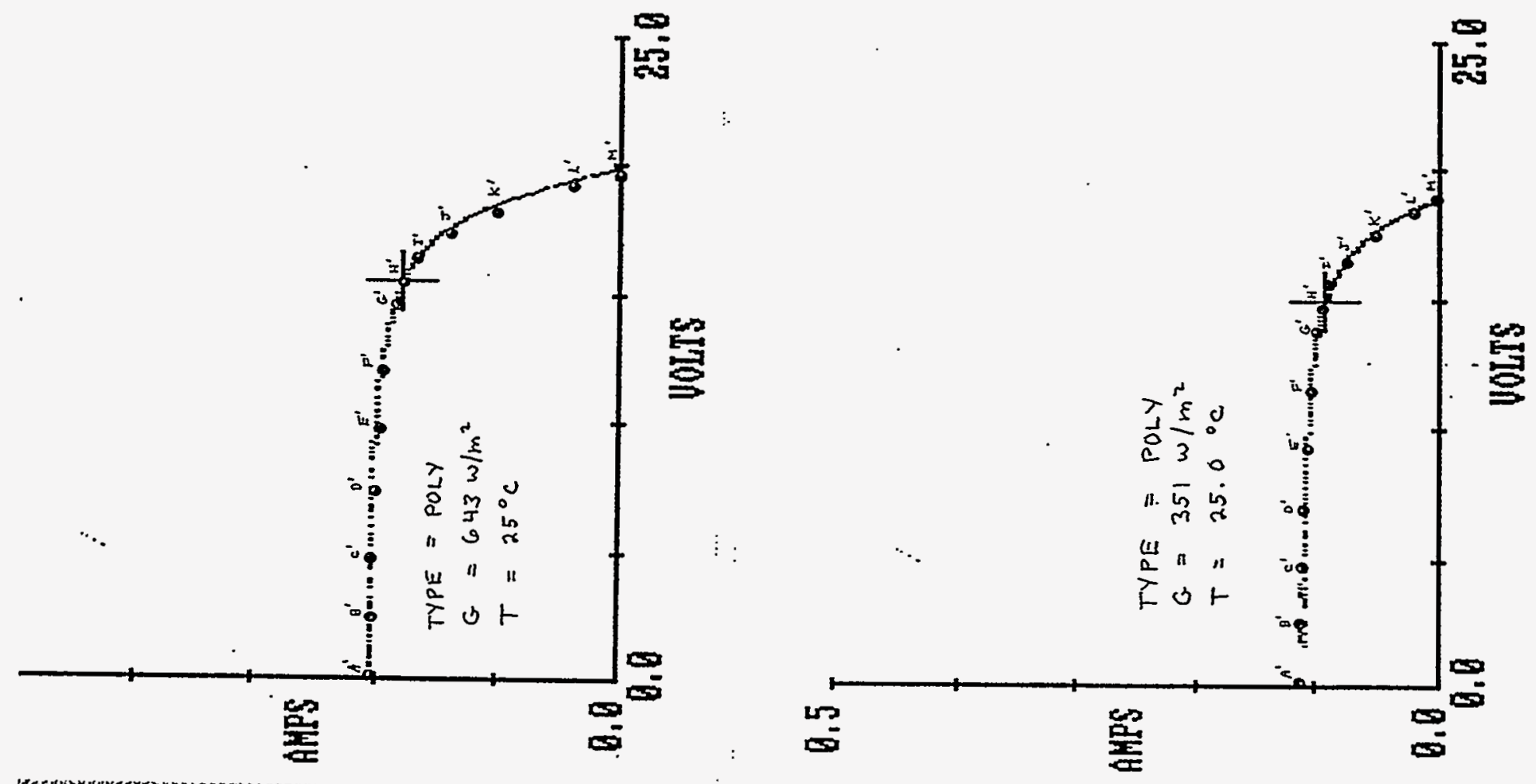

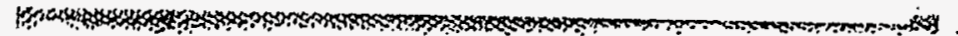
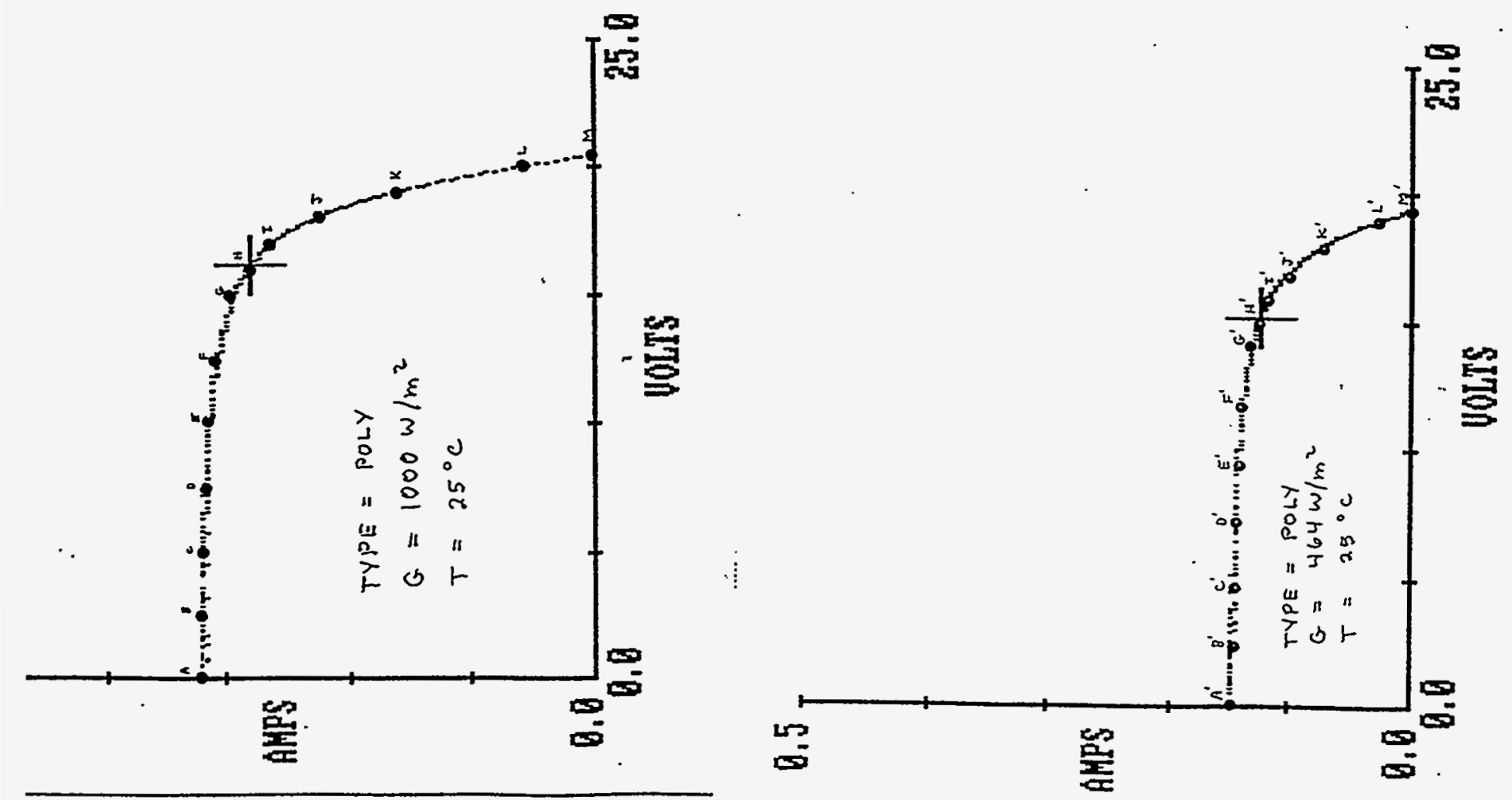


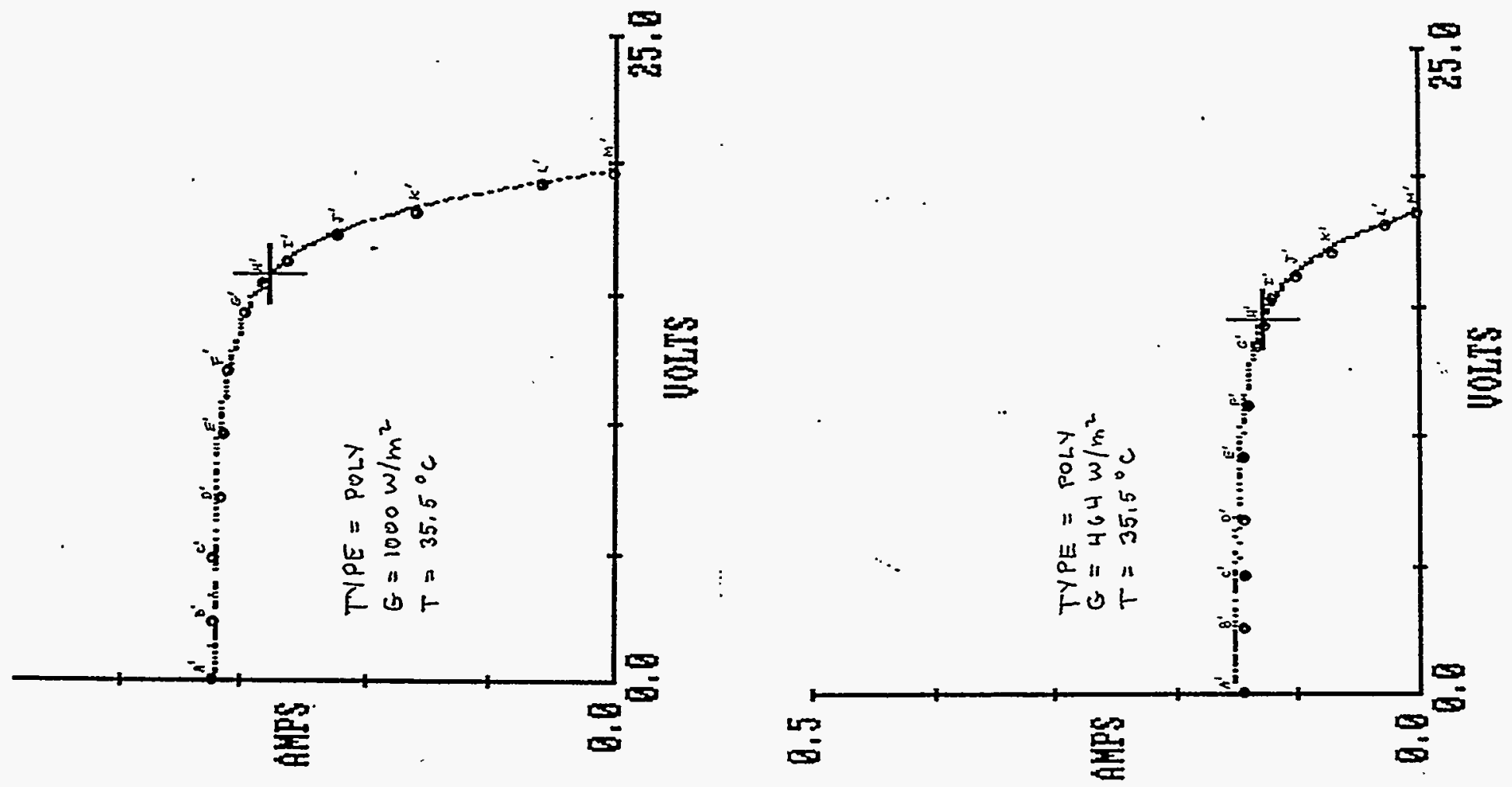

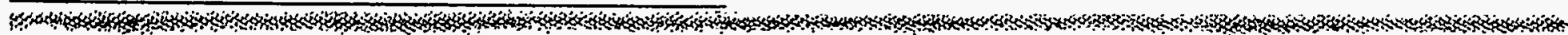
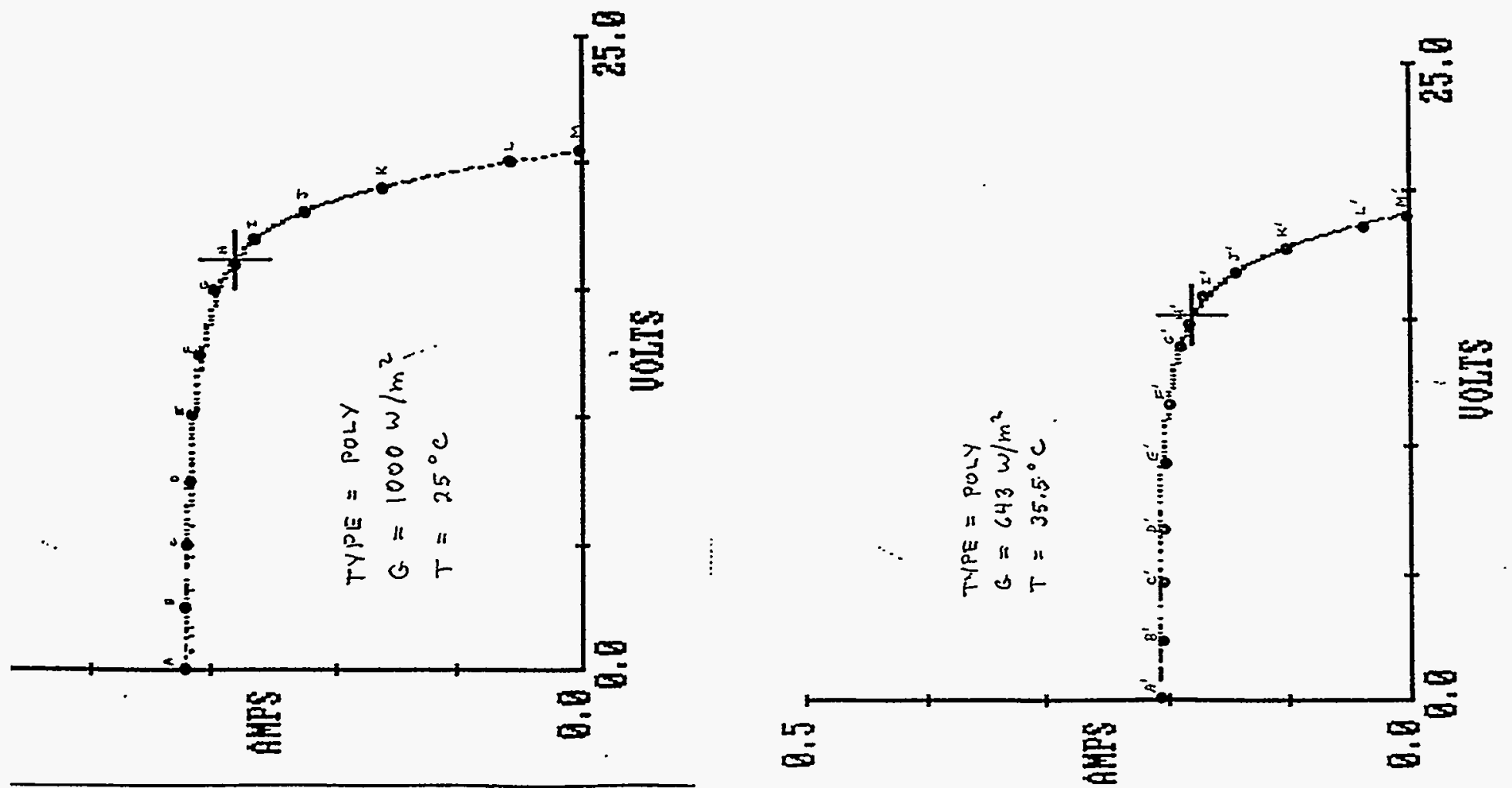

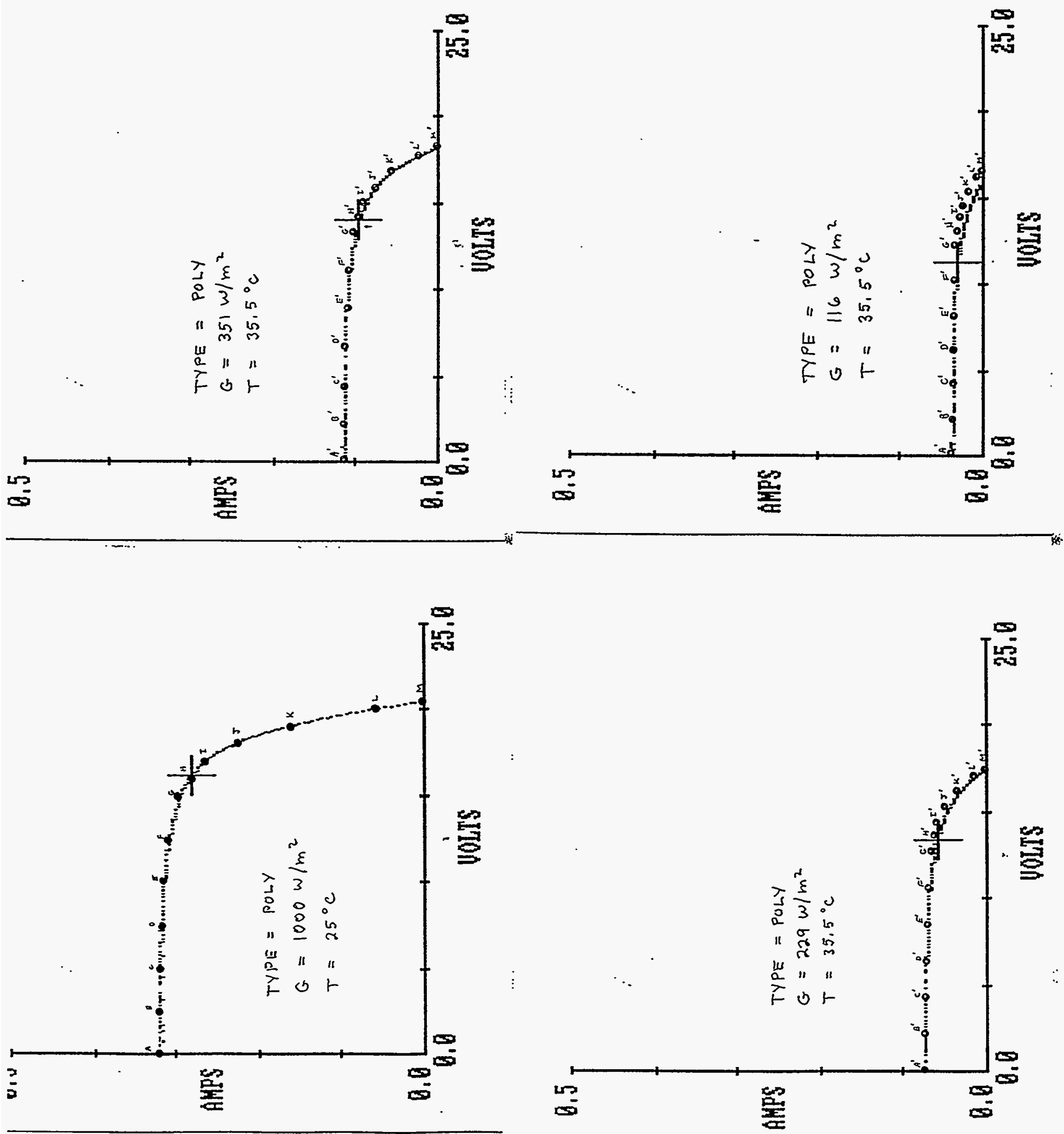

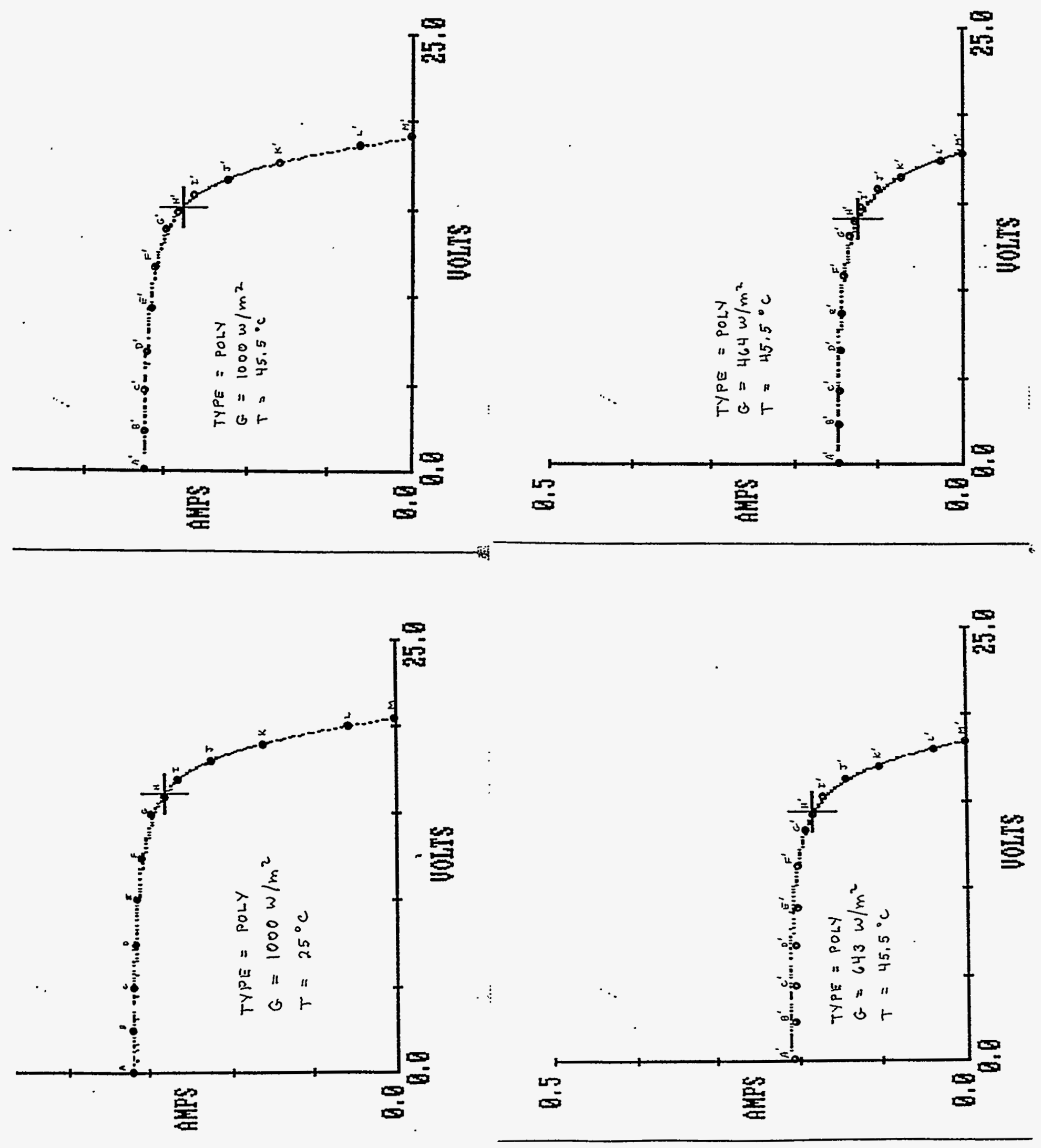

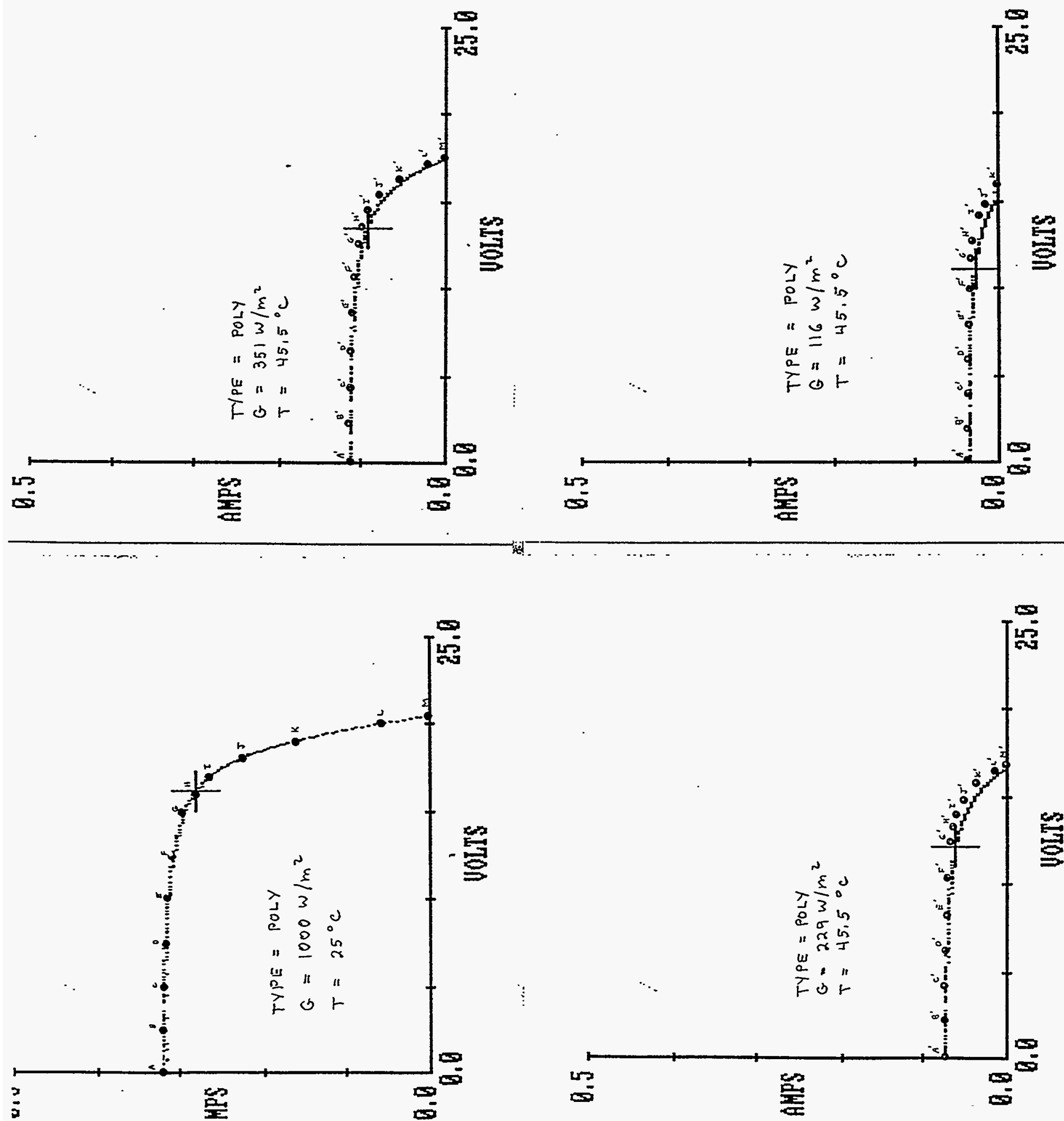

$\mid$
2
2
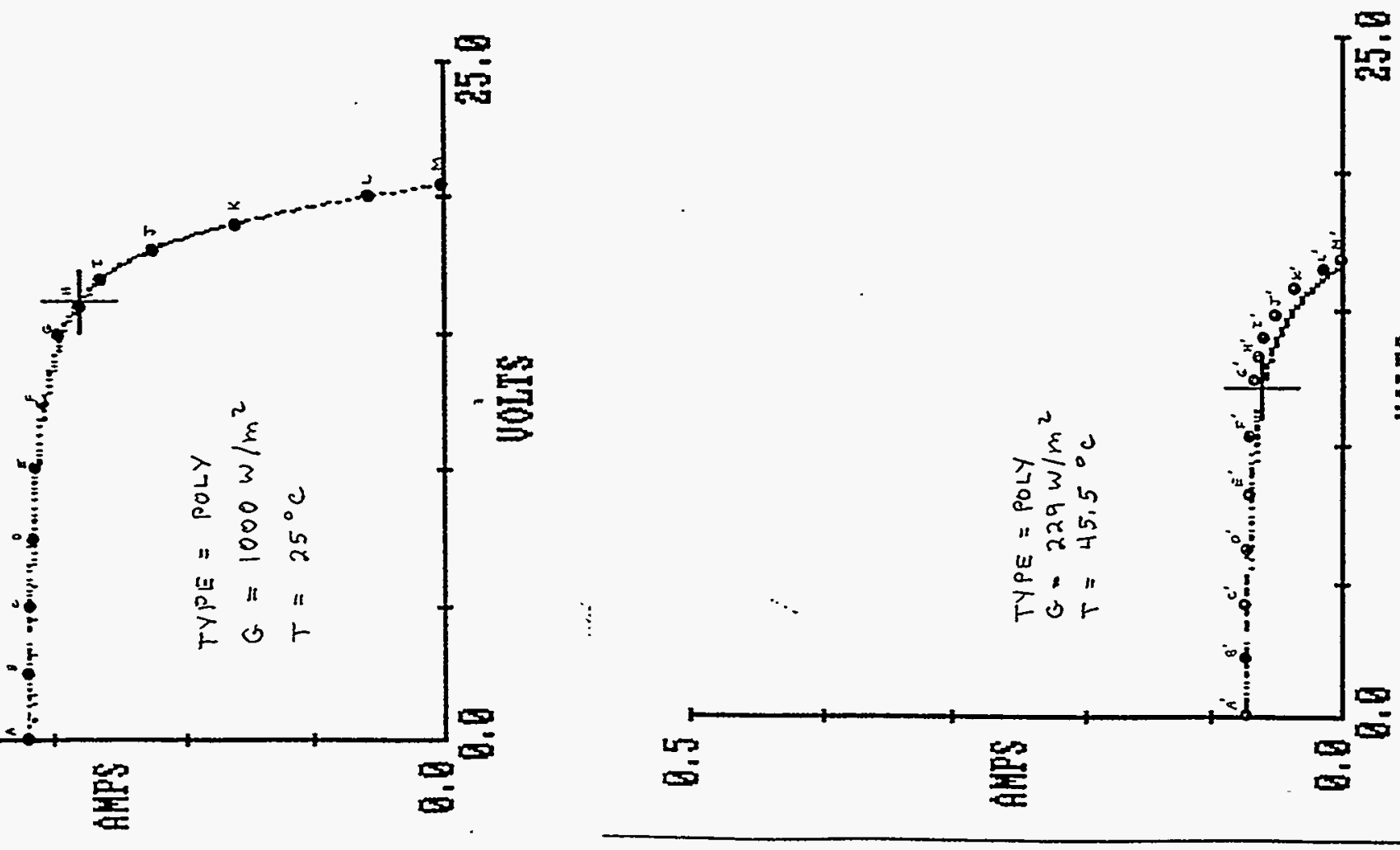

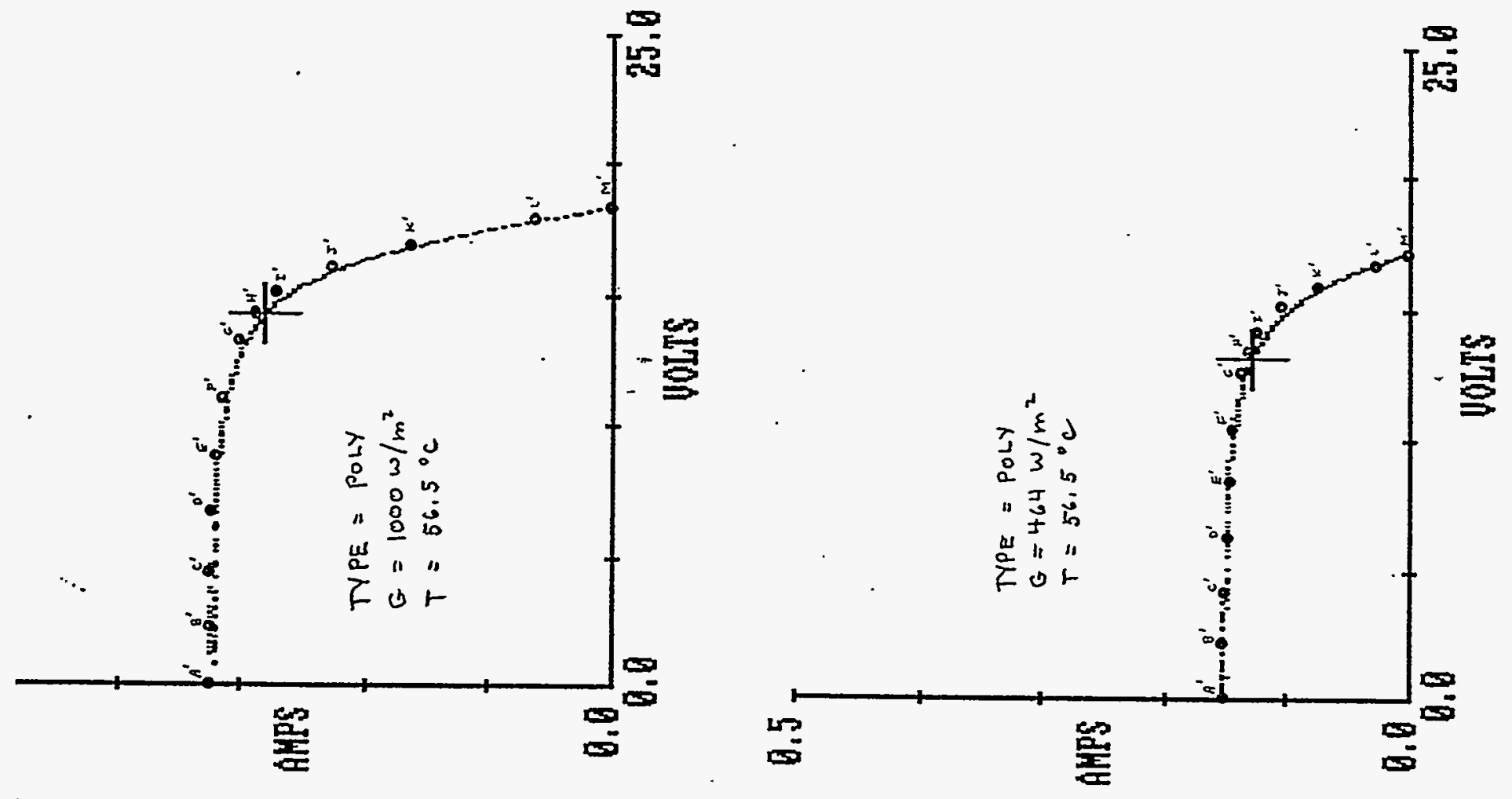

㱠
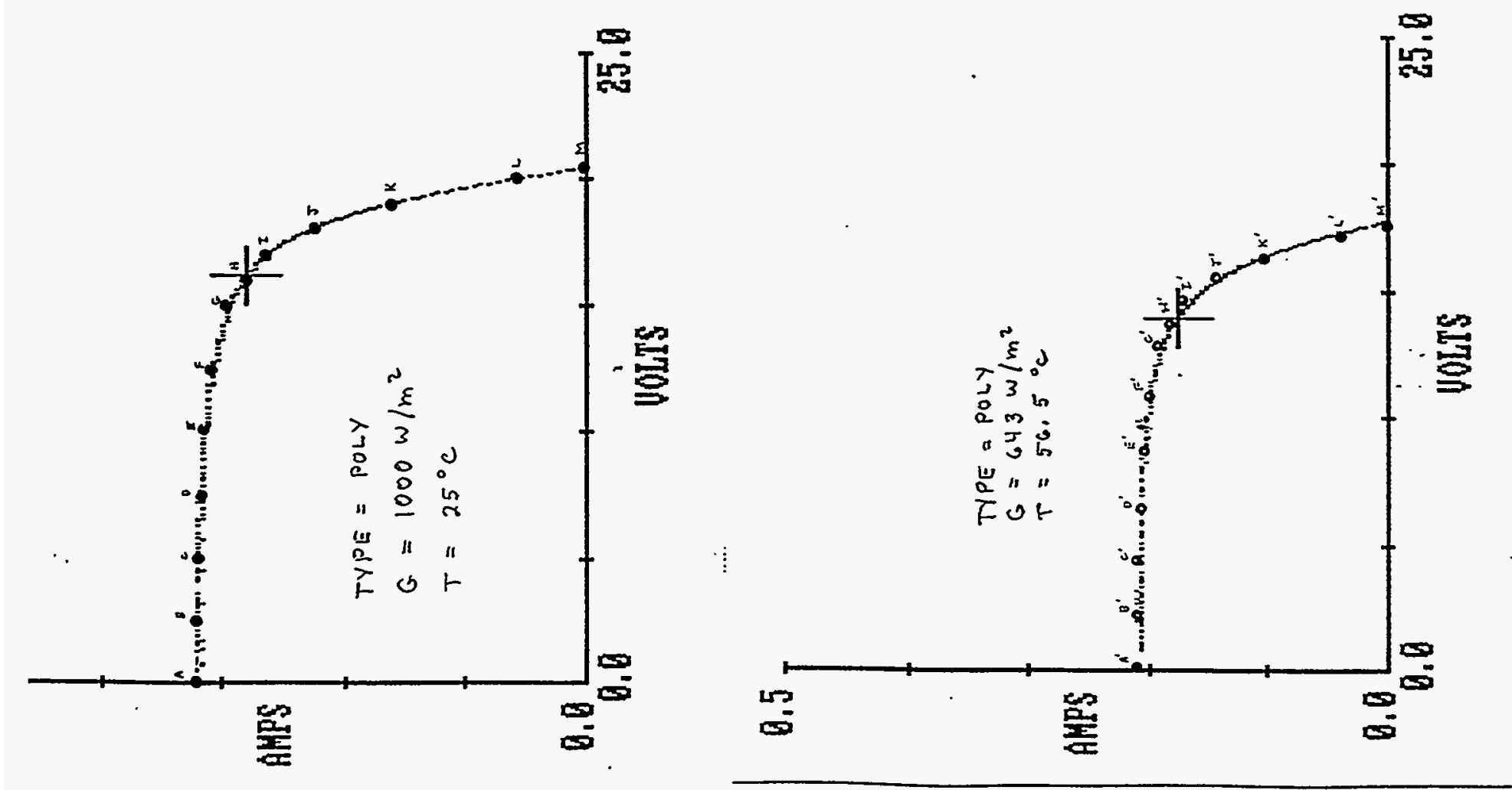

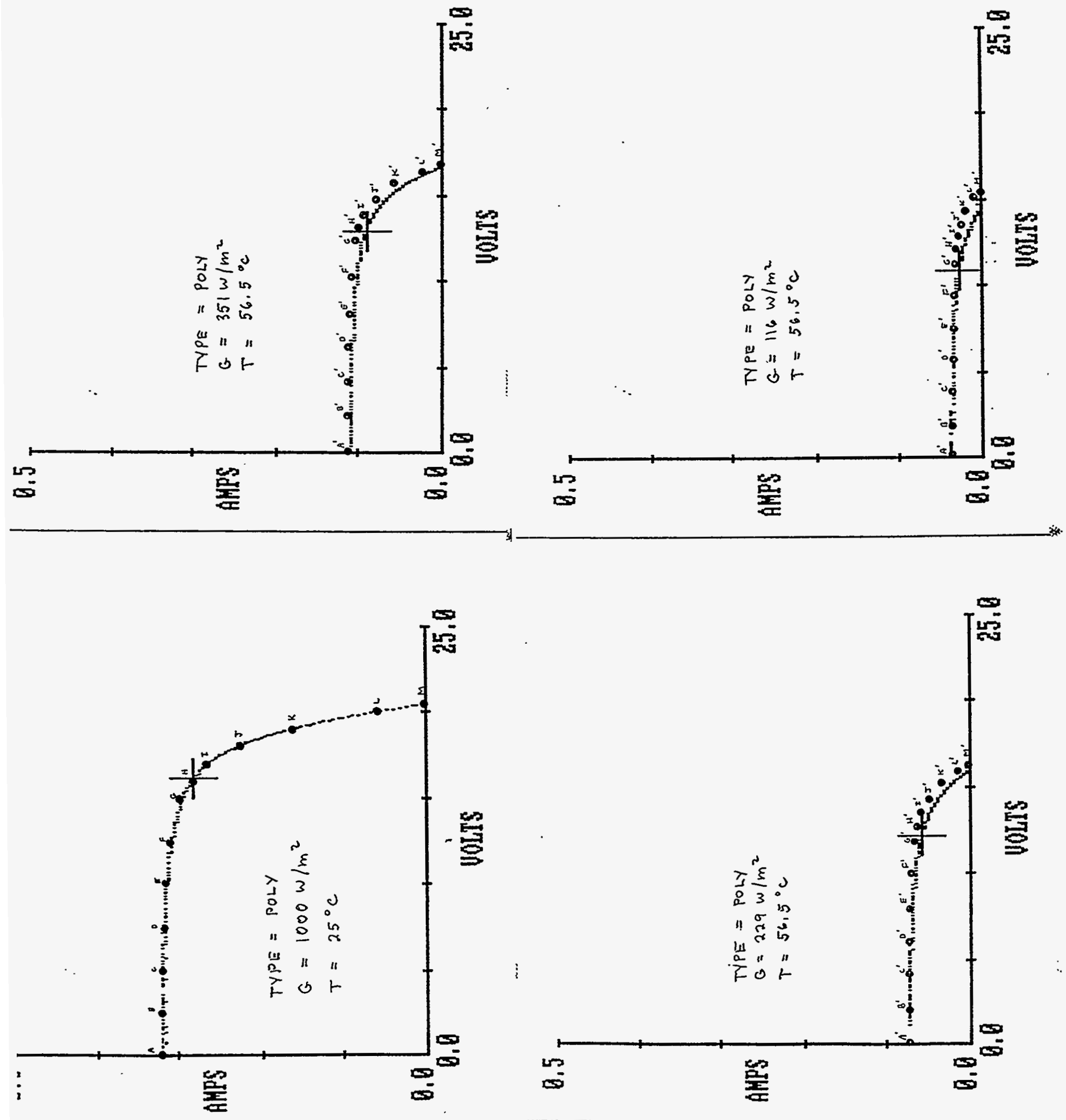

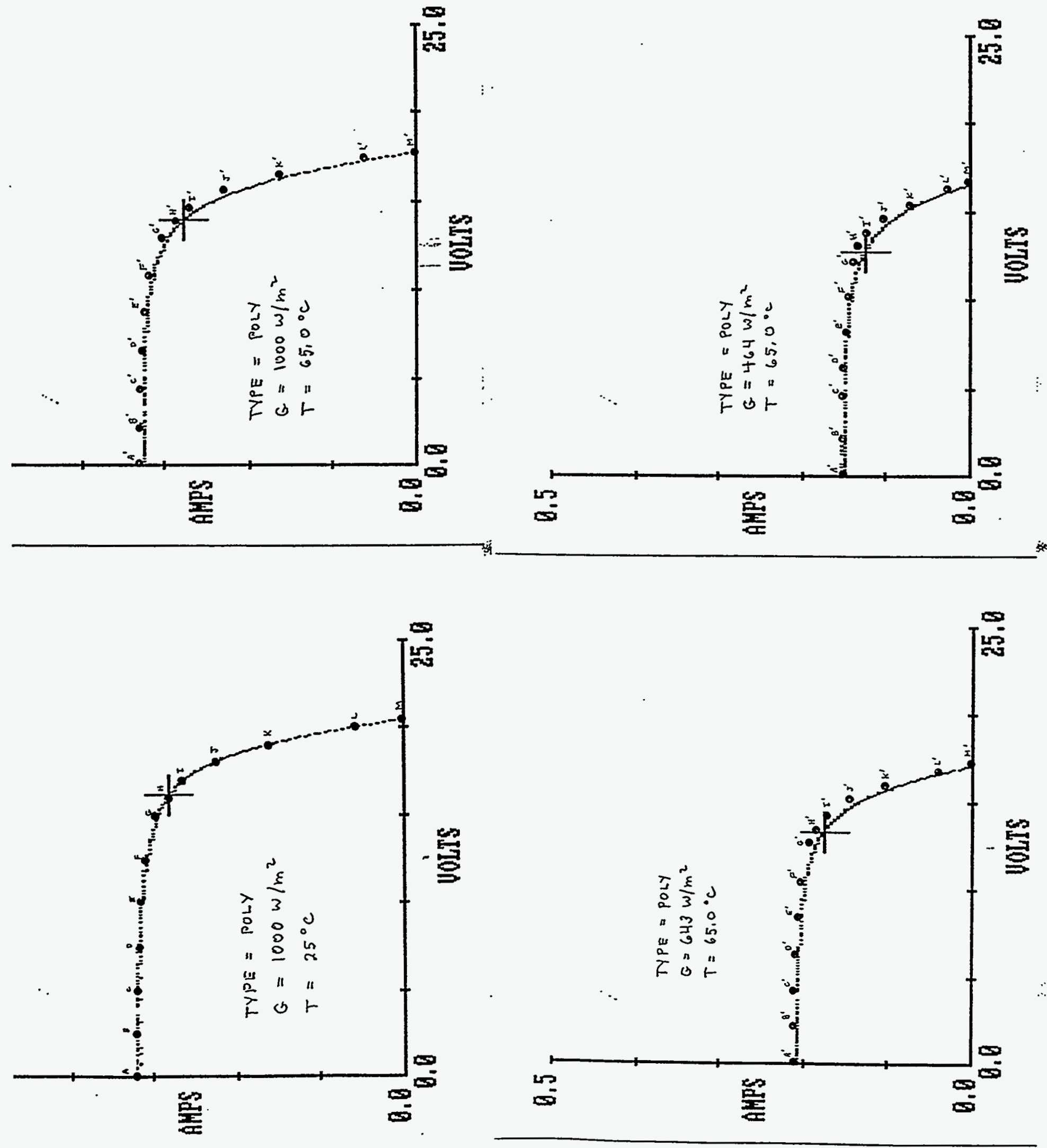


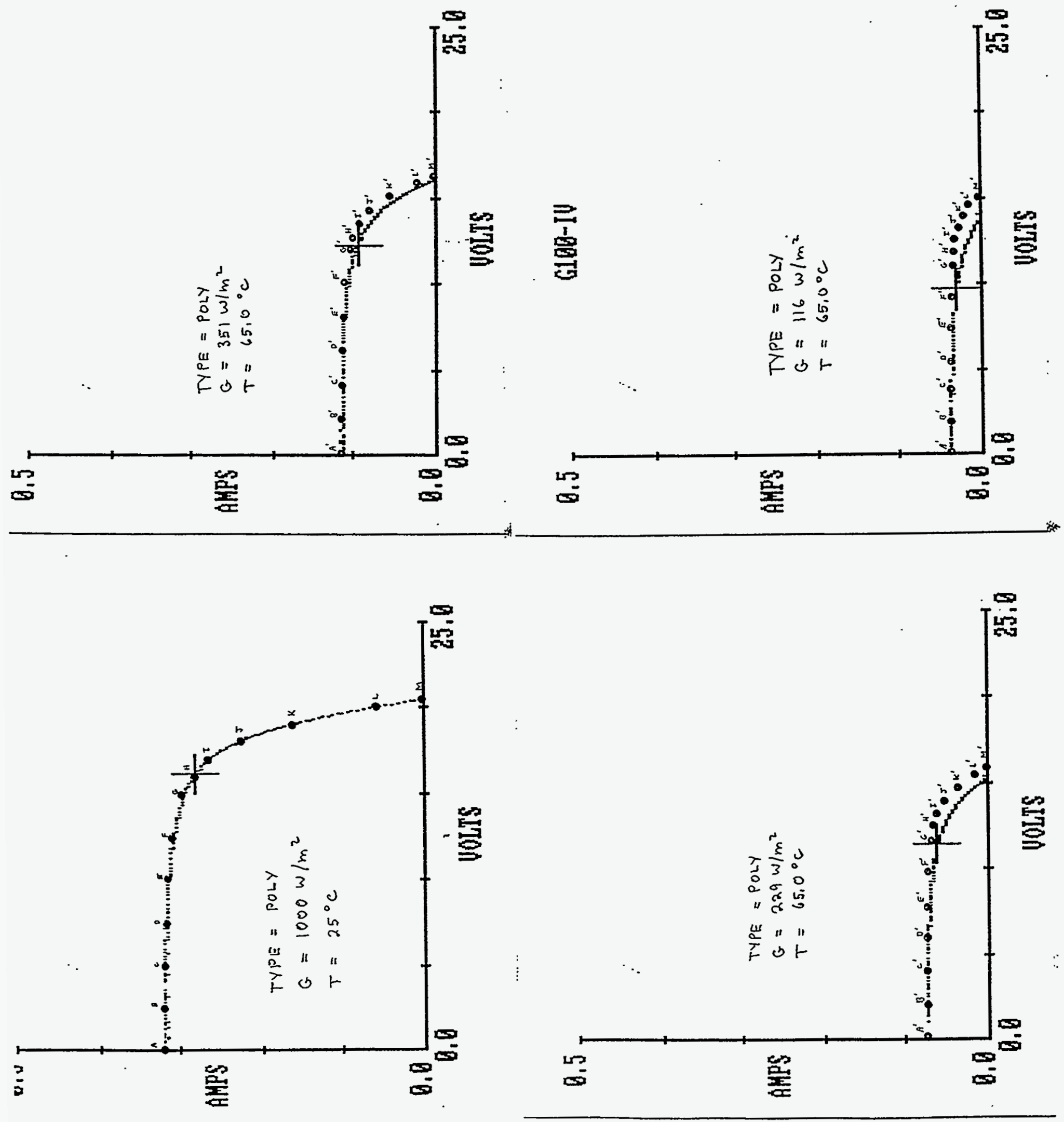



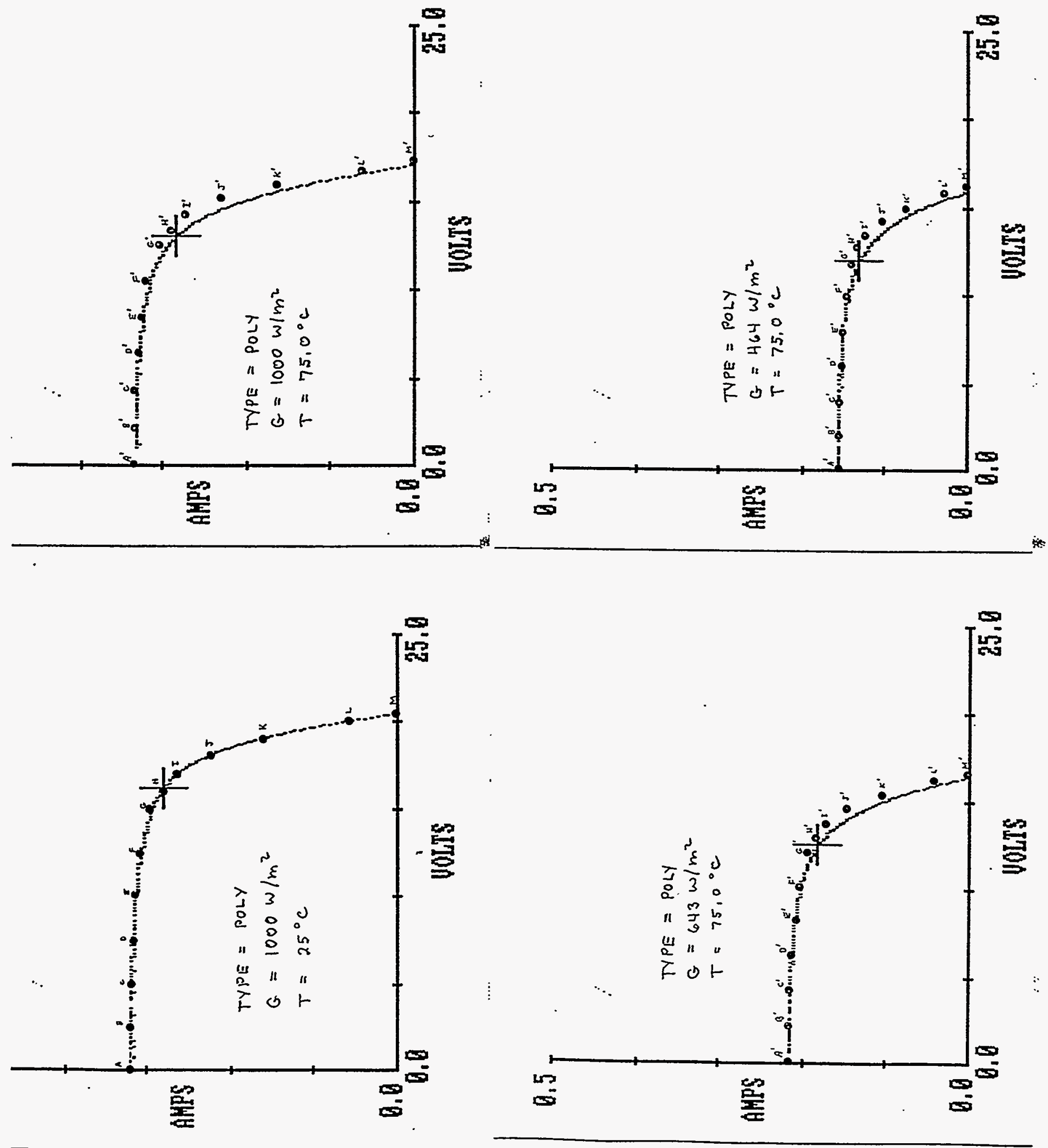
I-V TRANSLATION EQUATION CHECK FOR

THIN FILM SILICON MODULE 

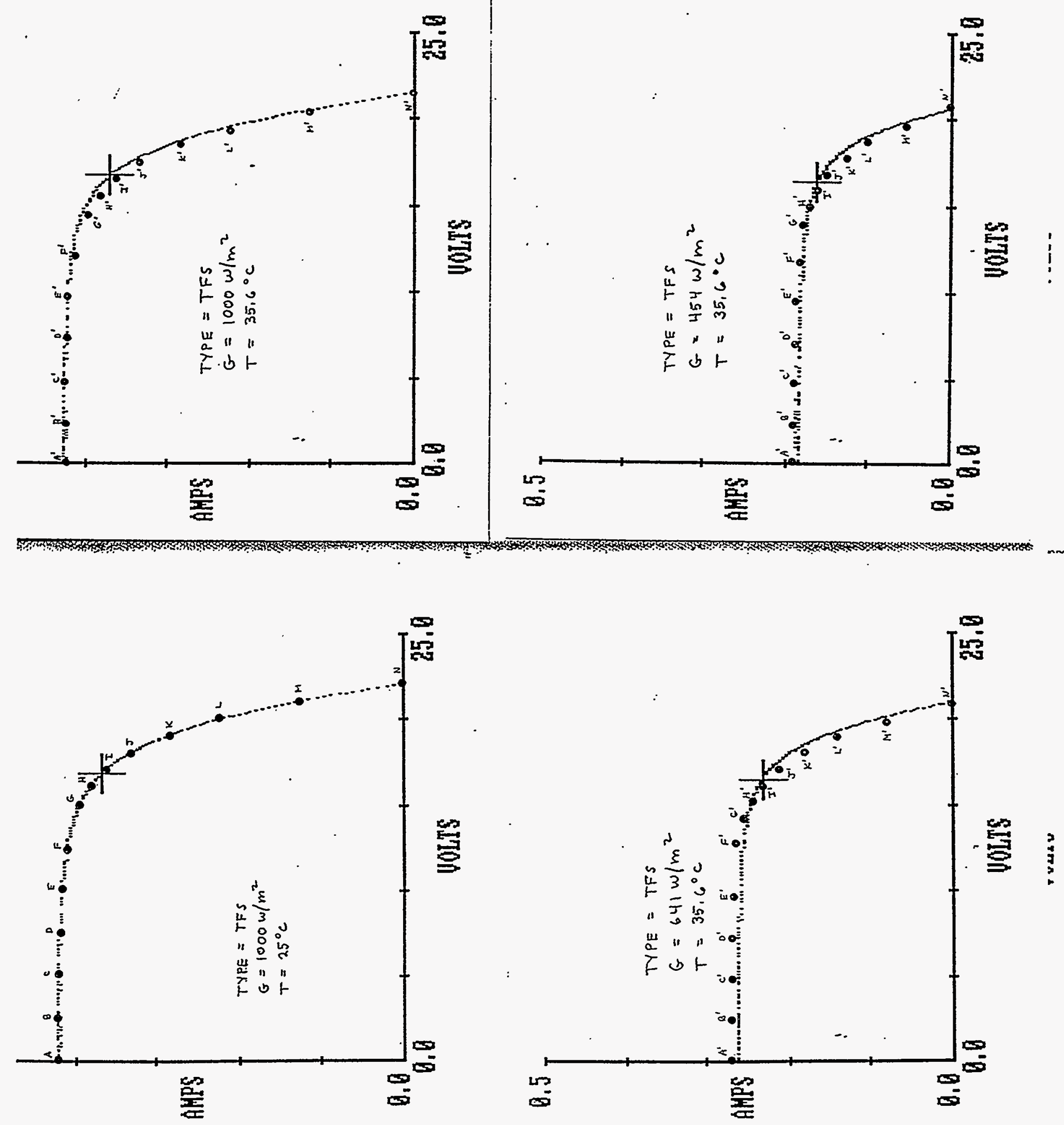

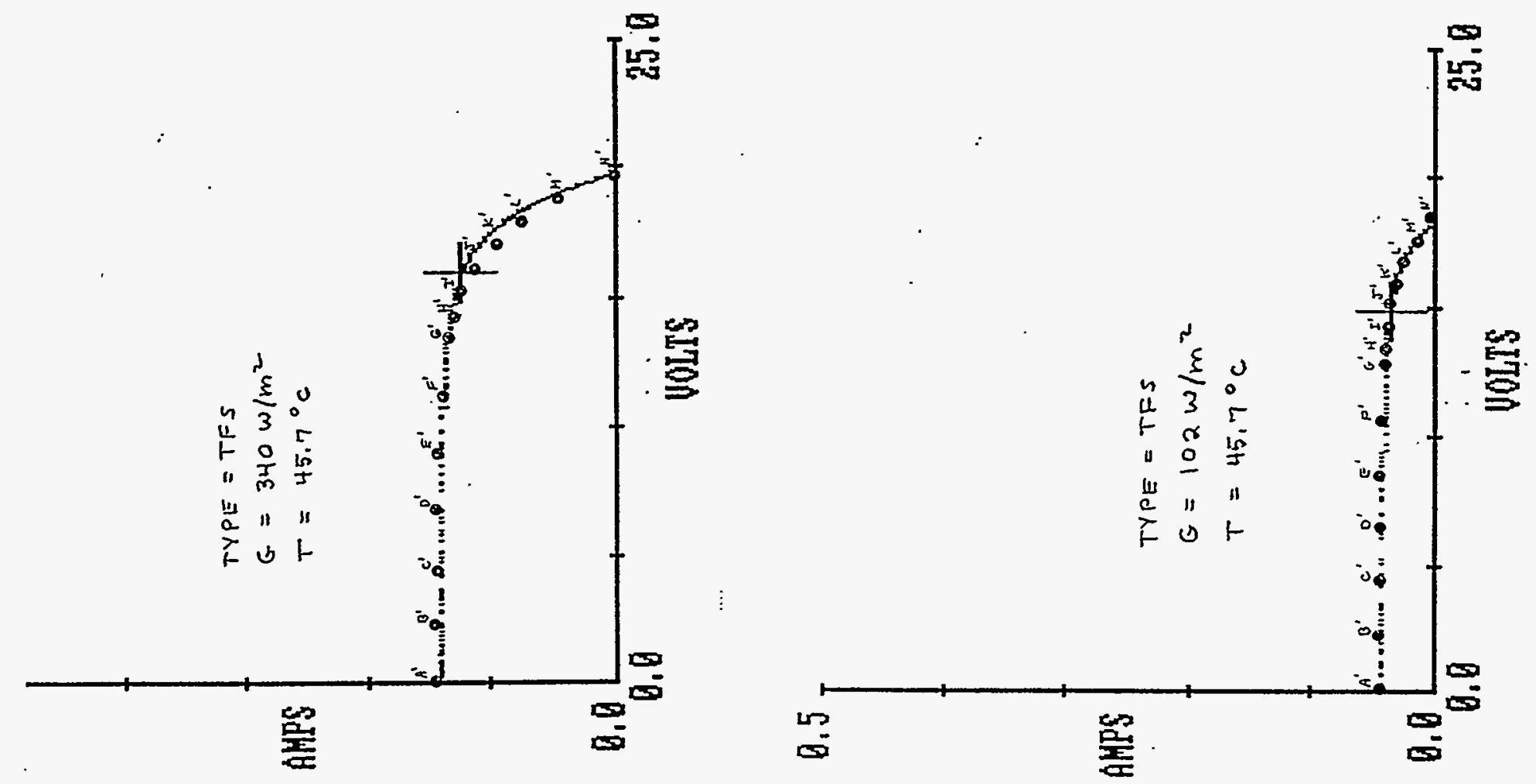

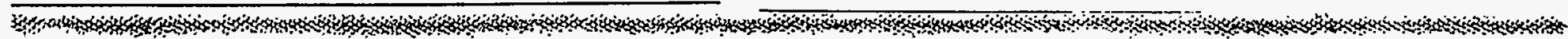
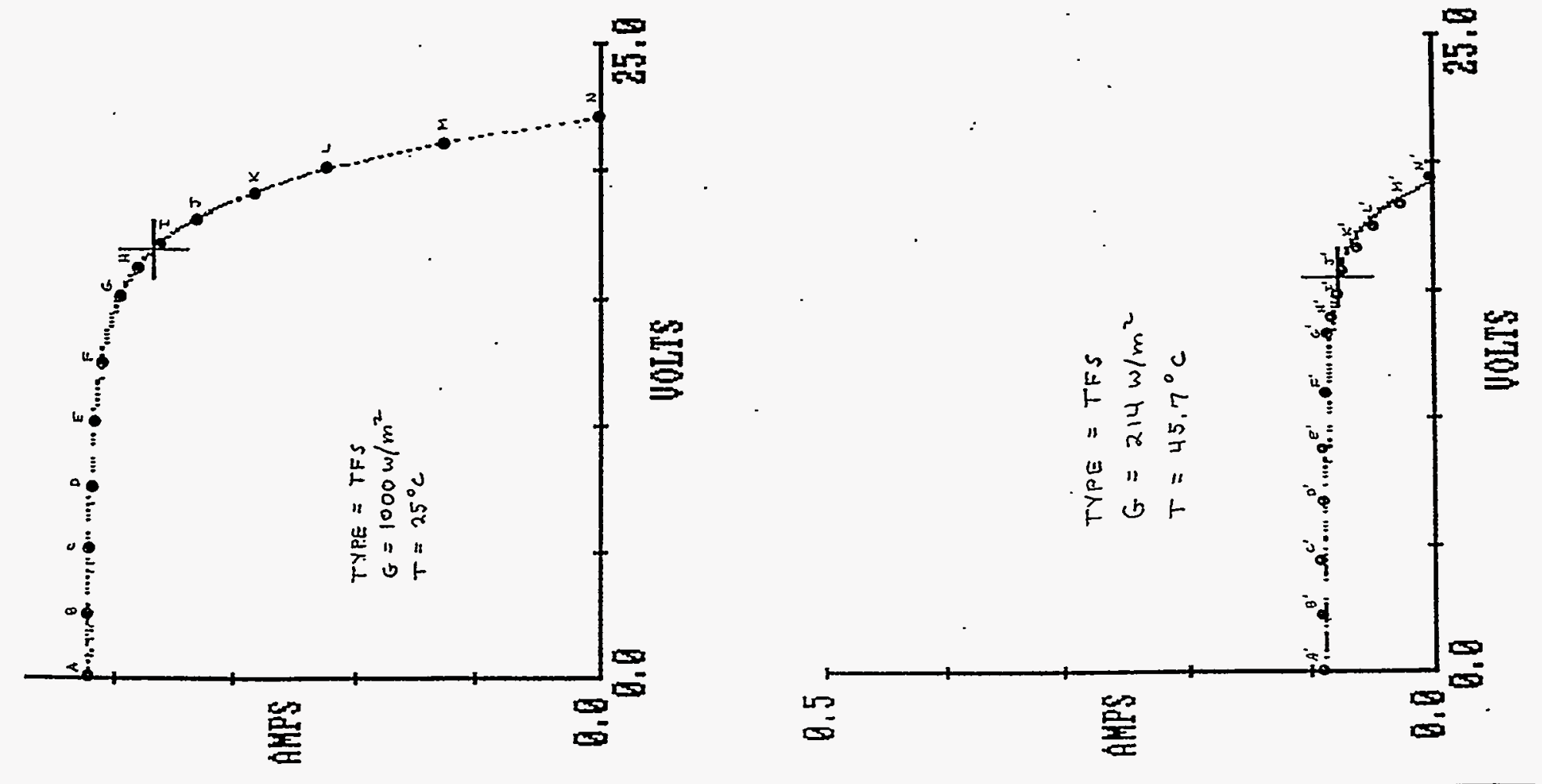

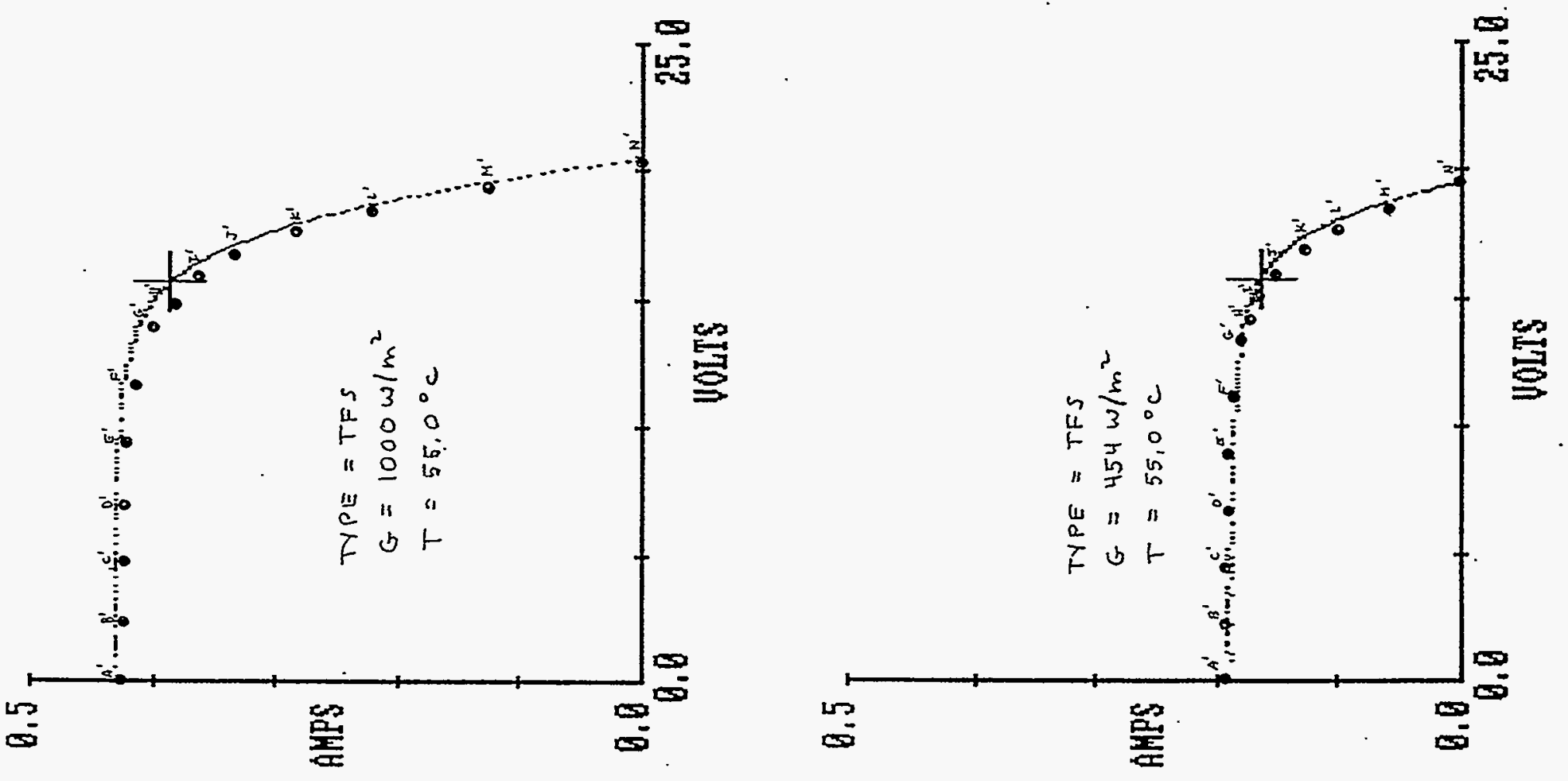

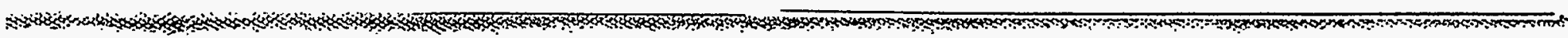
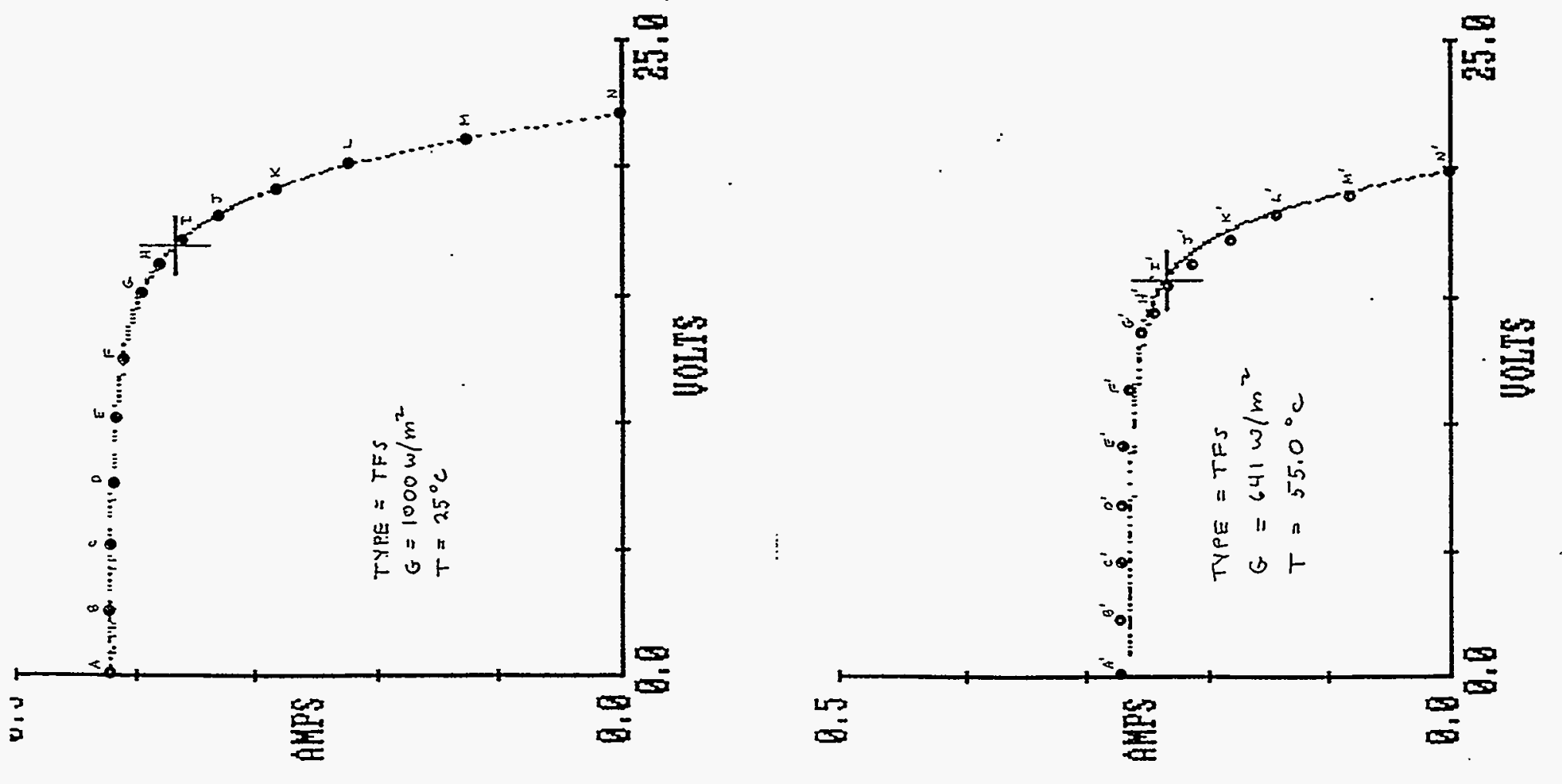

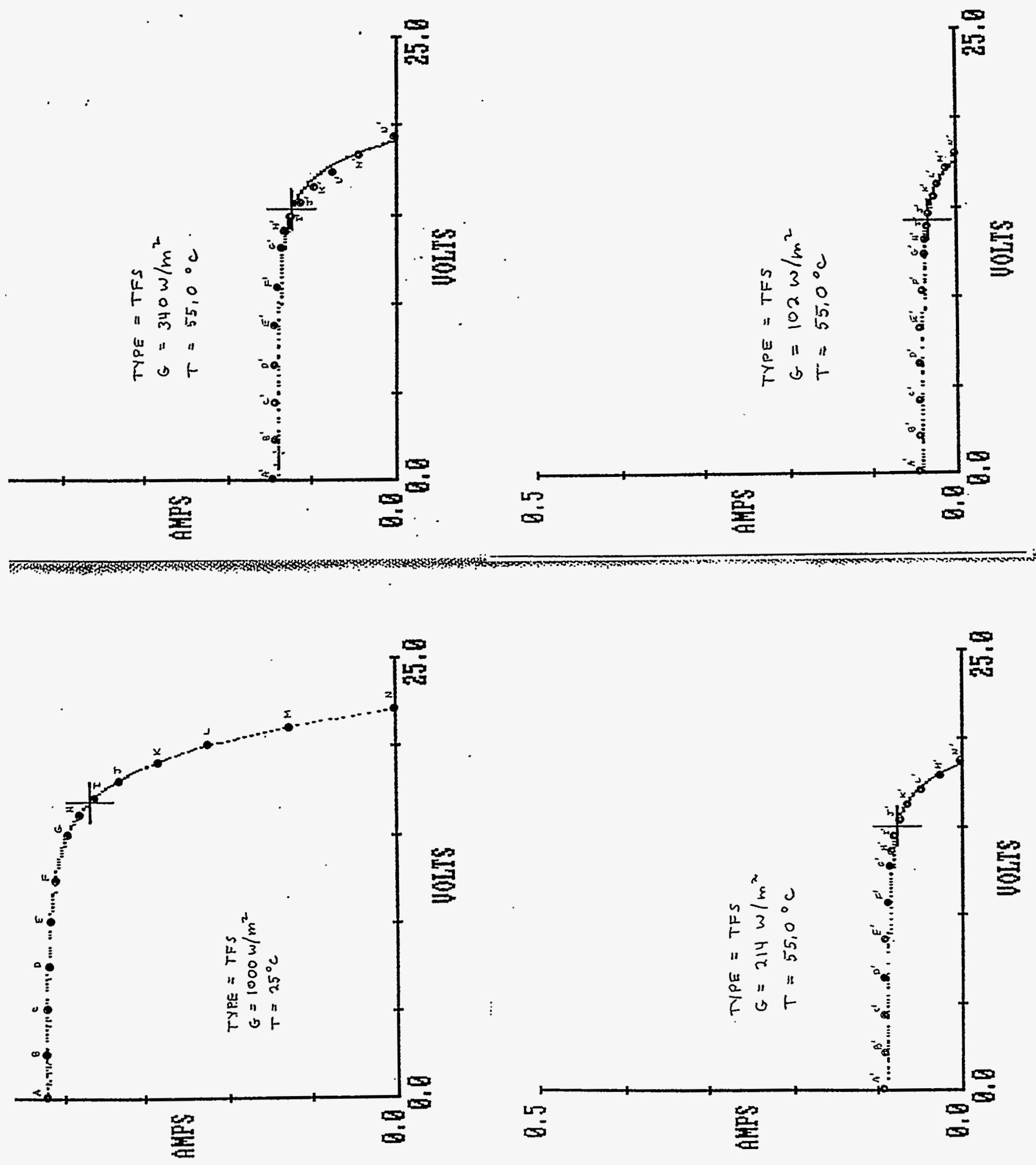

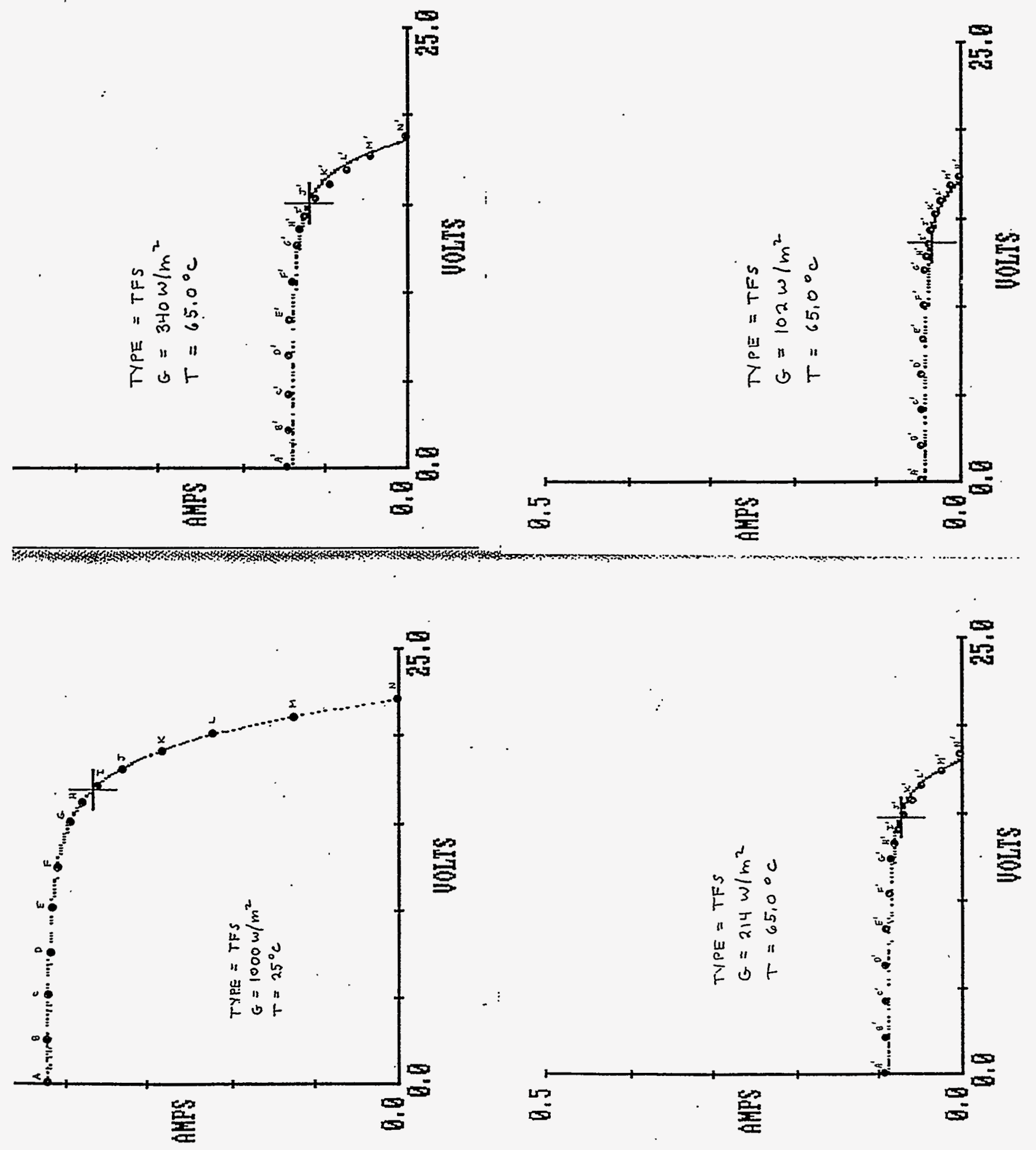

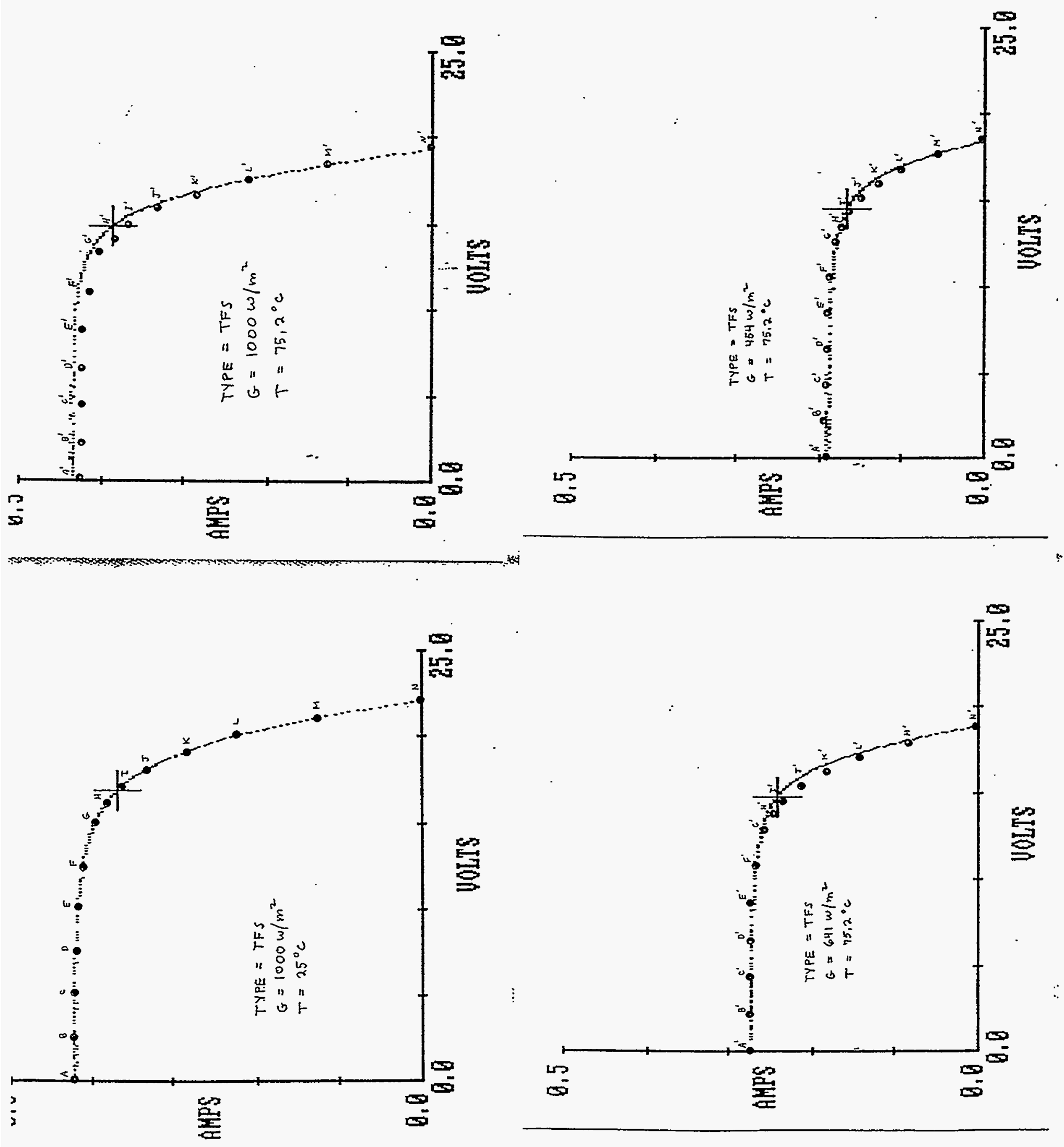

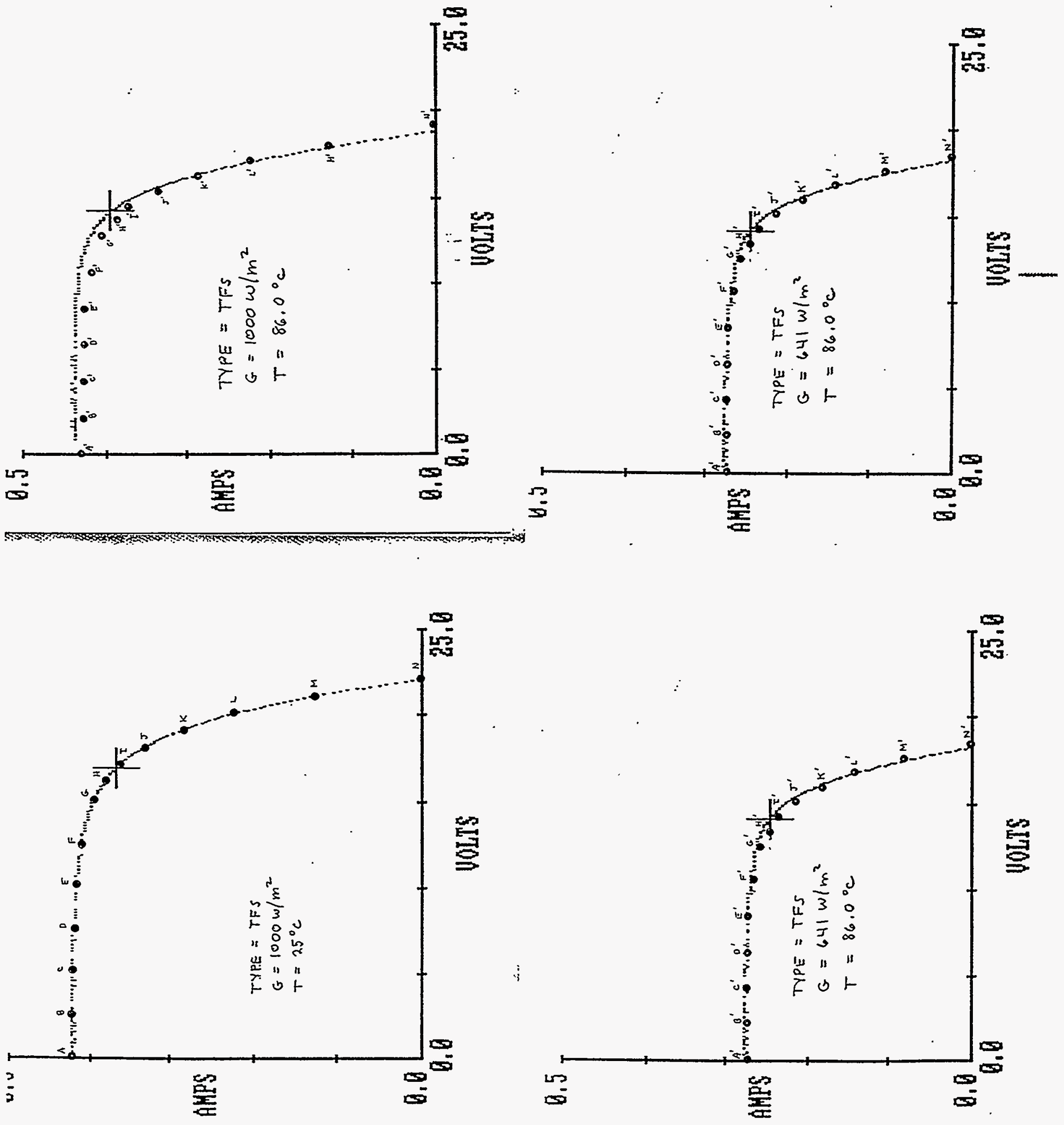

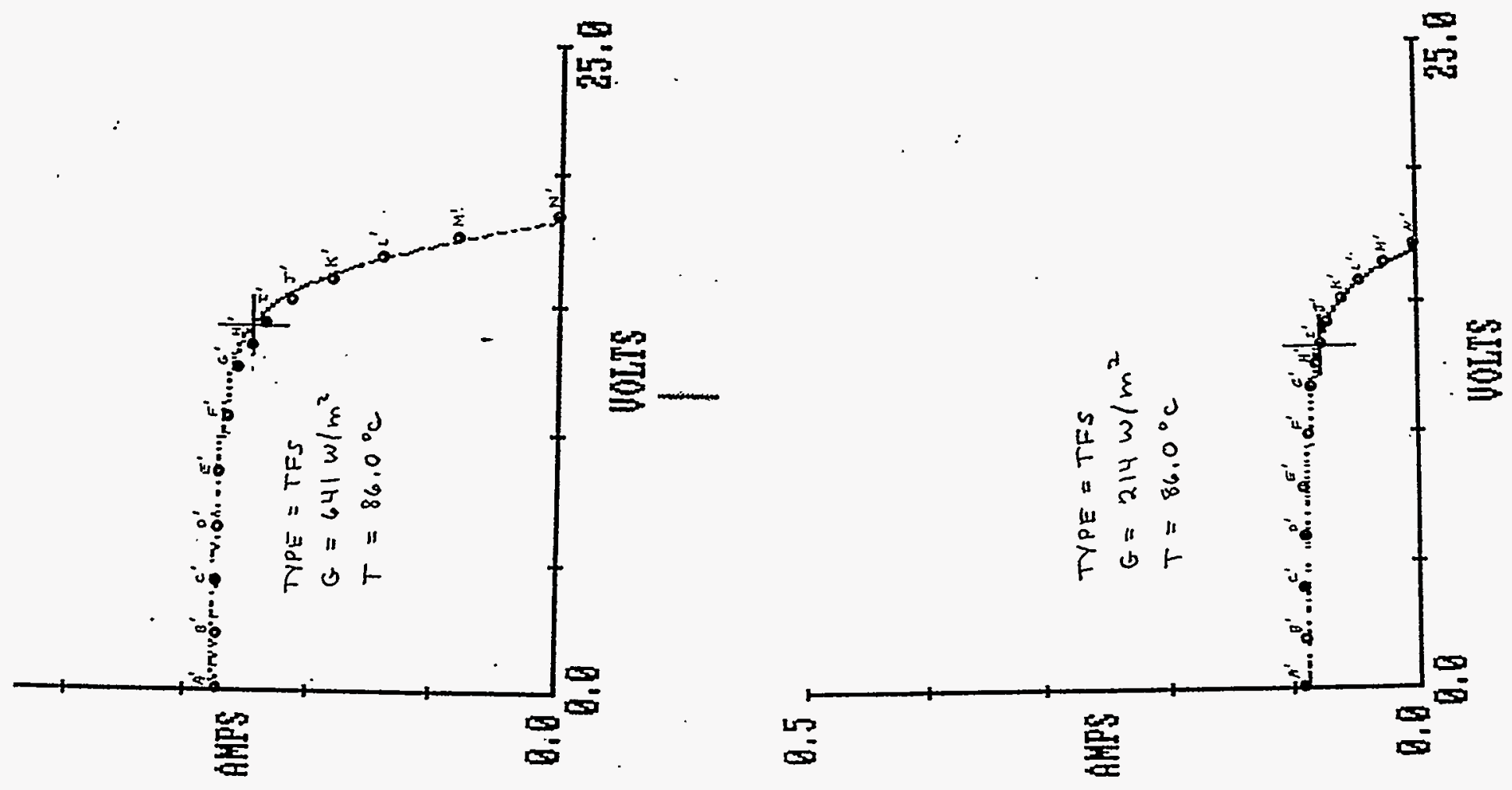

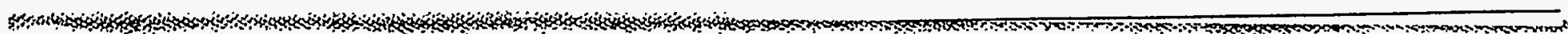
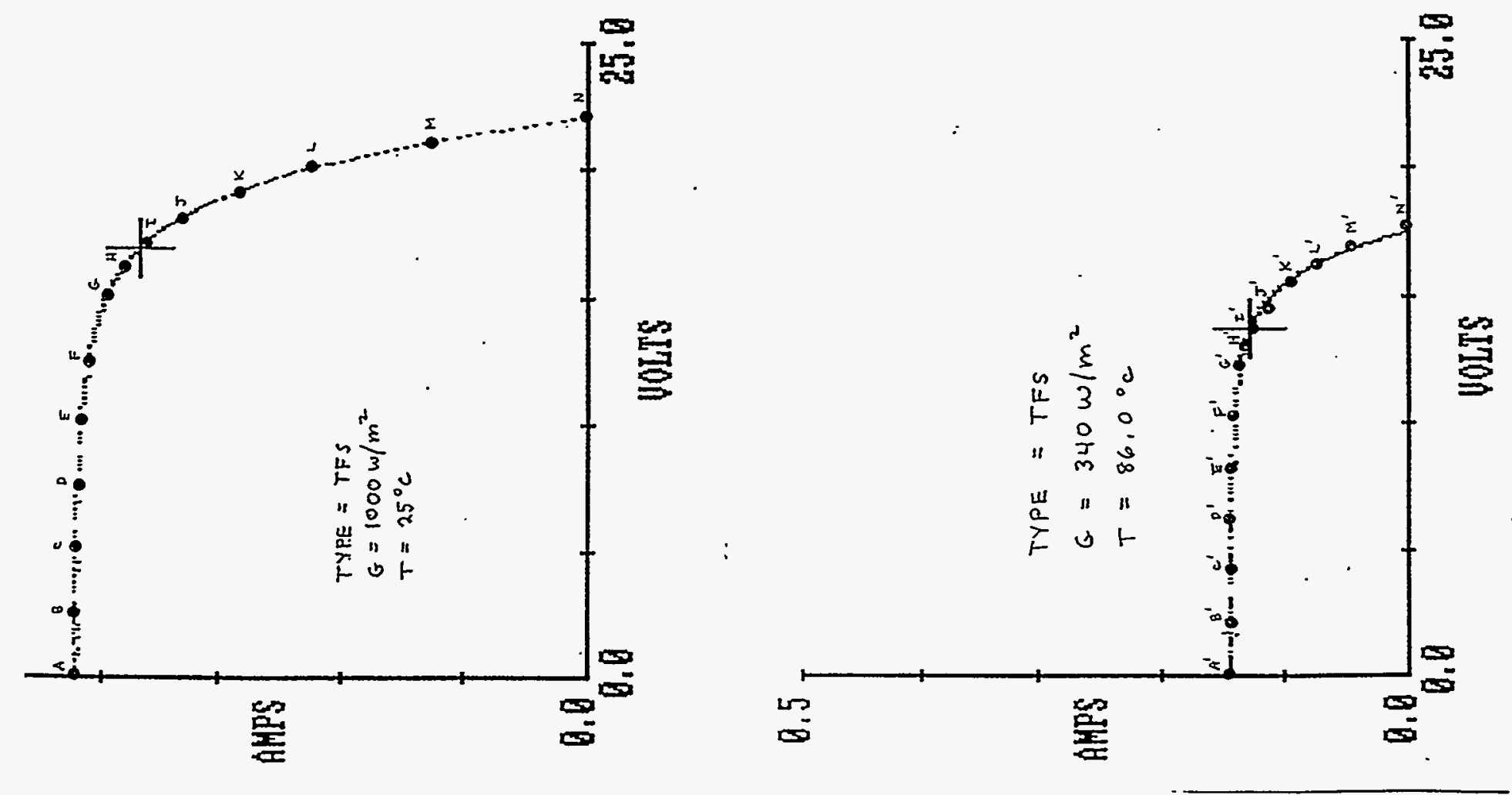


\section{APPENDIX C}

COMPARATIVE I-V DATA POINT PAIRS FOR THE

NEW EQUATIONS VS ASTM E1036 EQUATIONS

VS ACTUAL I-V CURVE CHARACTERISTICS 


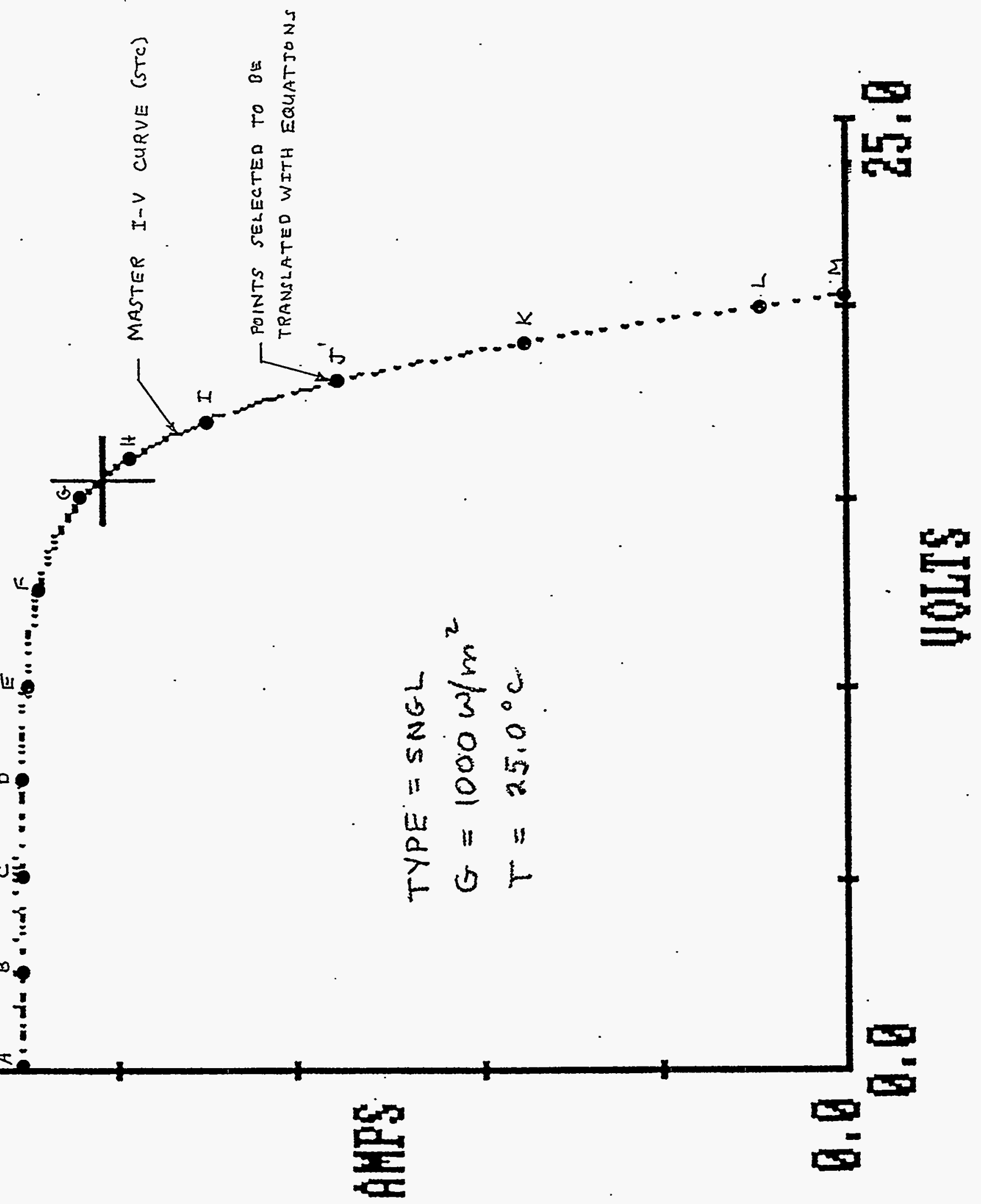




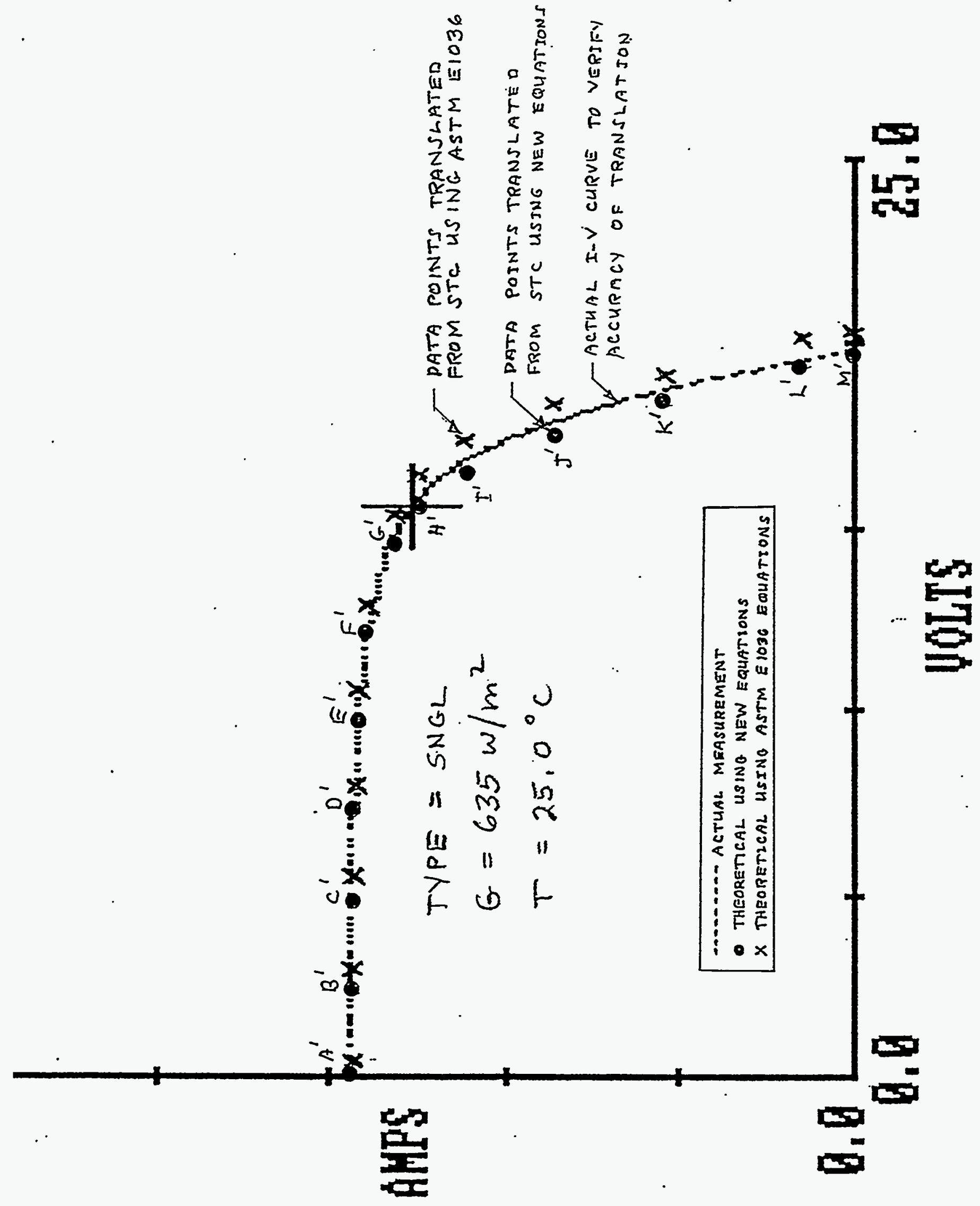




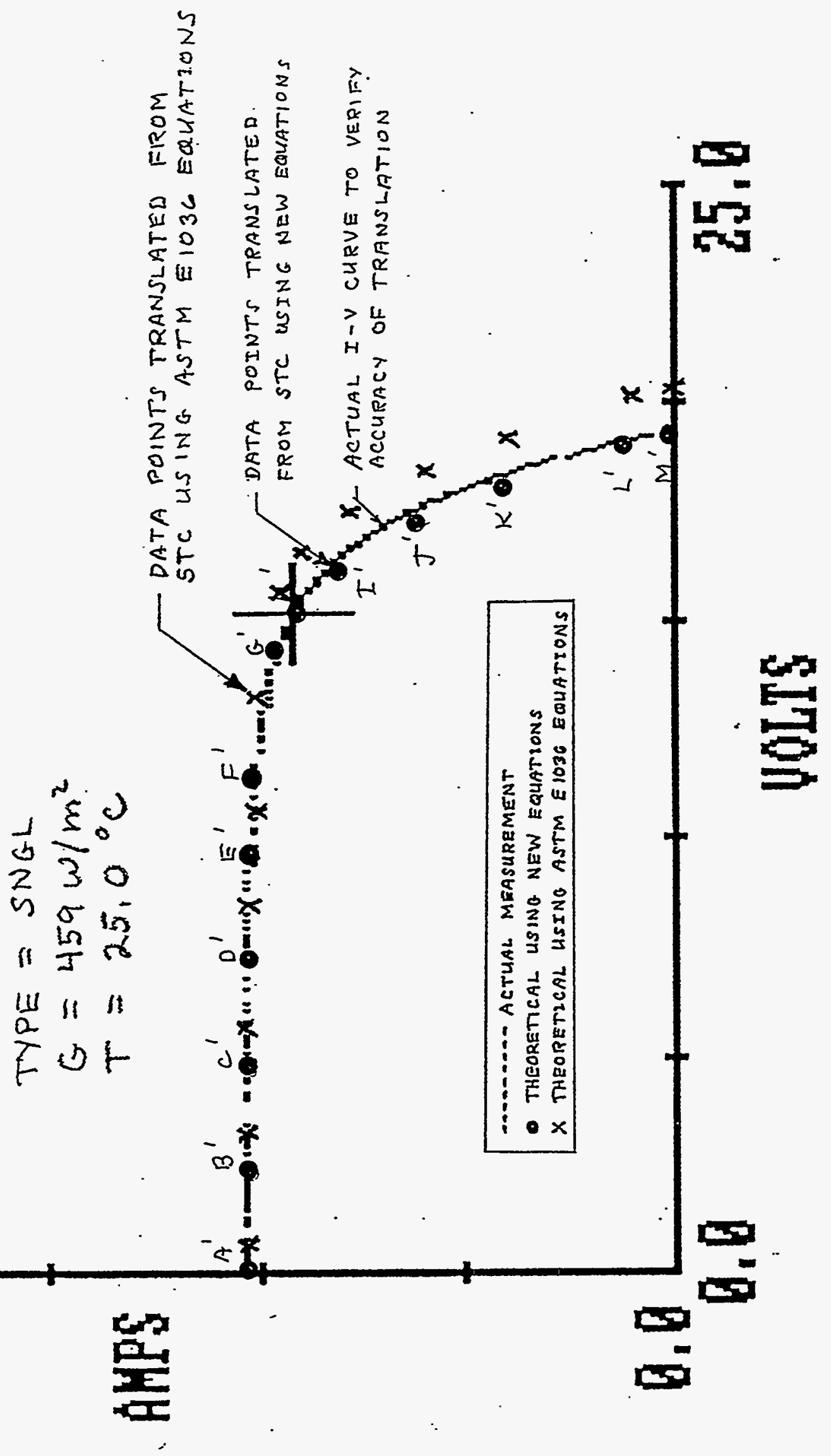




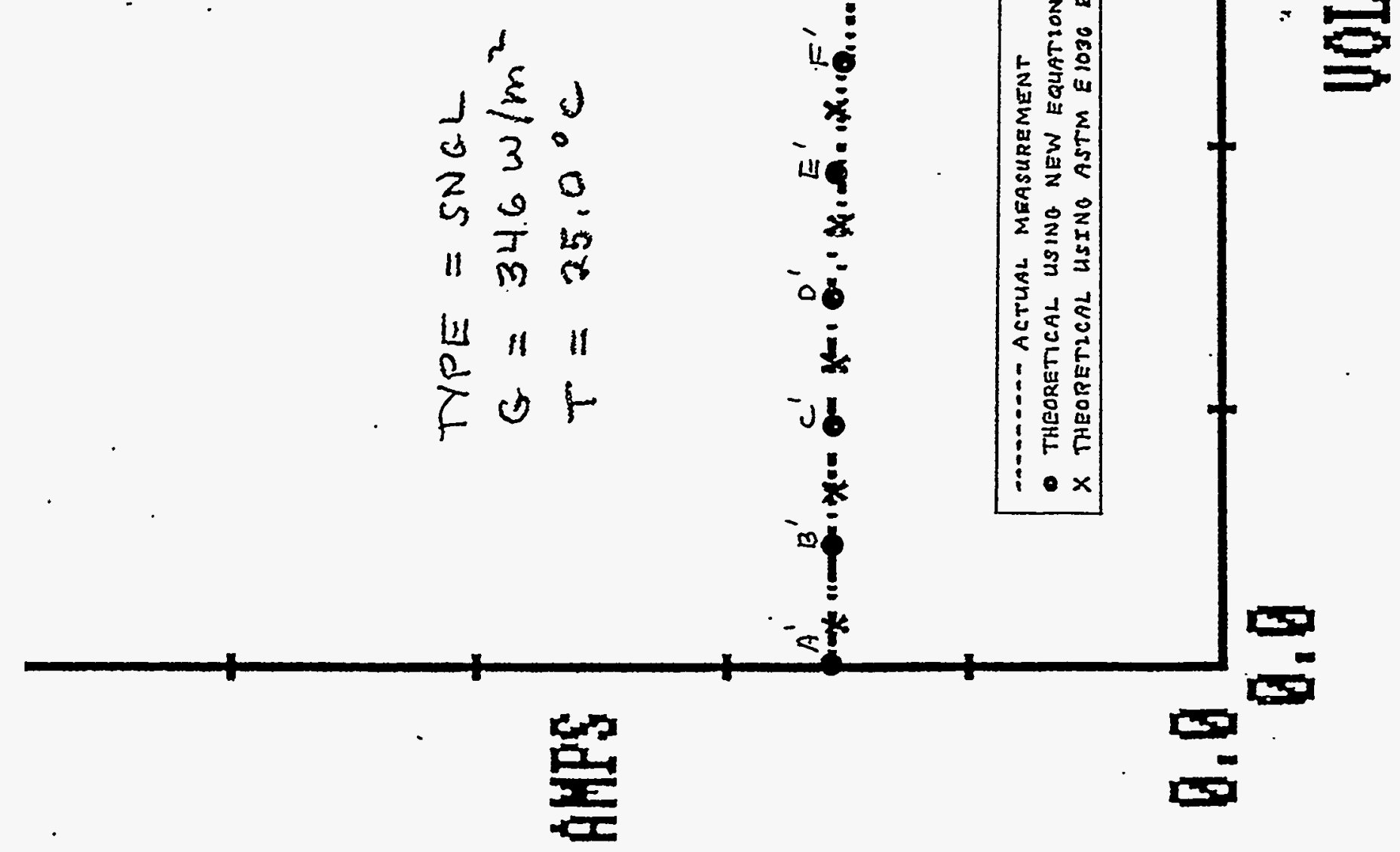




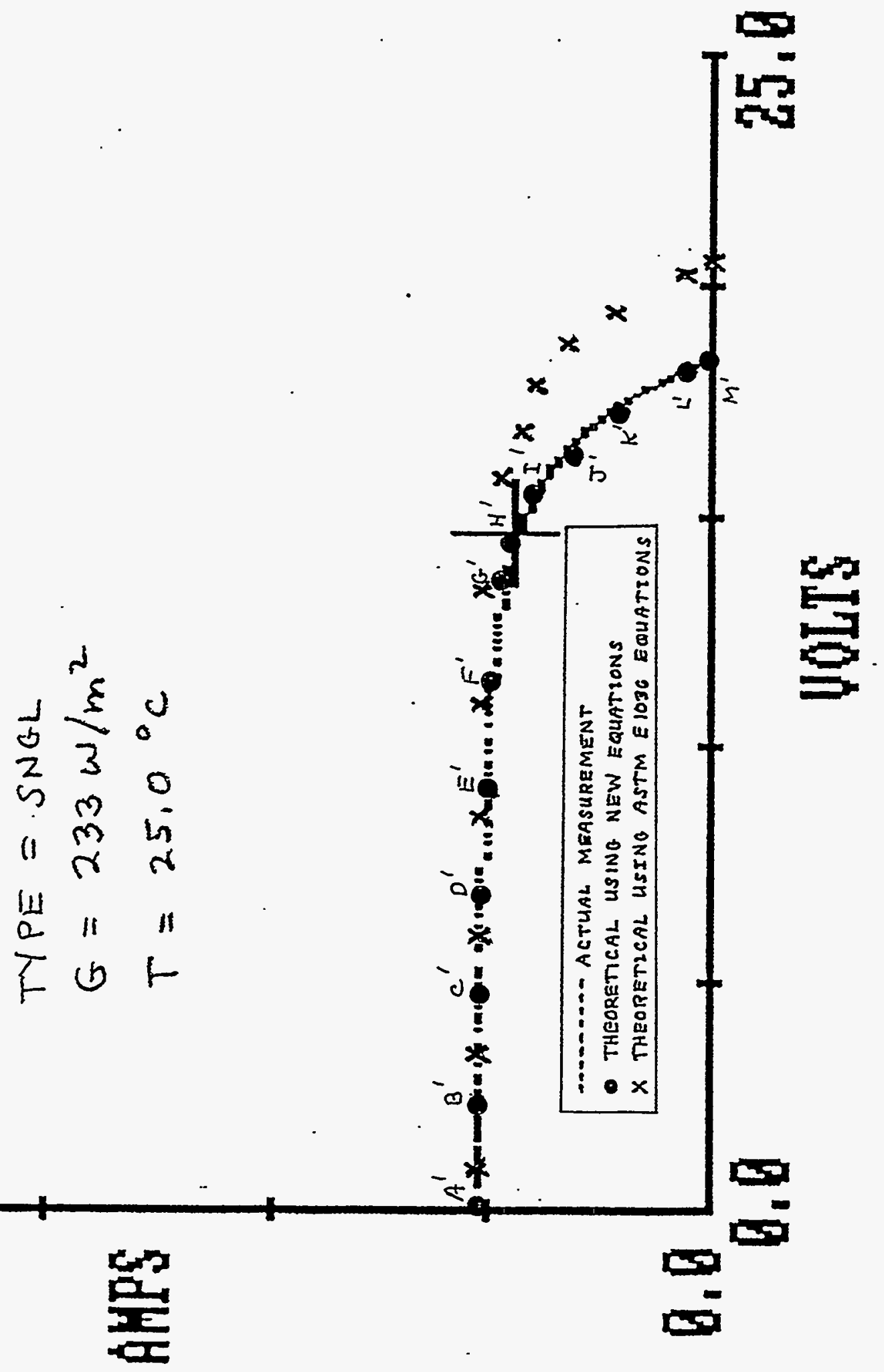




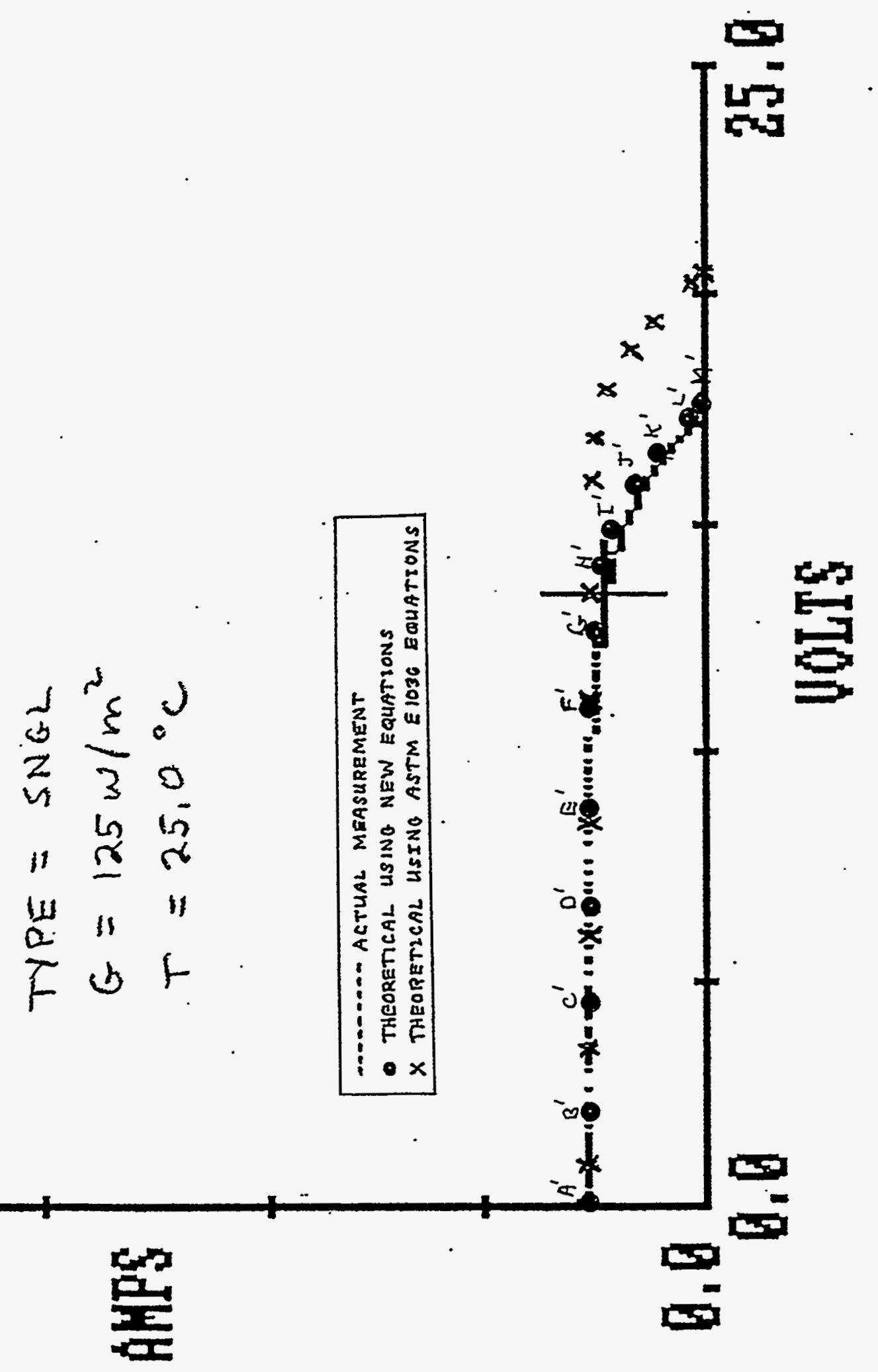




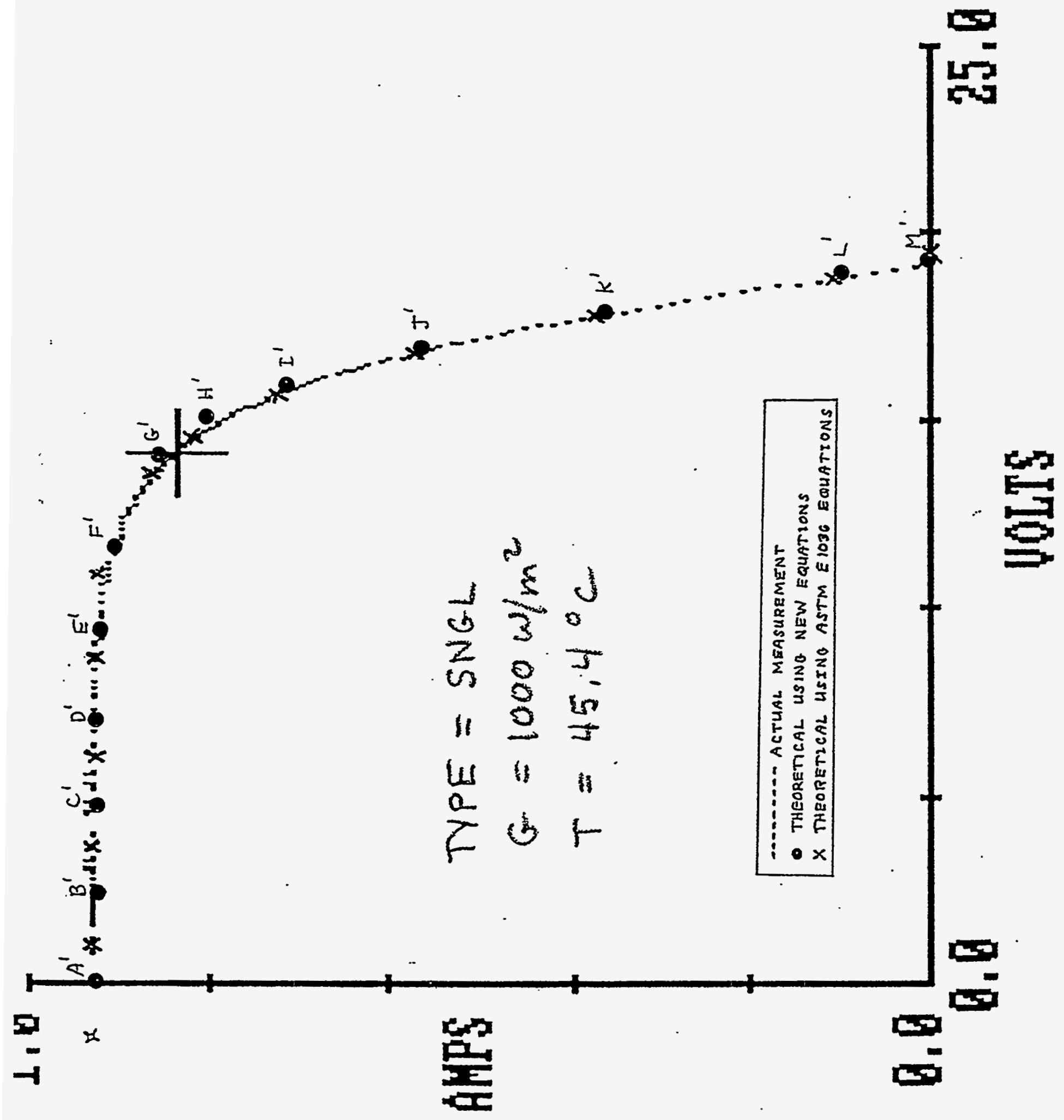




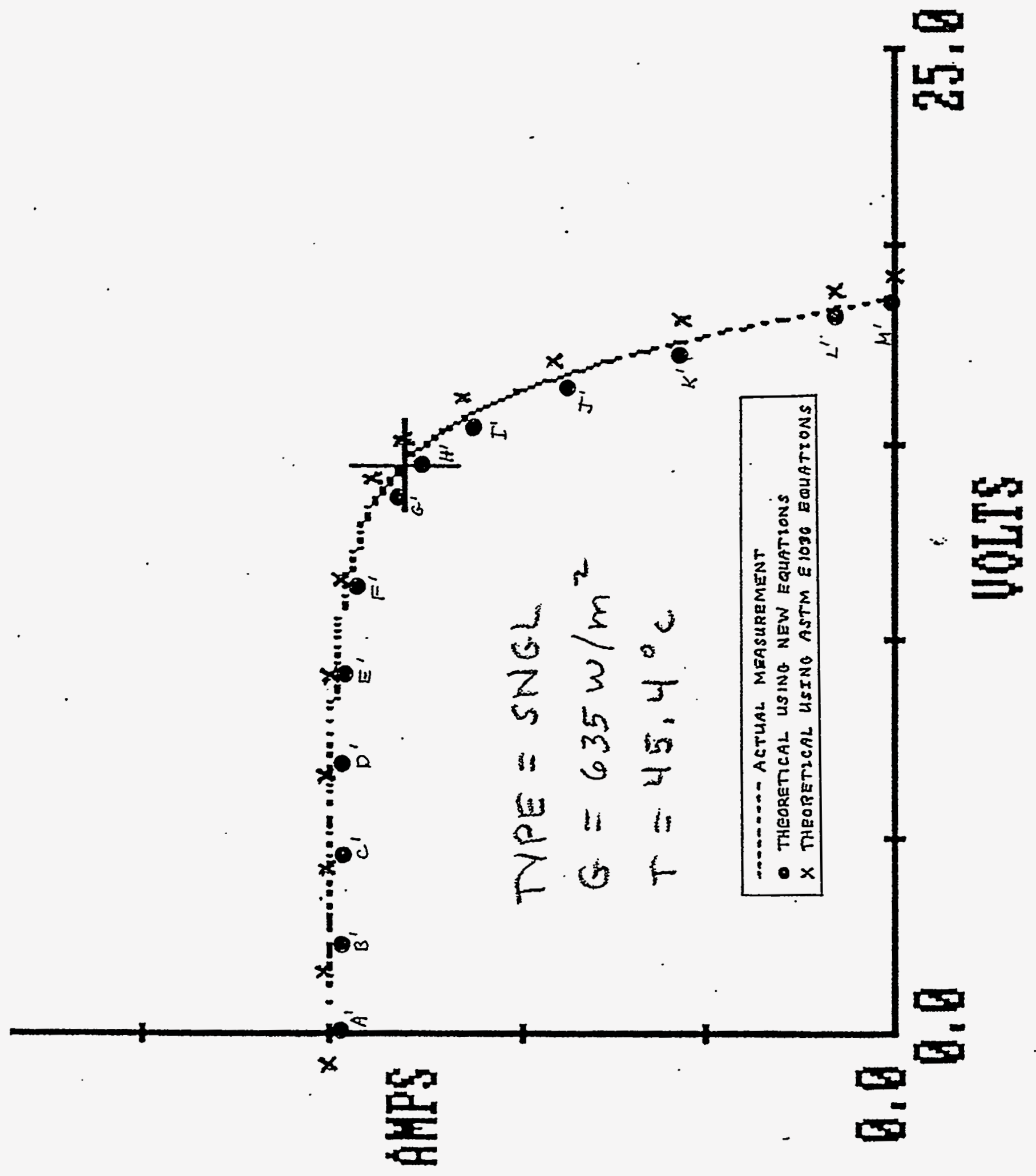




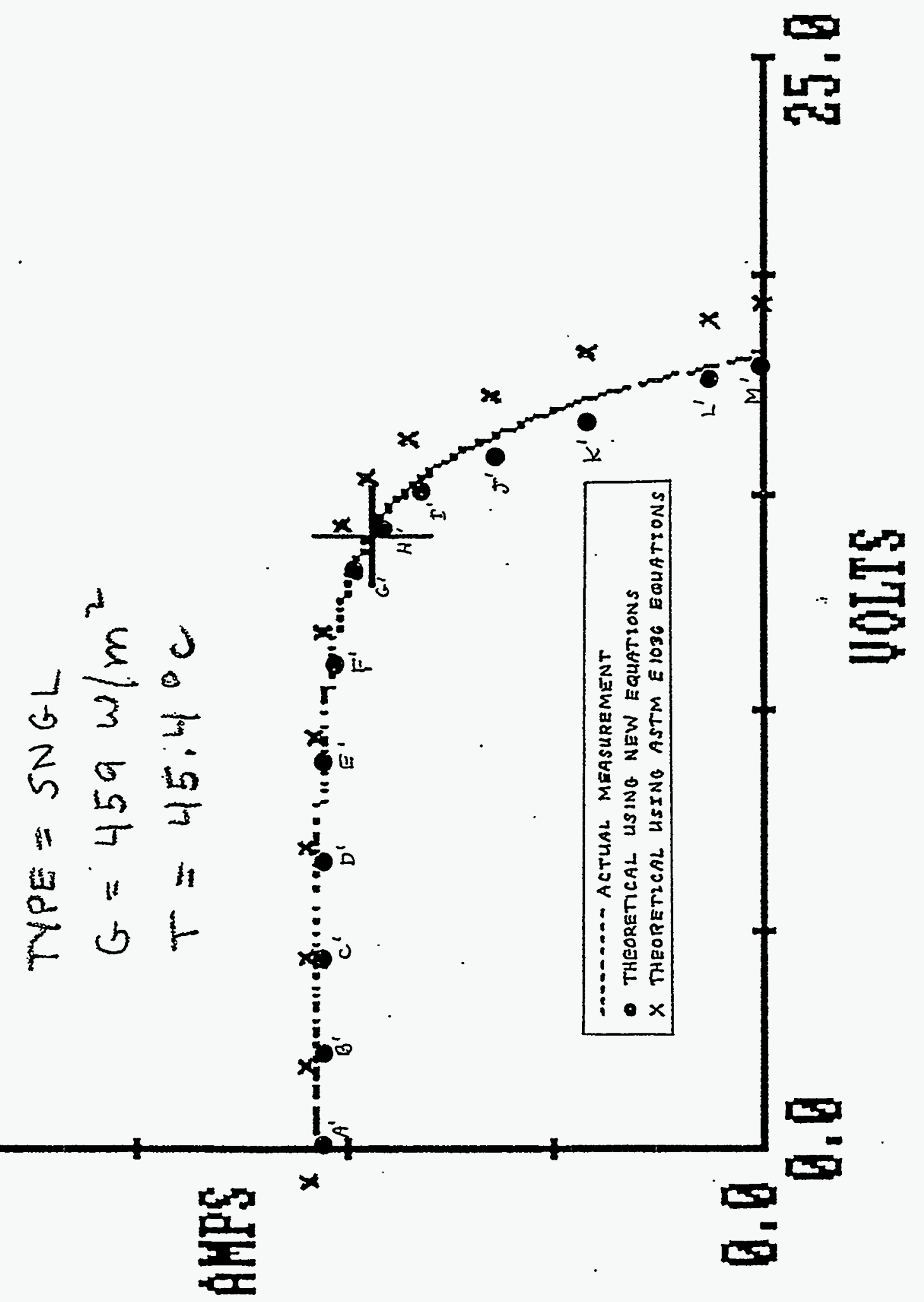




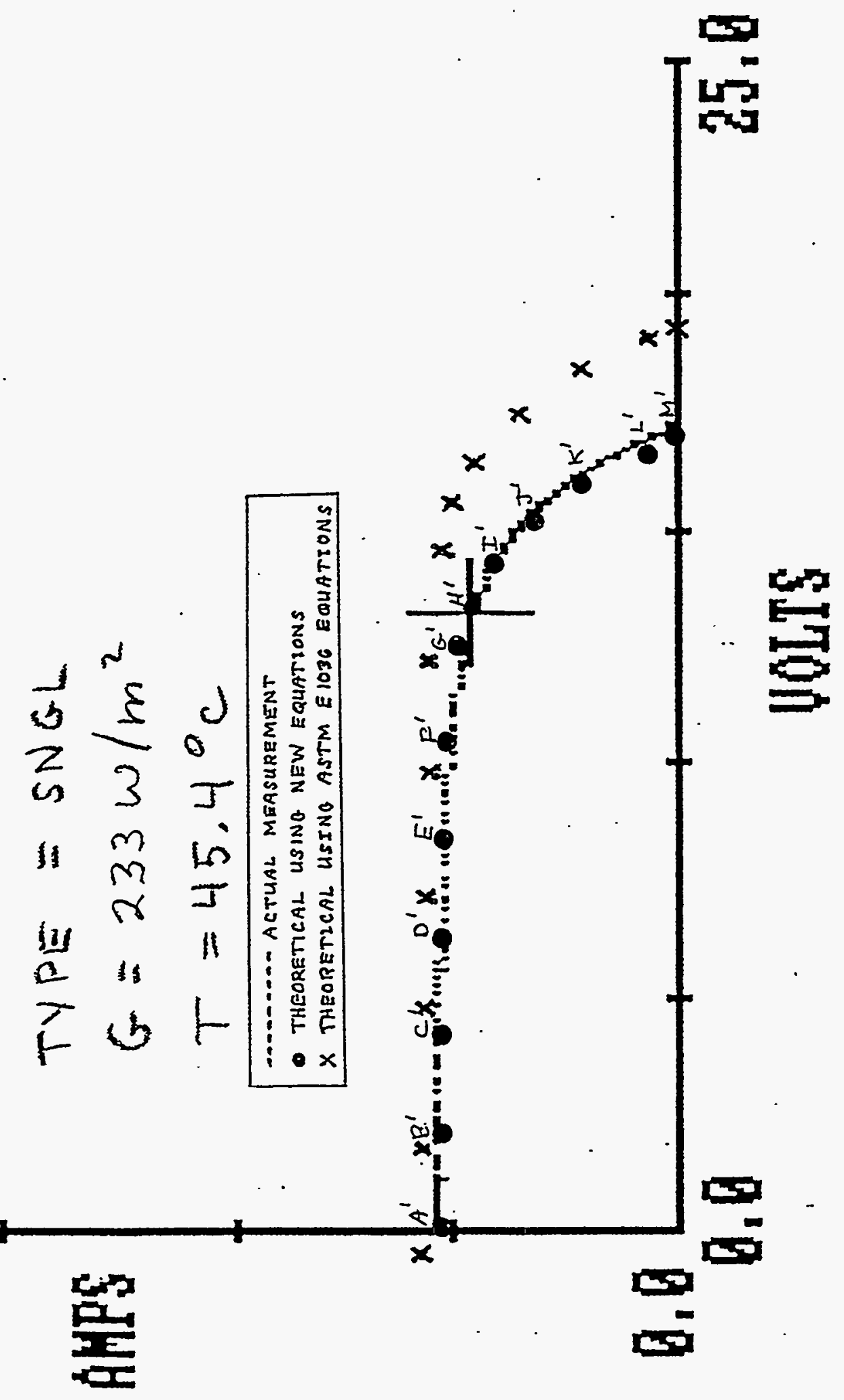




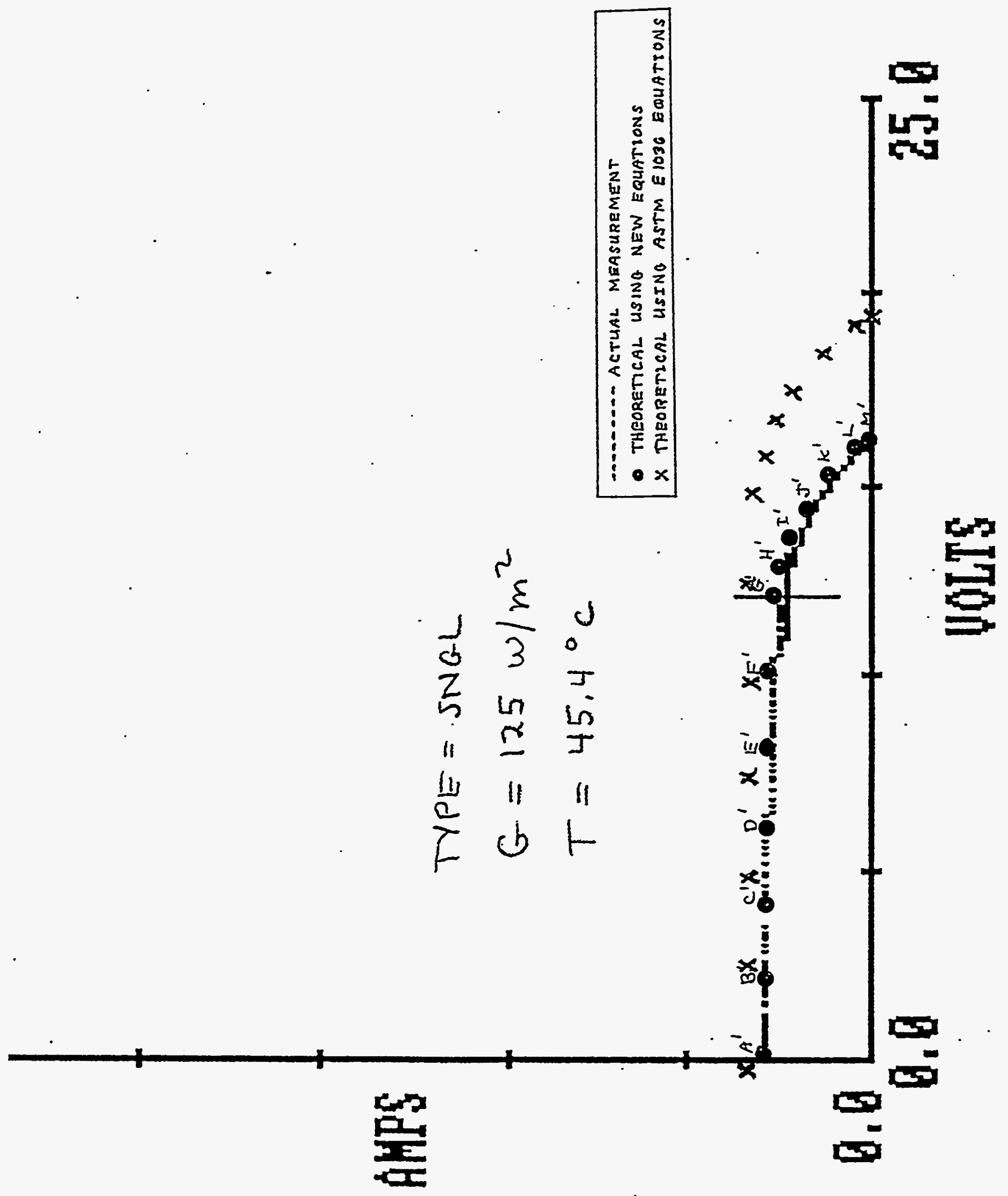




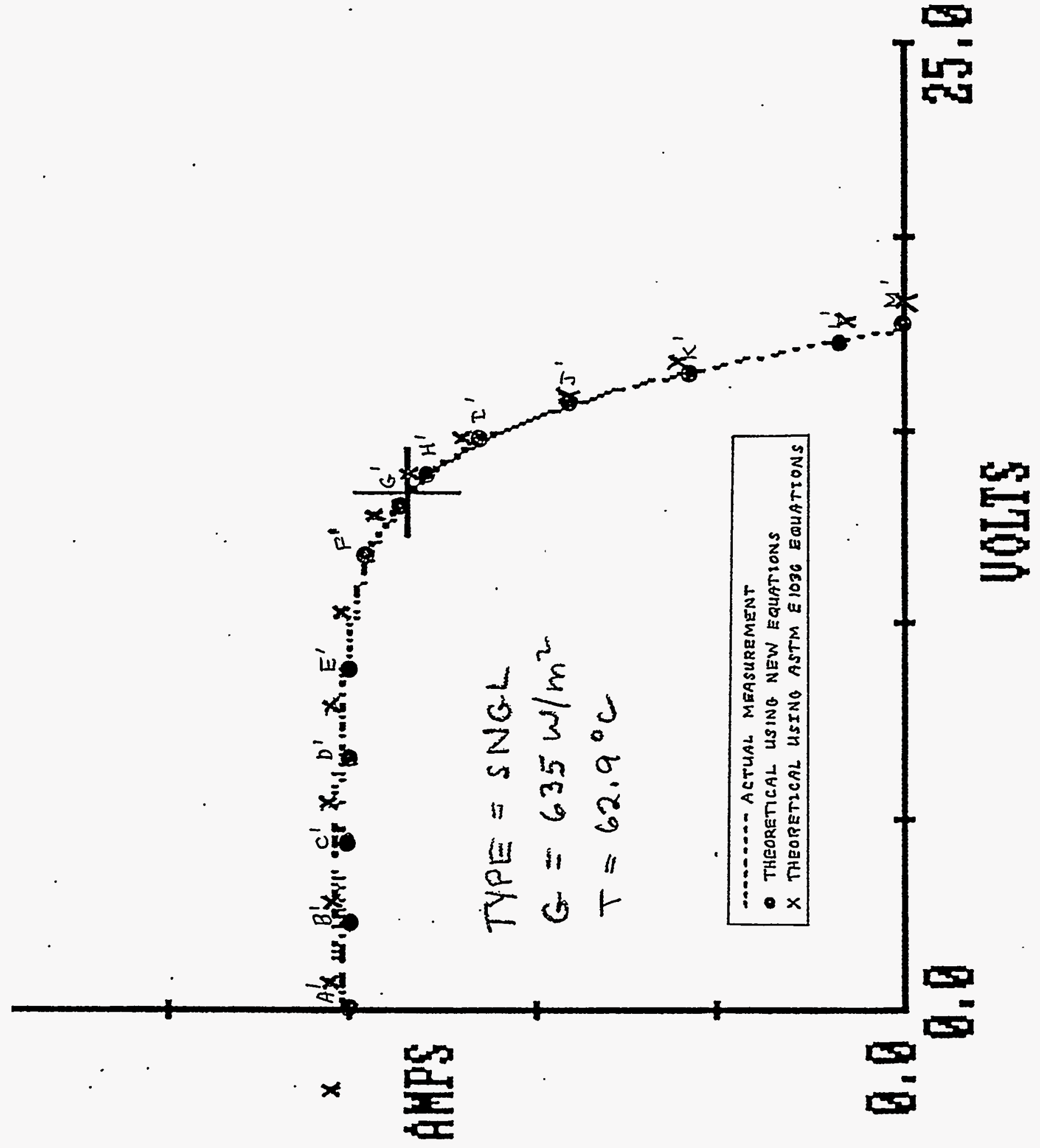




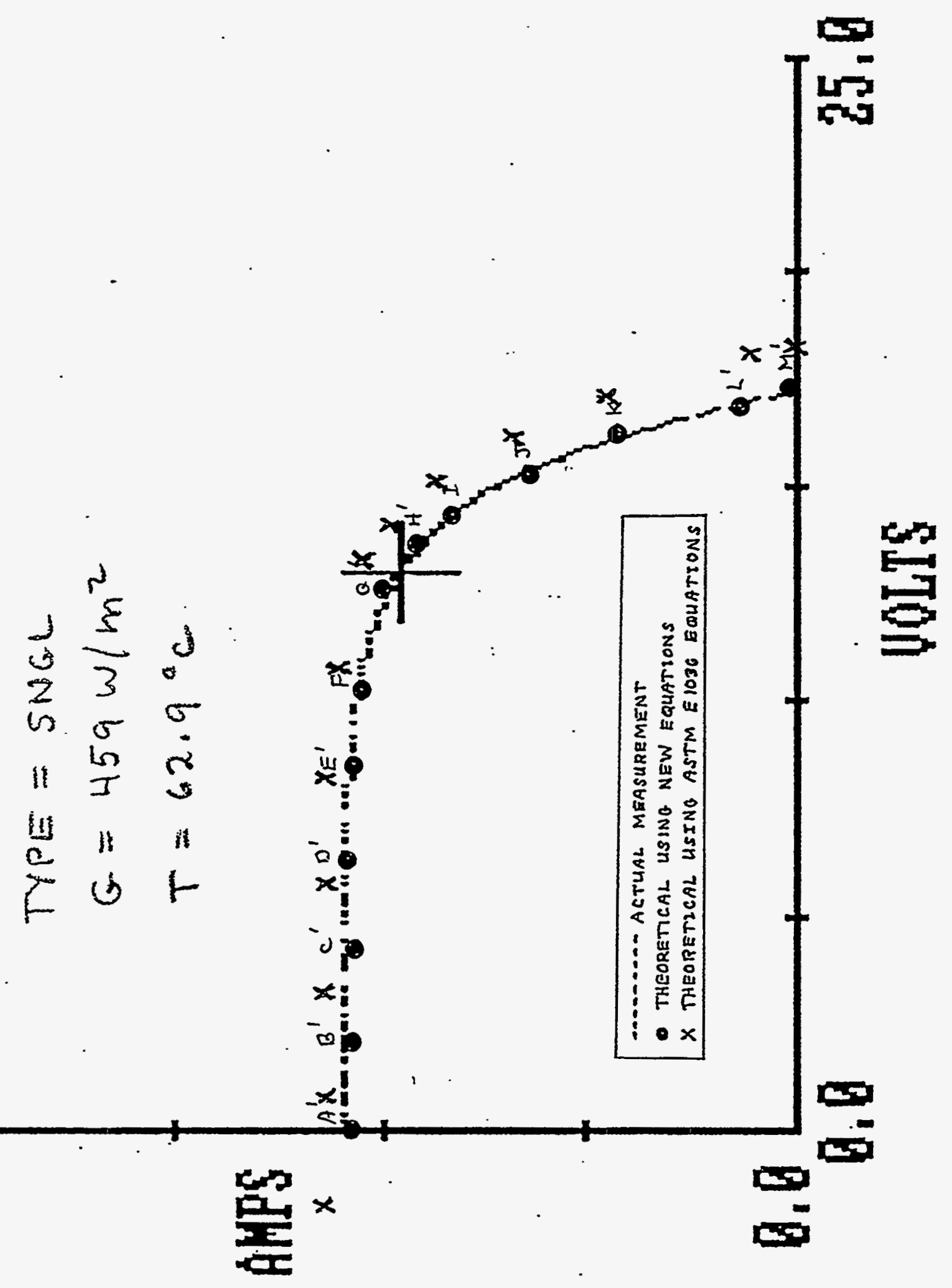




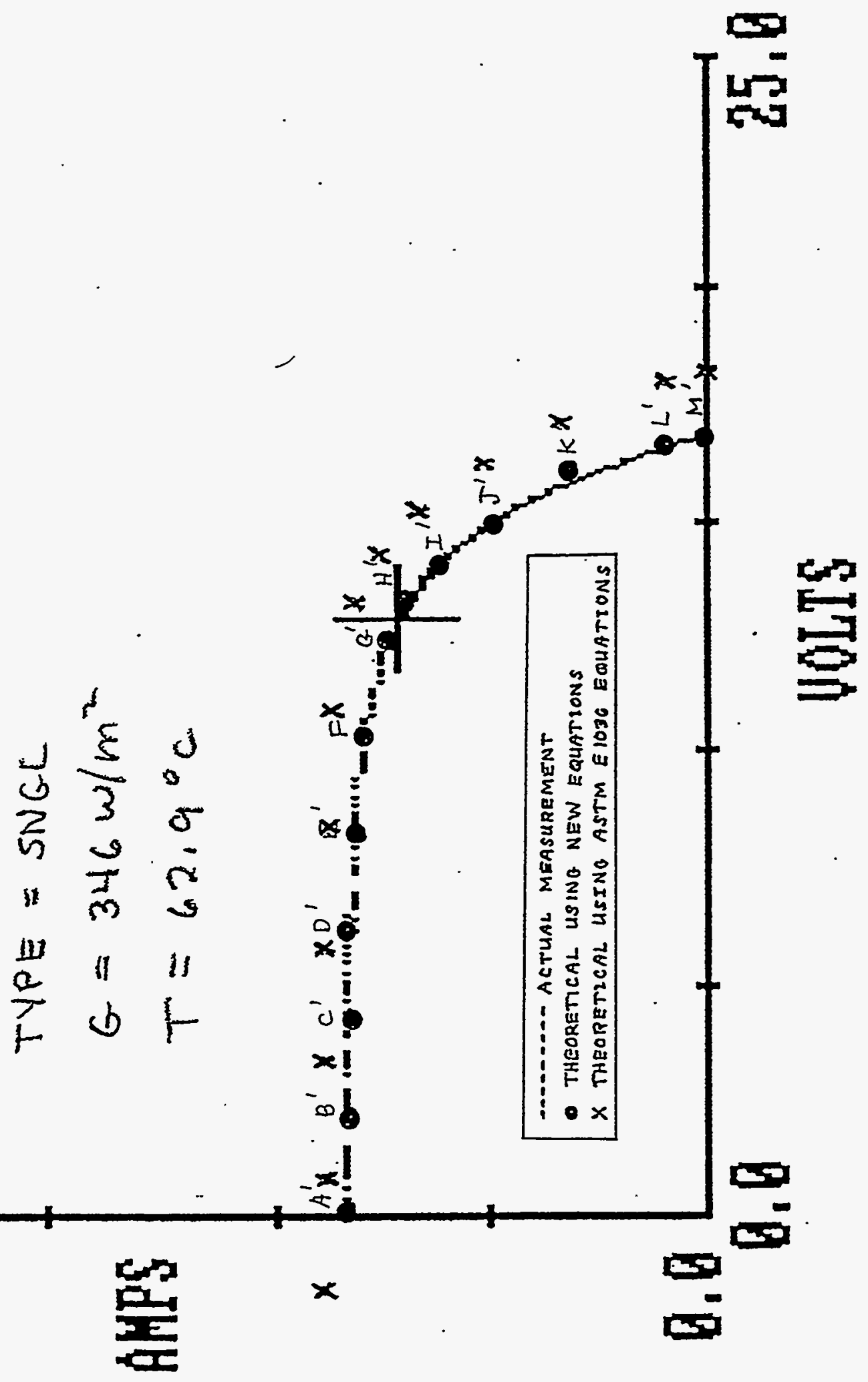




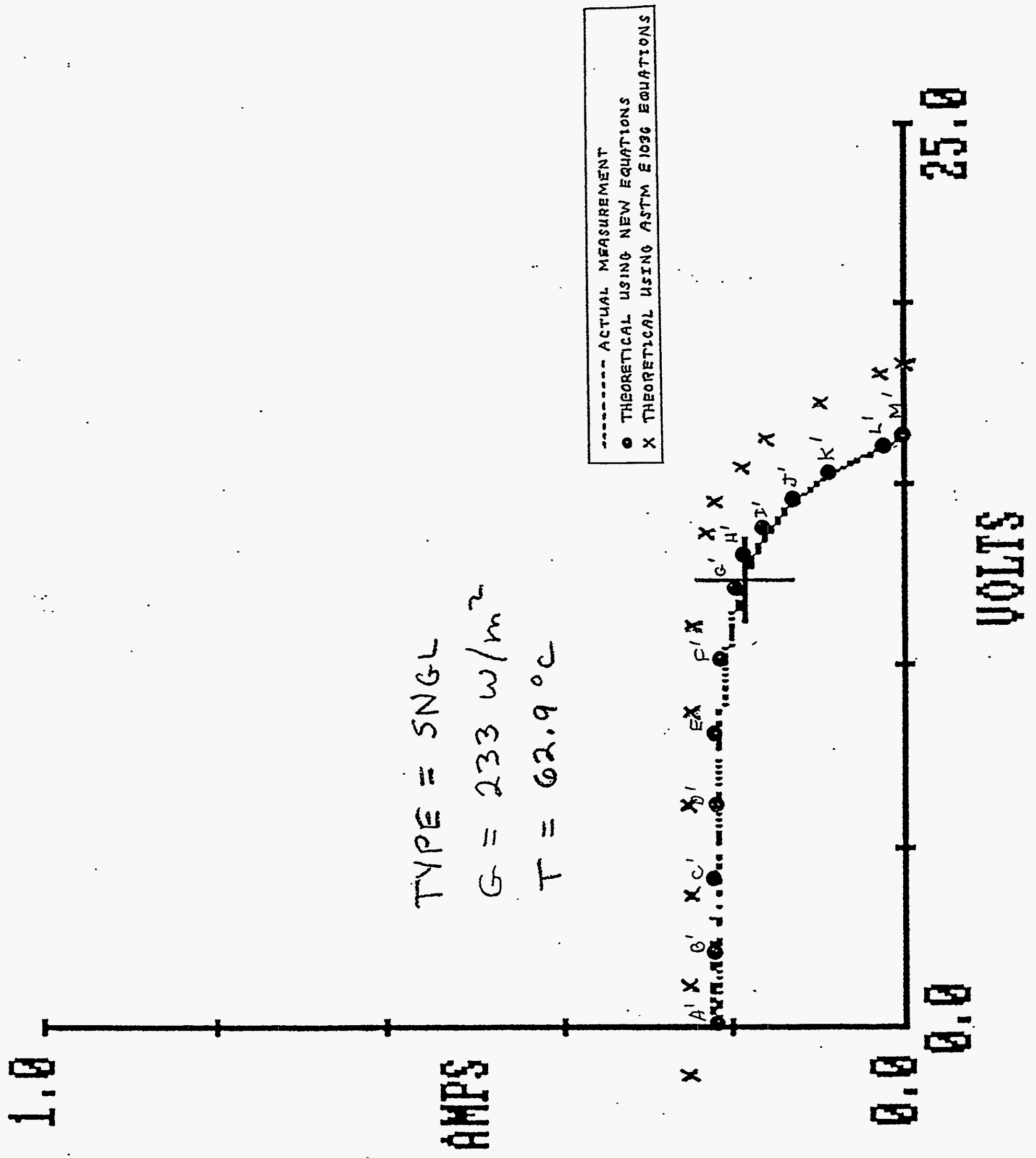




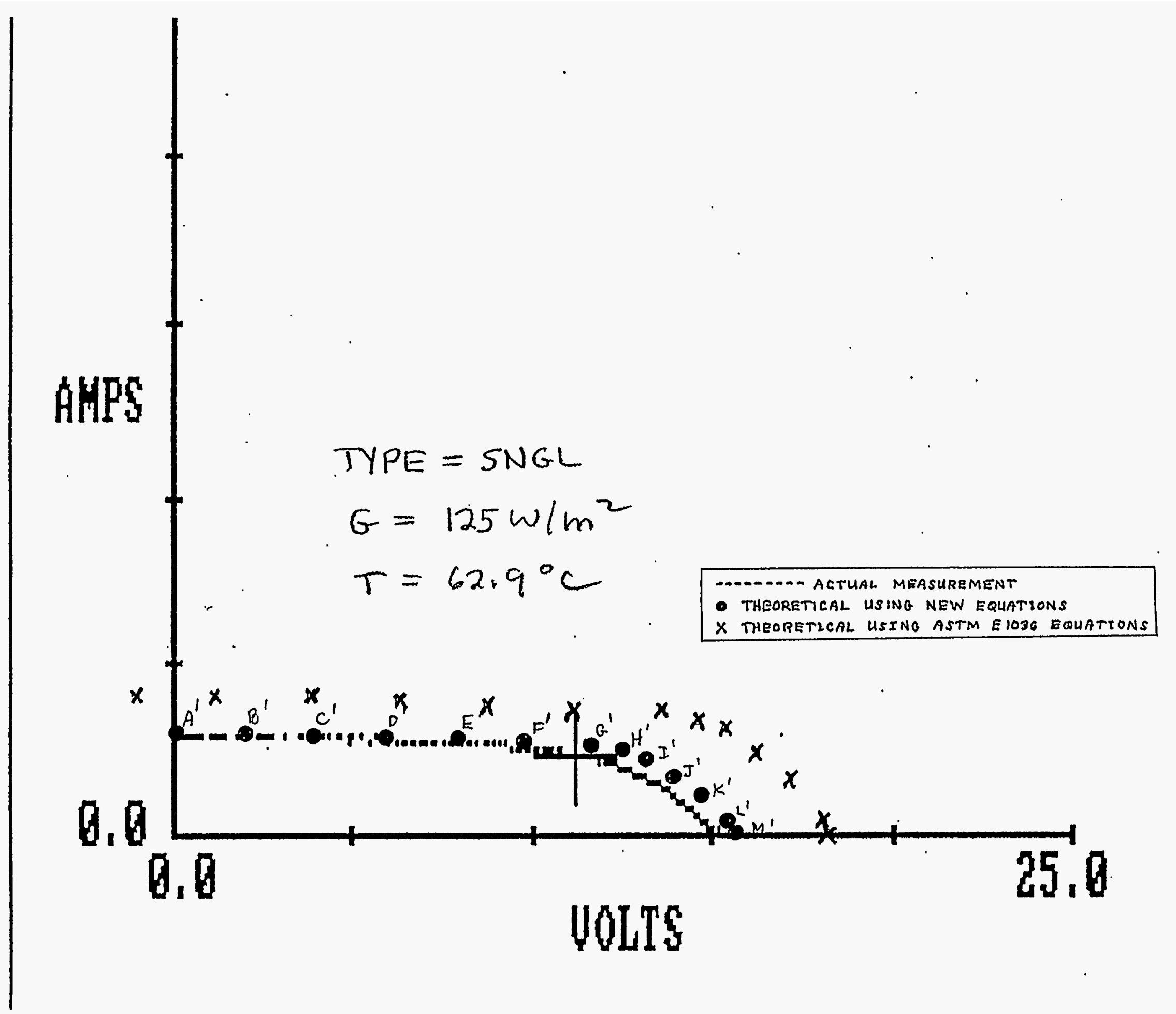




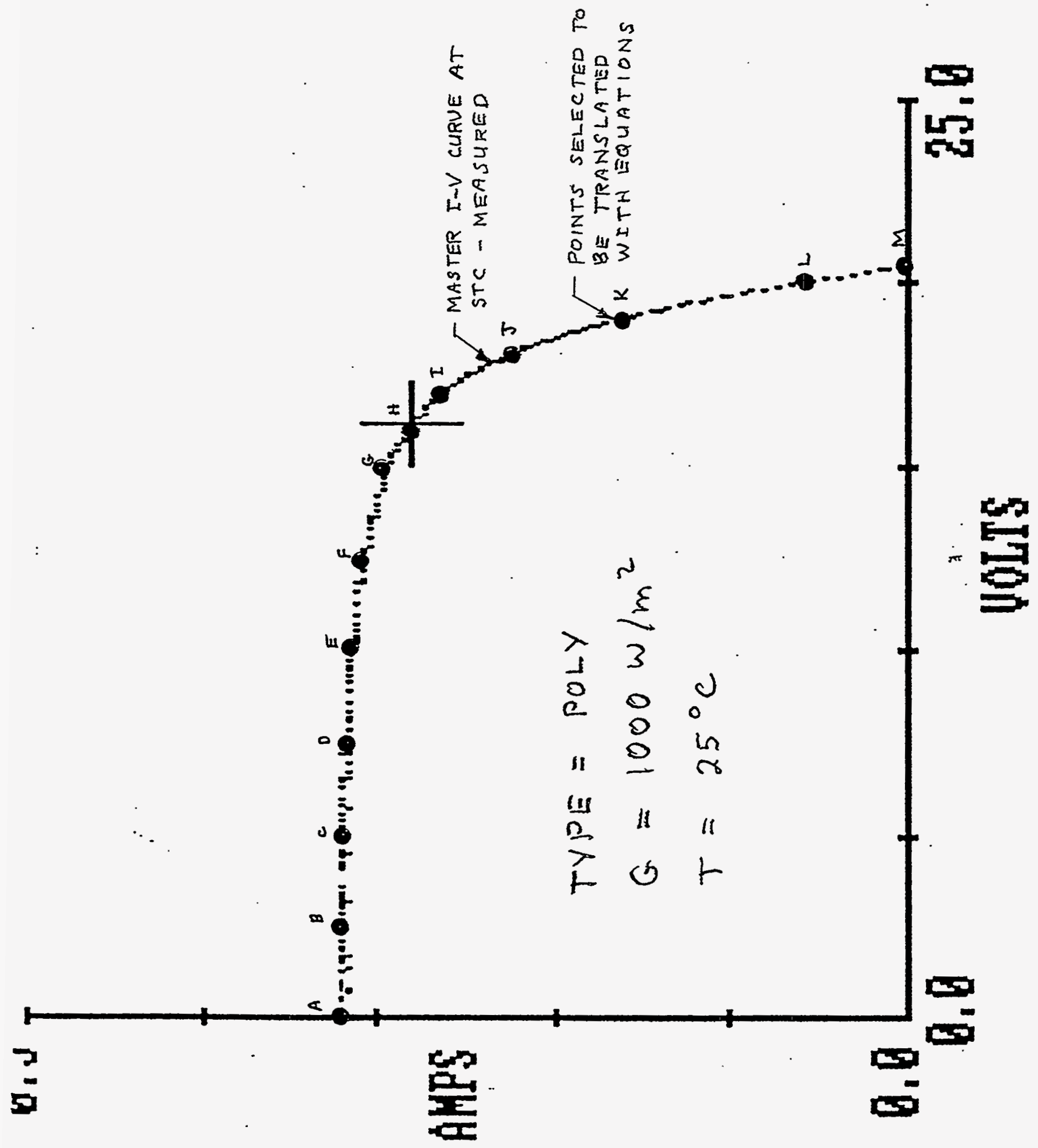




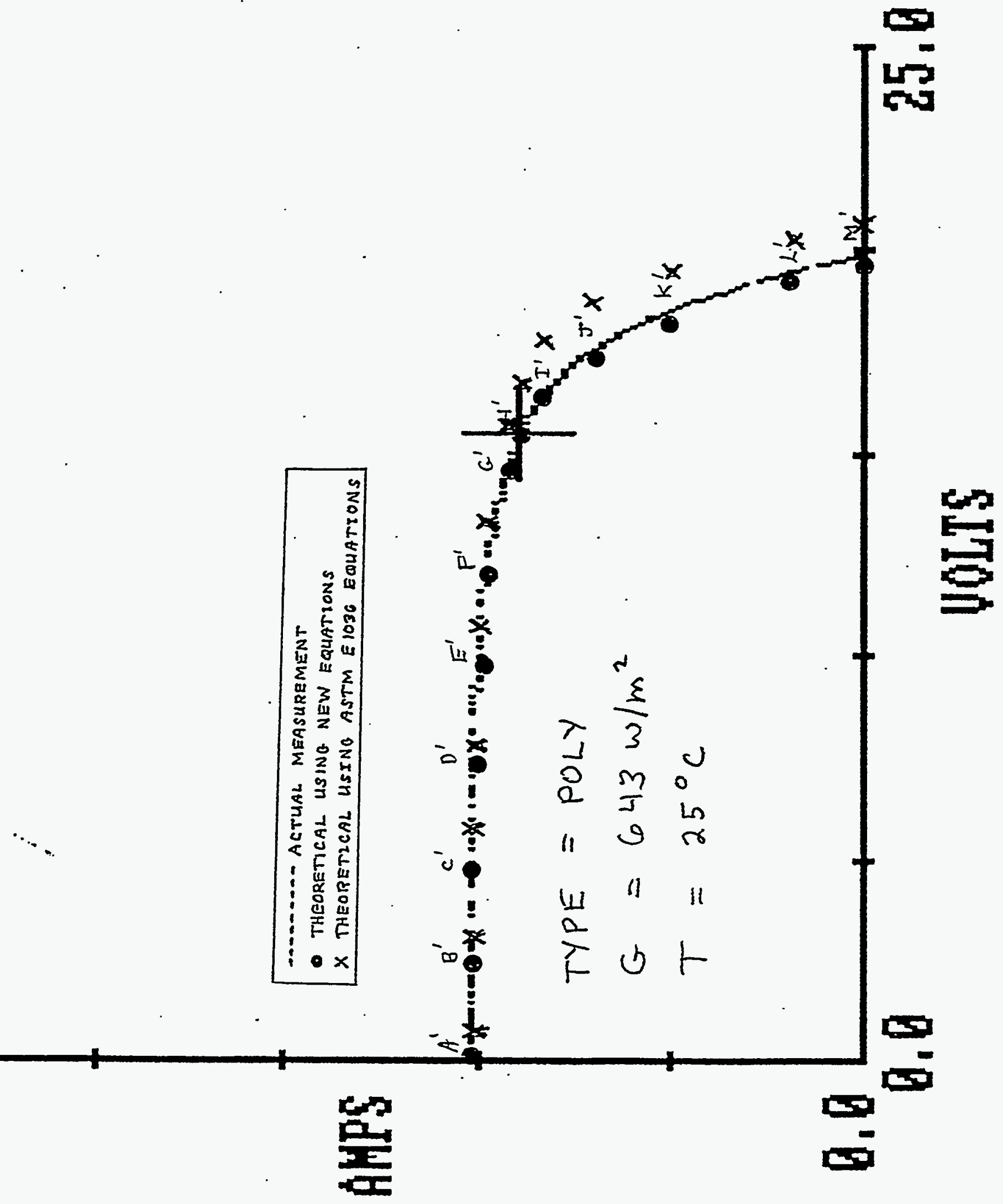




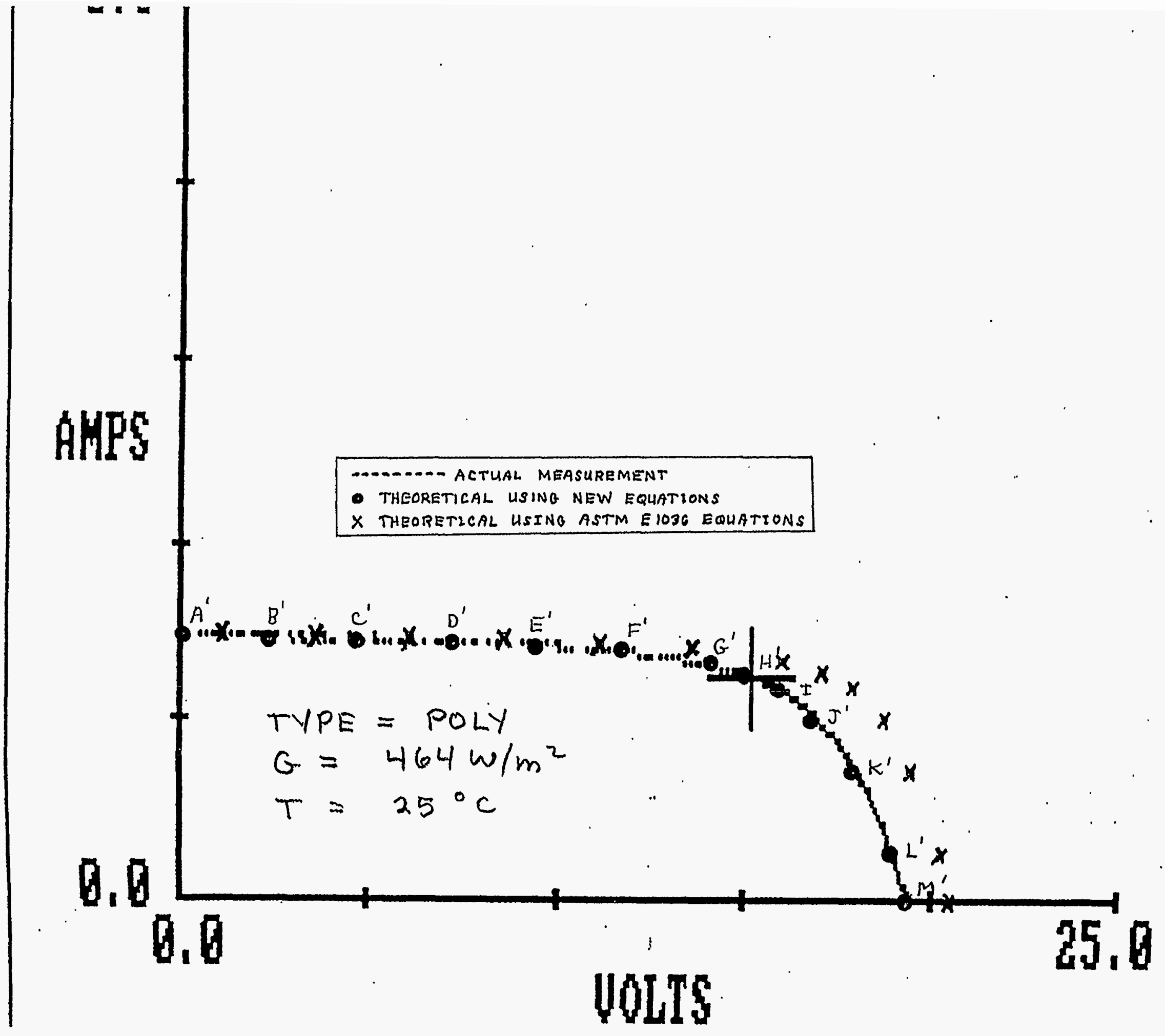




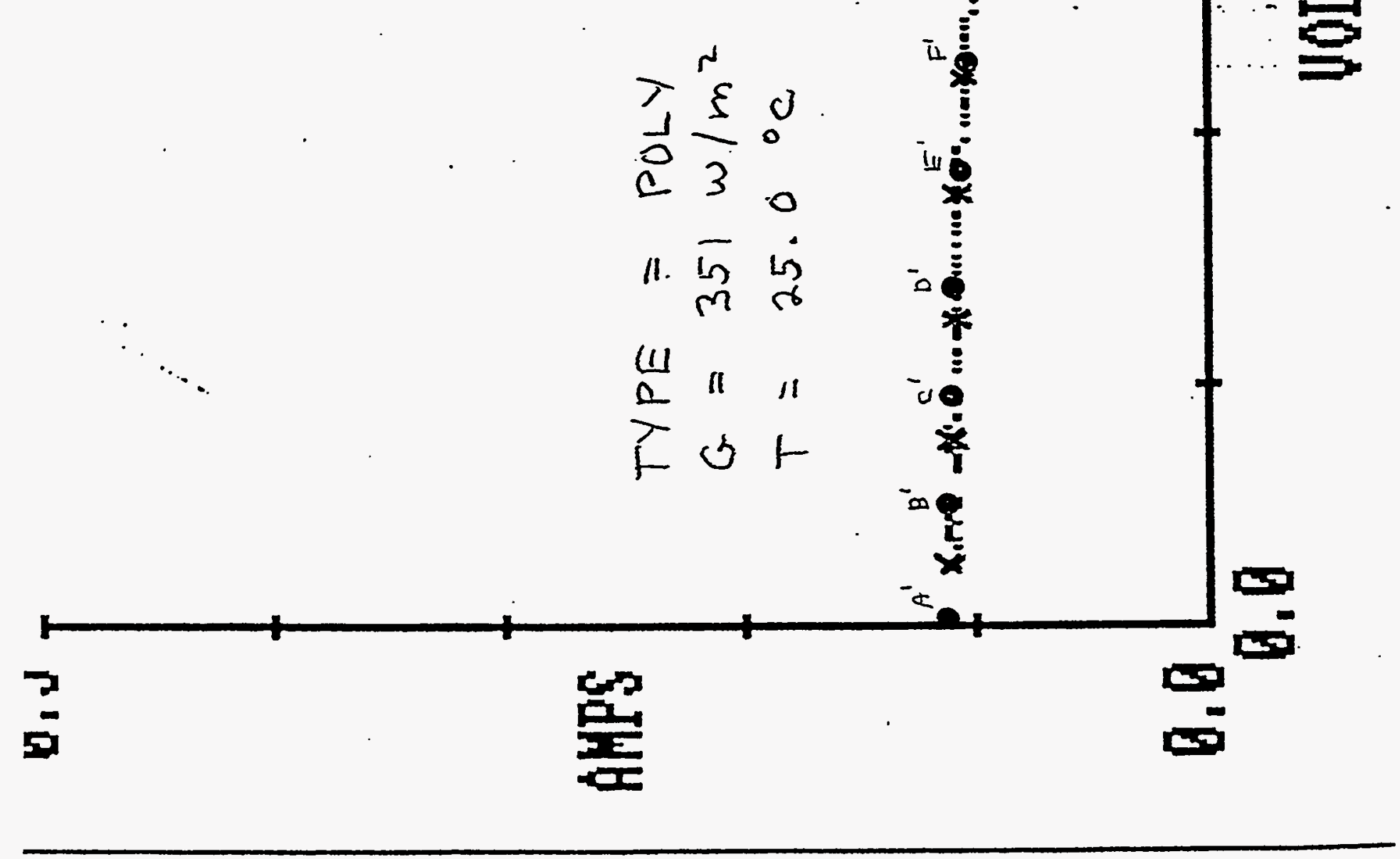




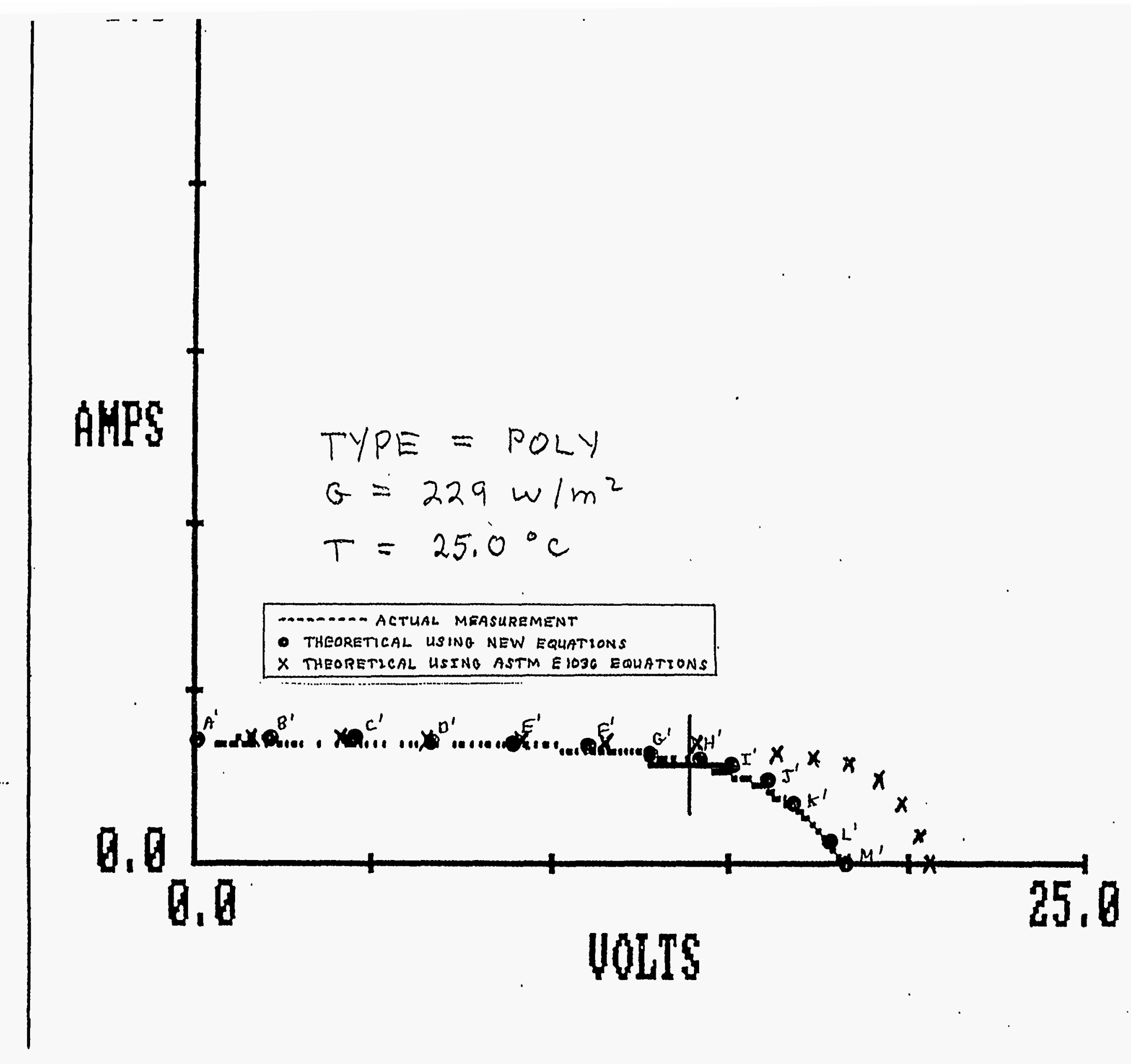




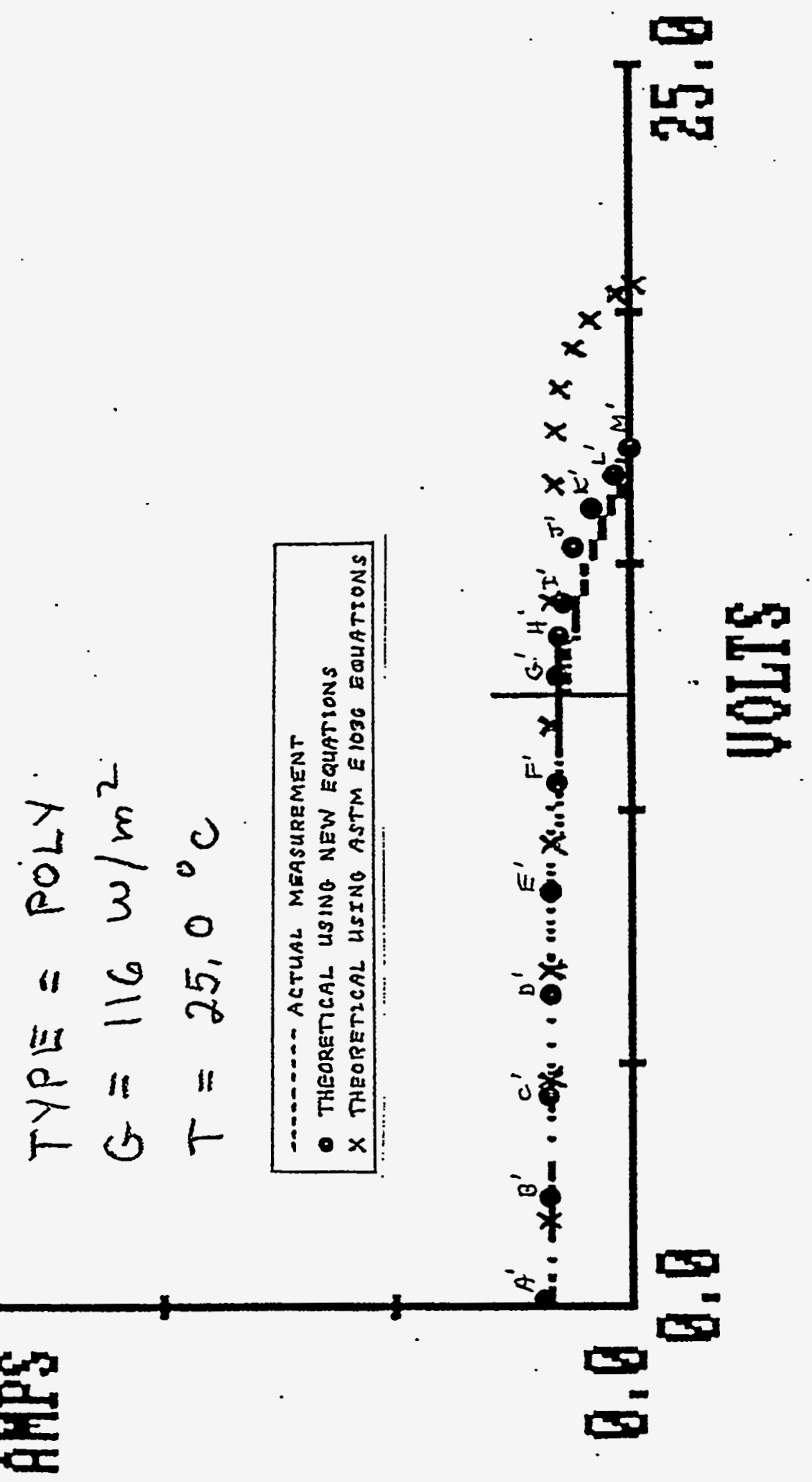




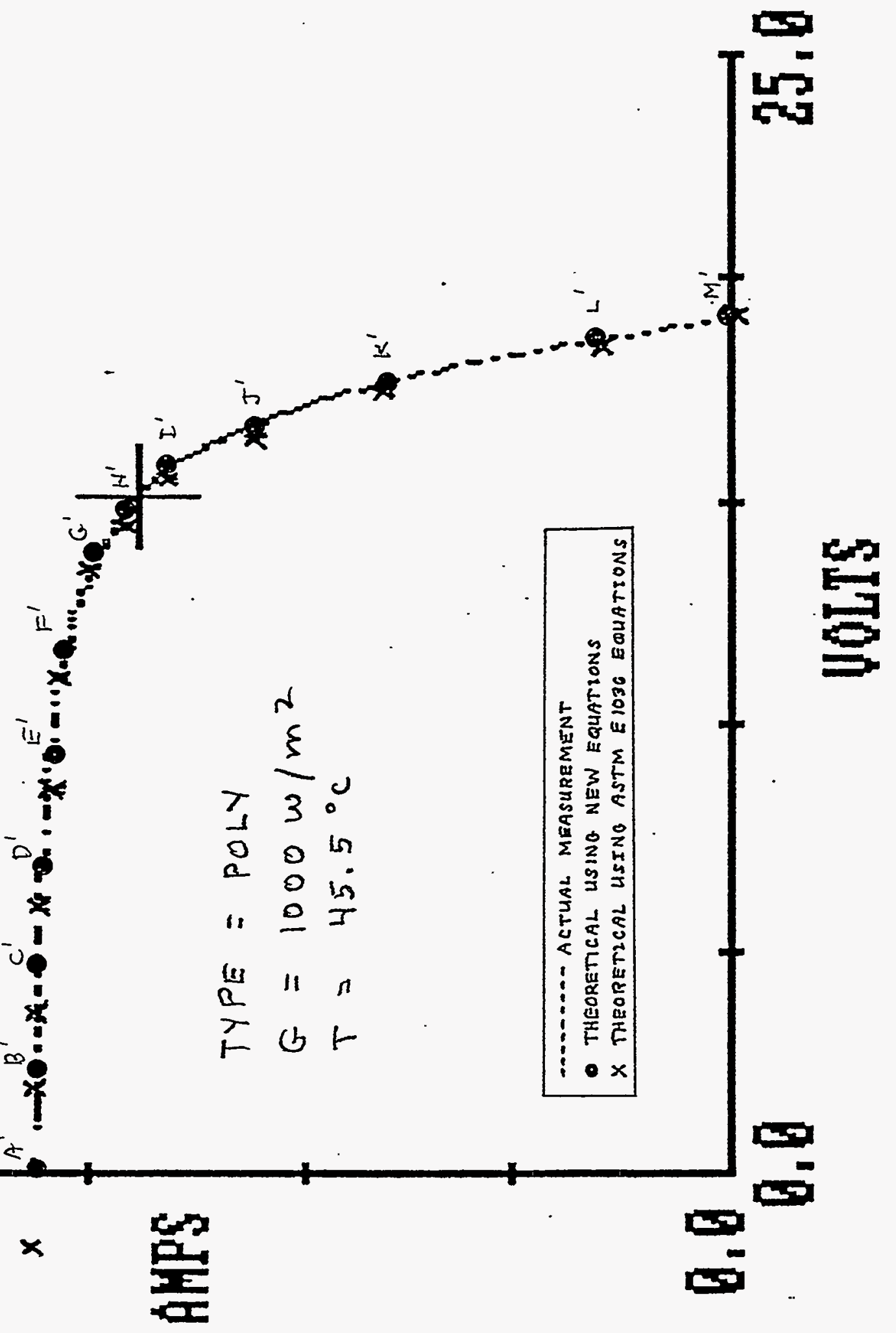




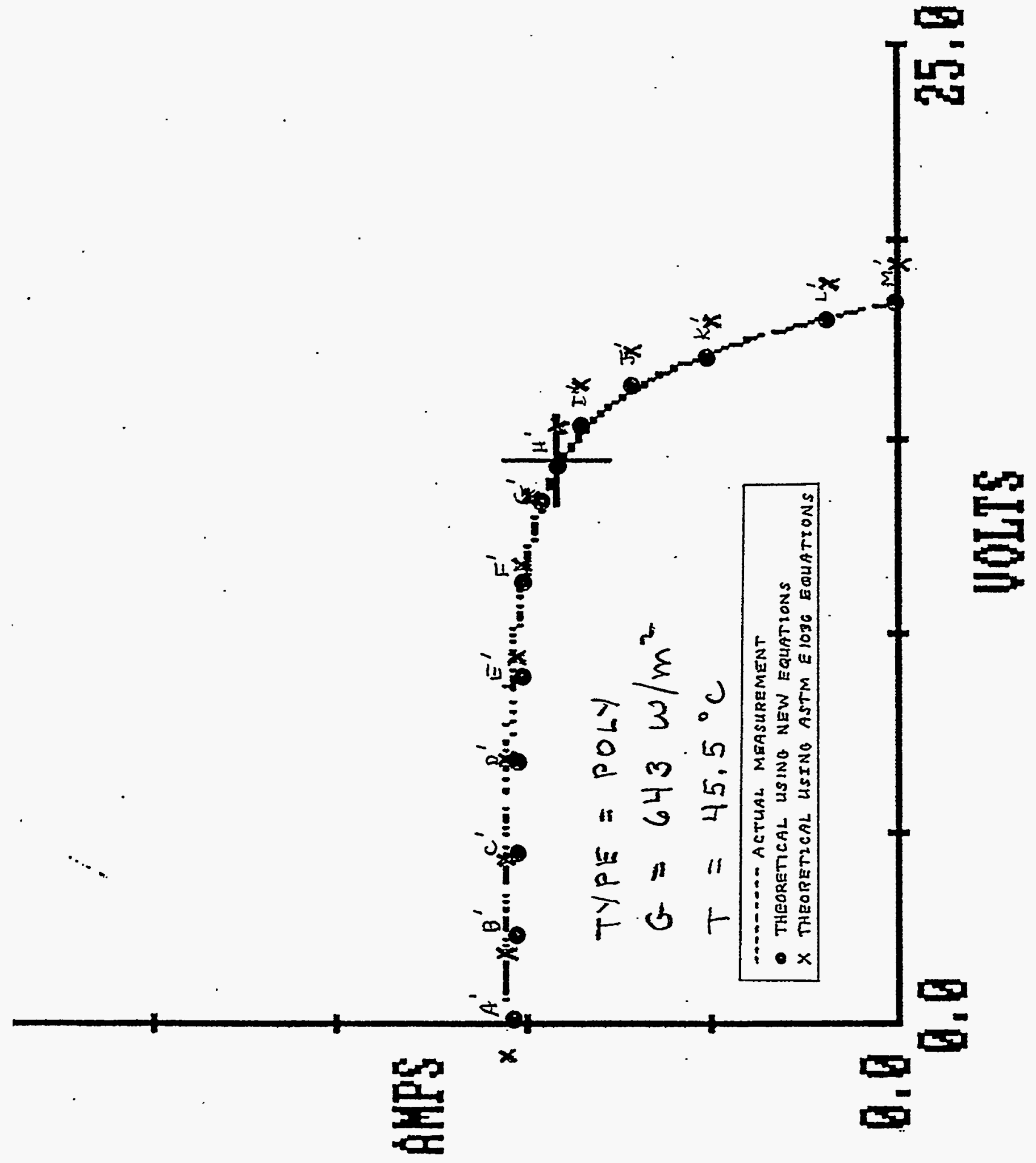




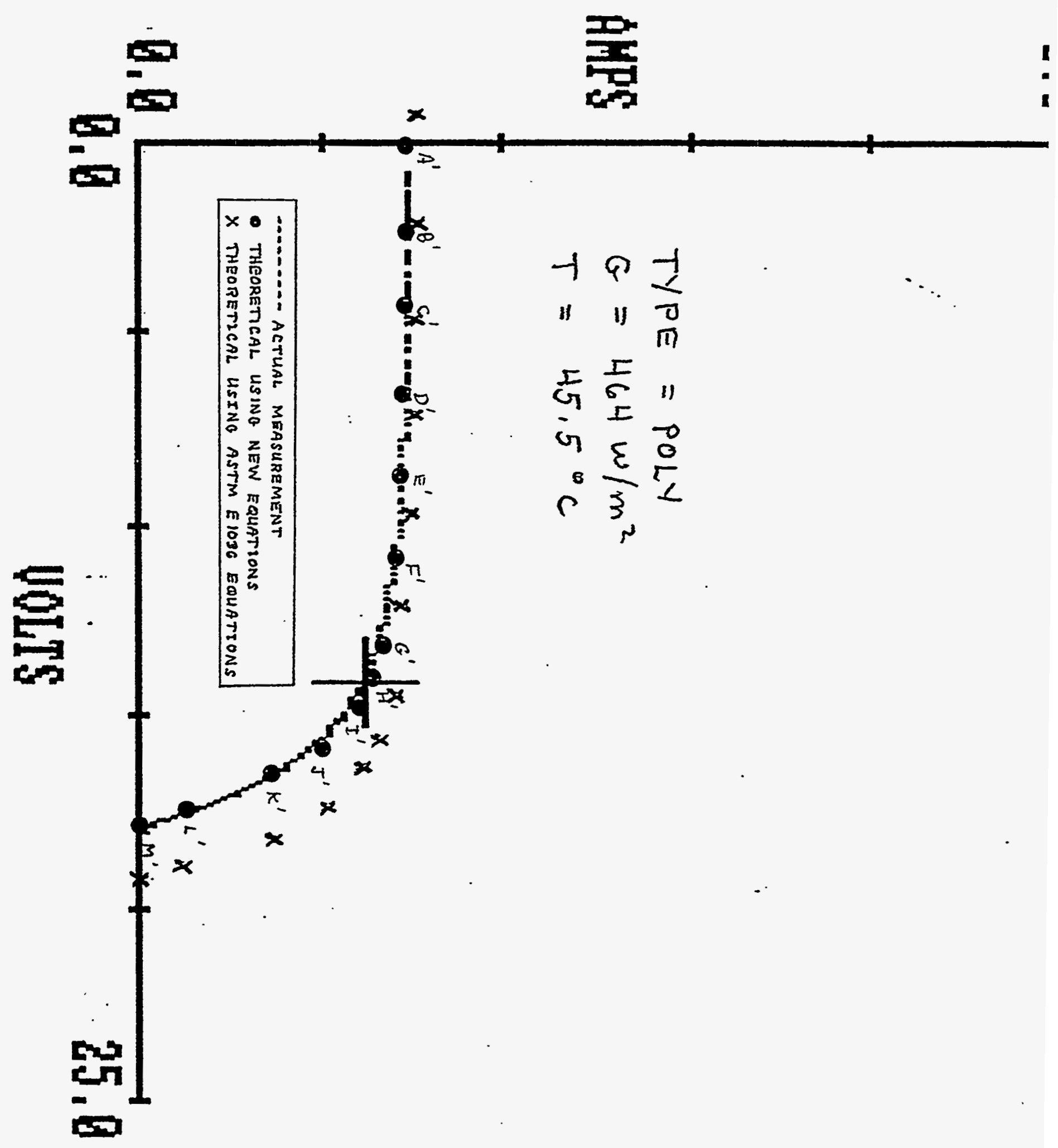




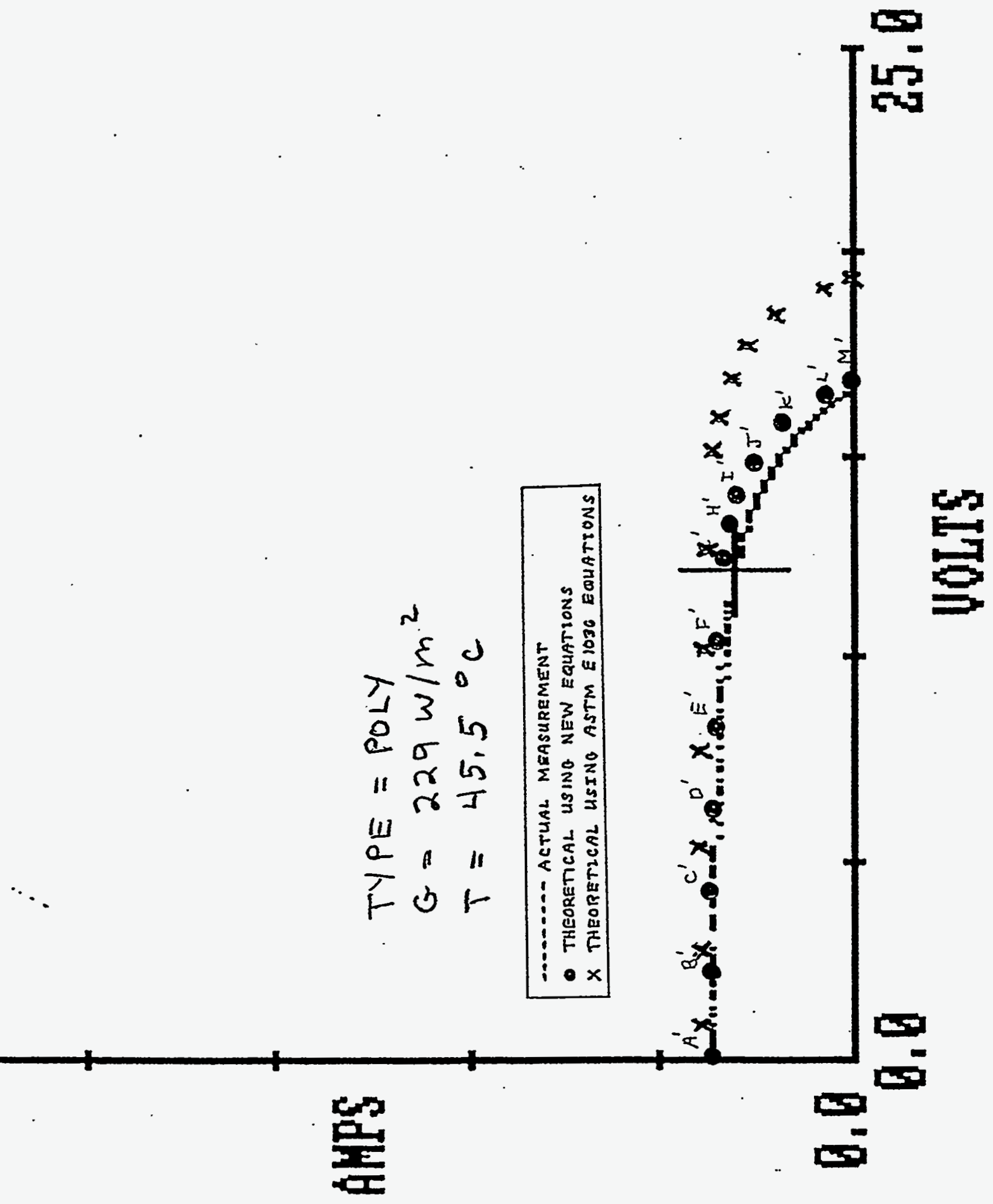




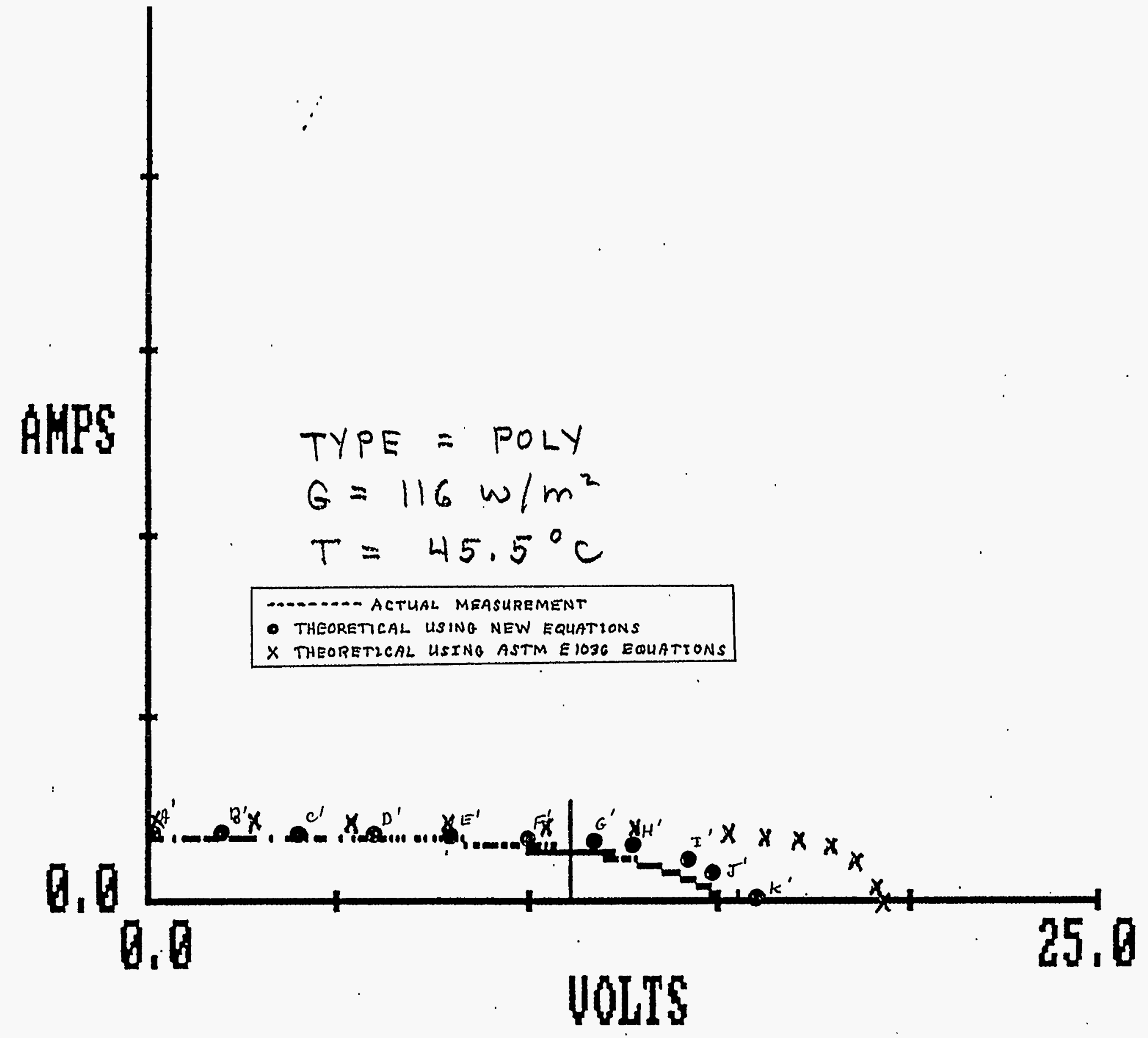




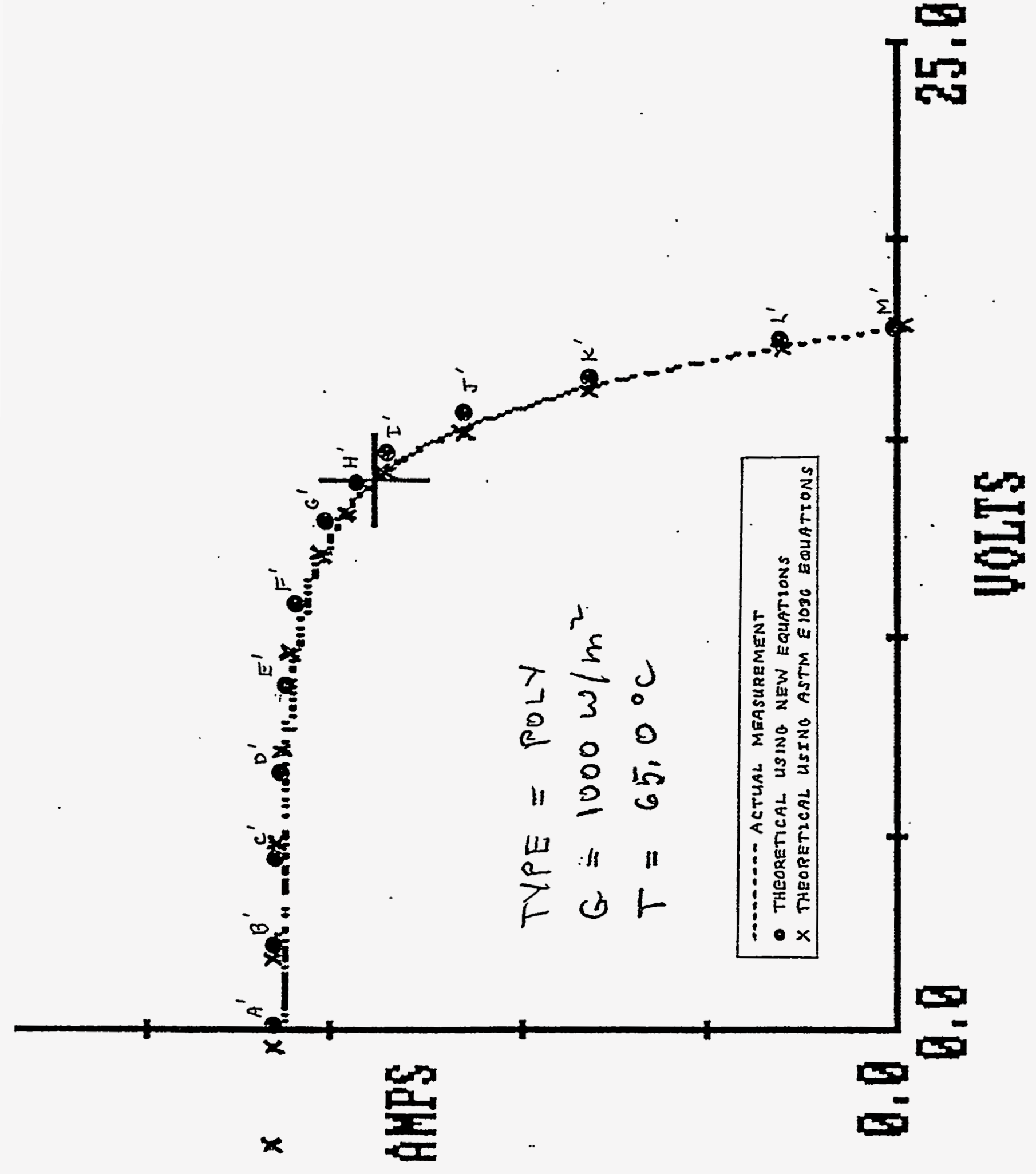




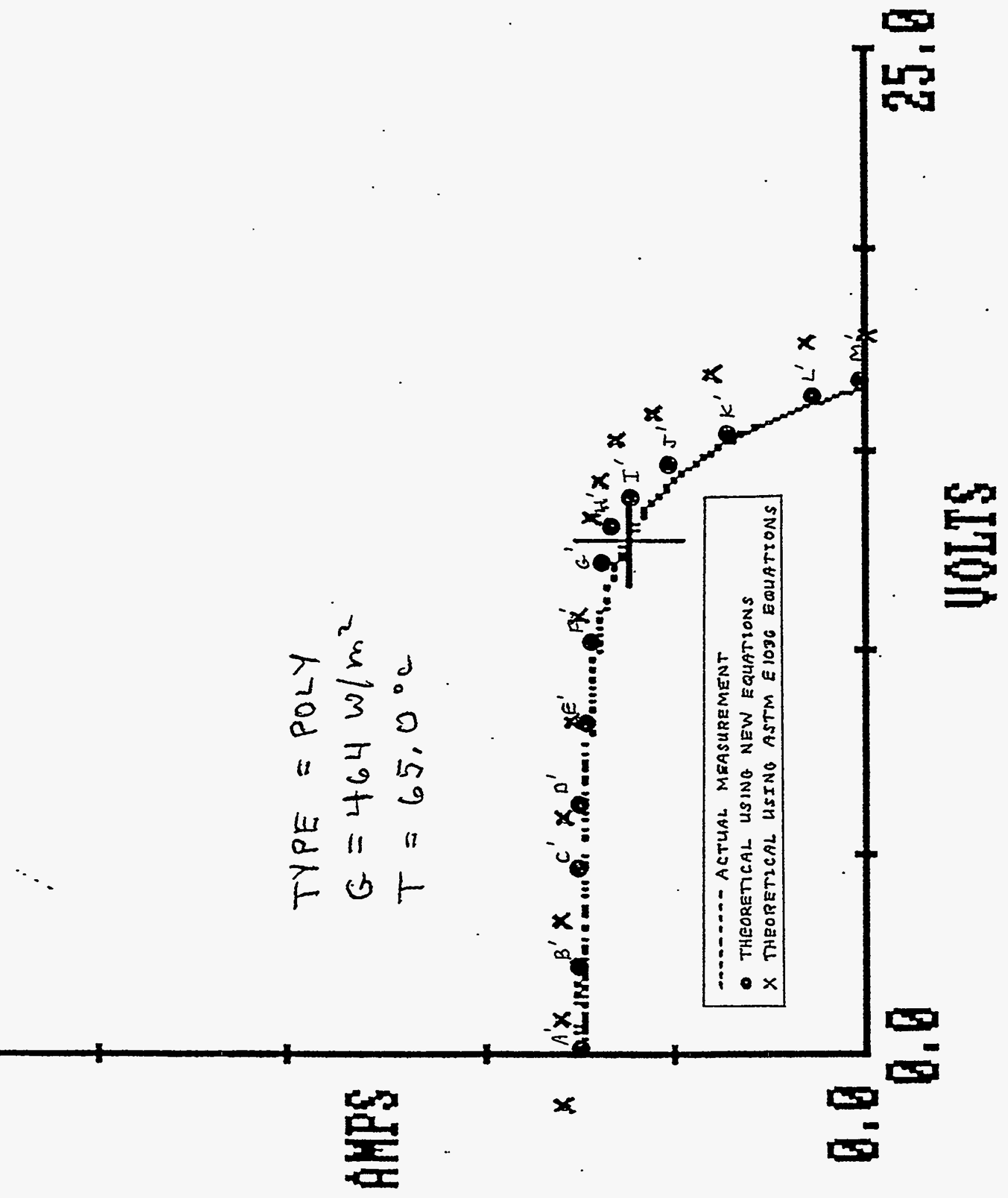




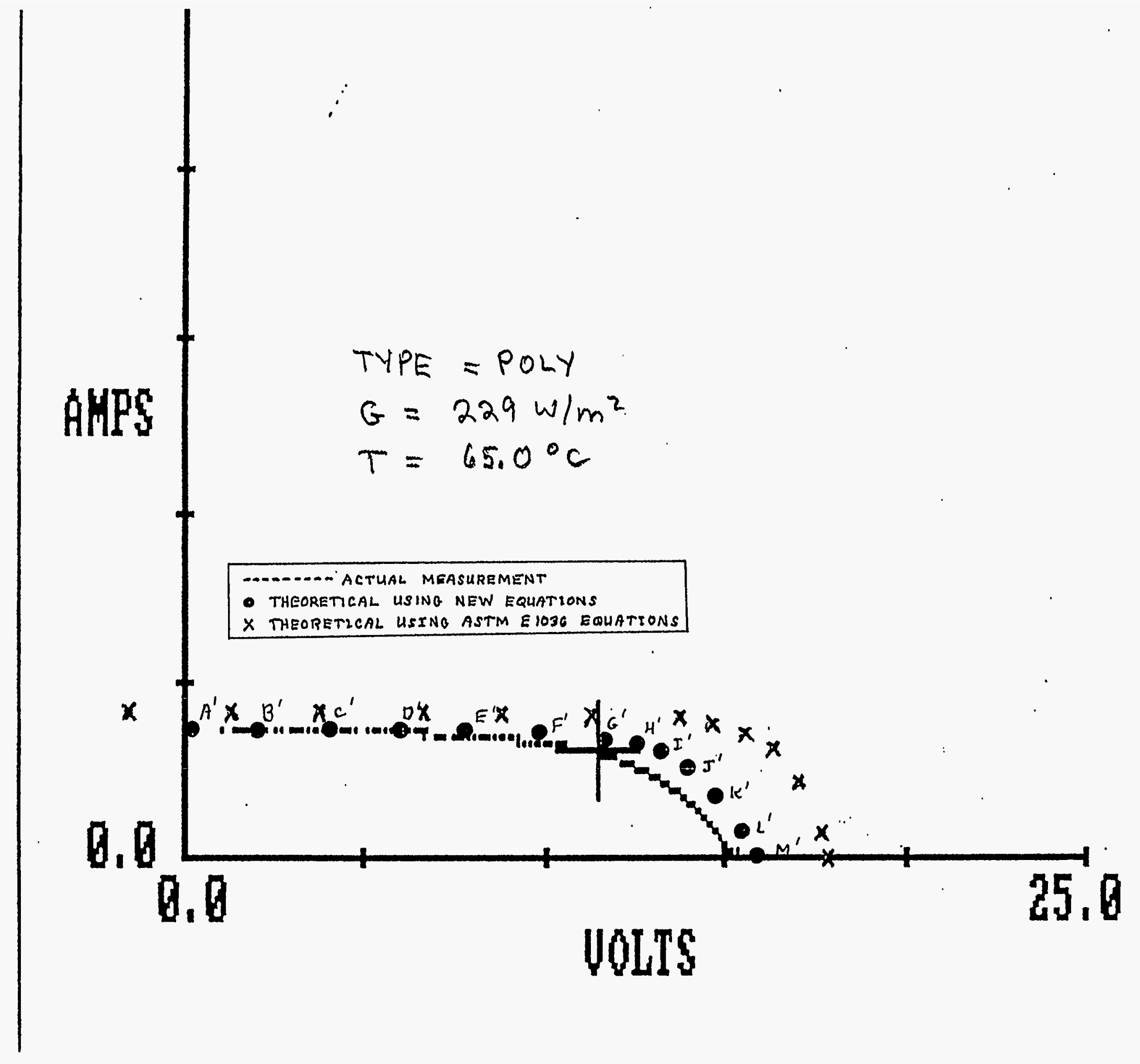




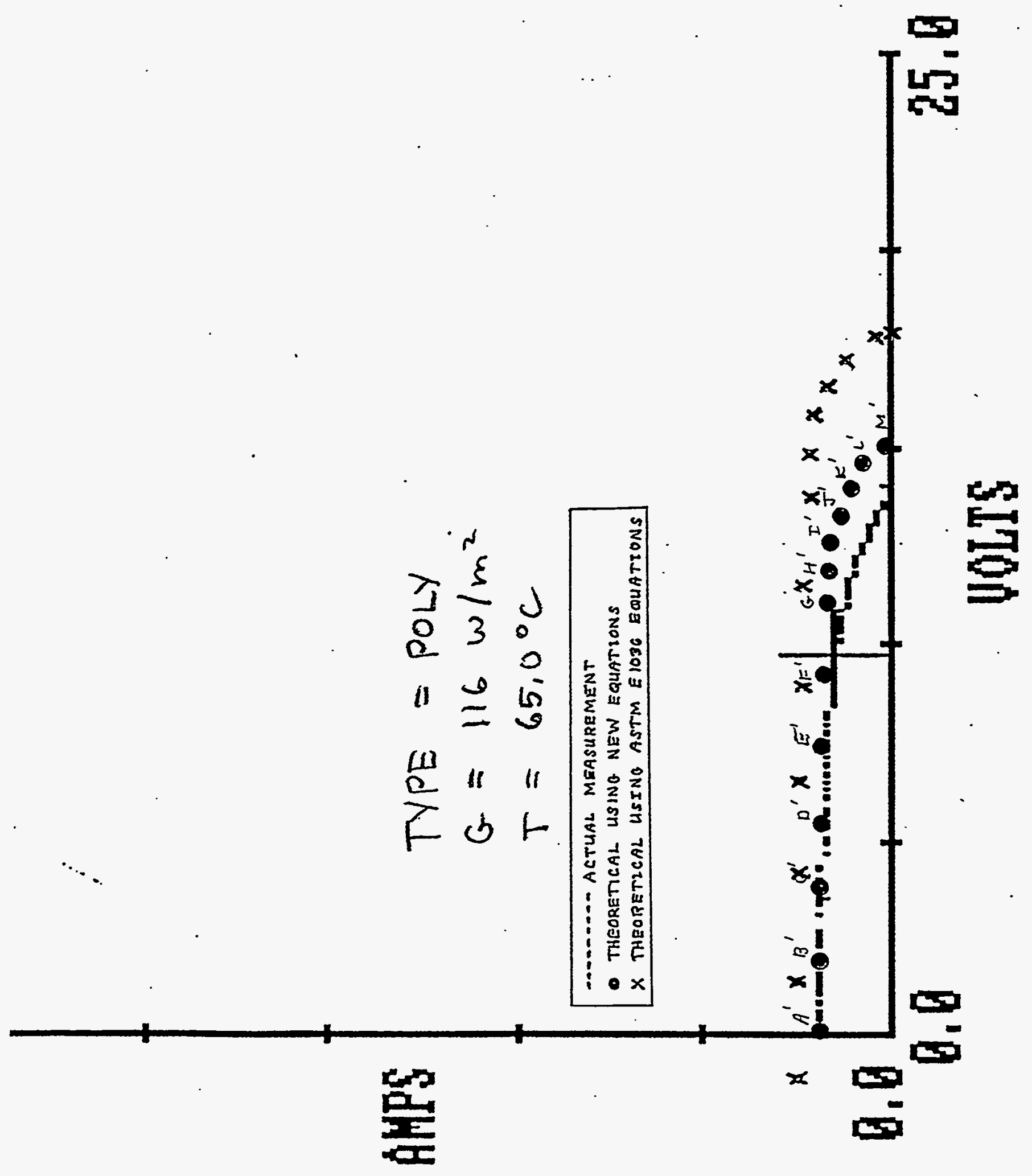




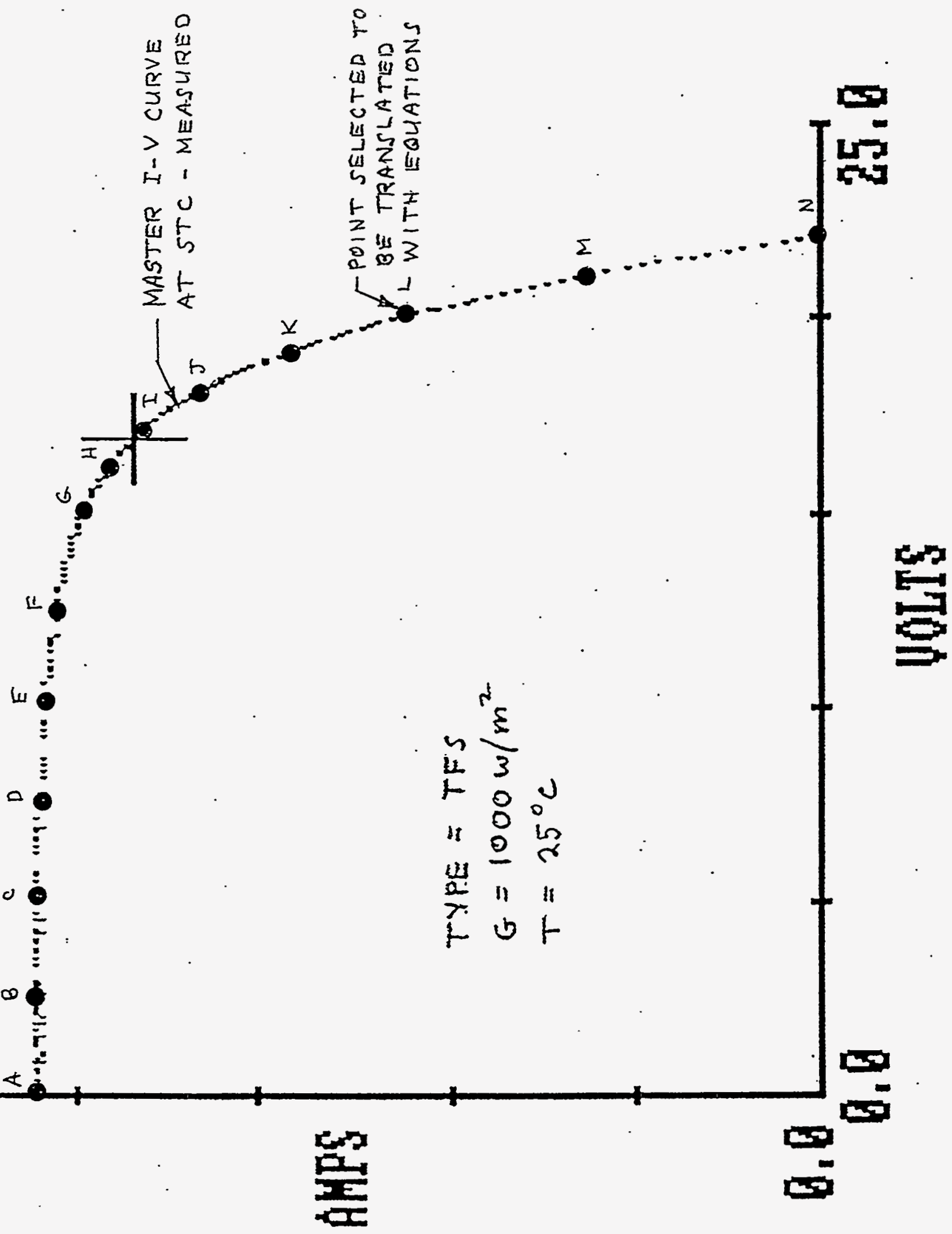




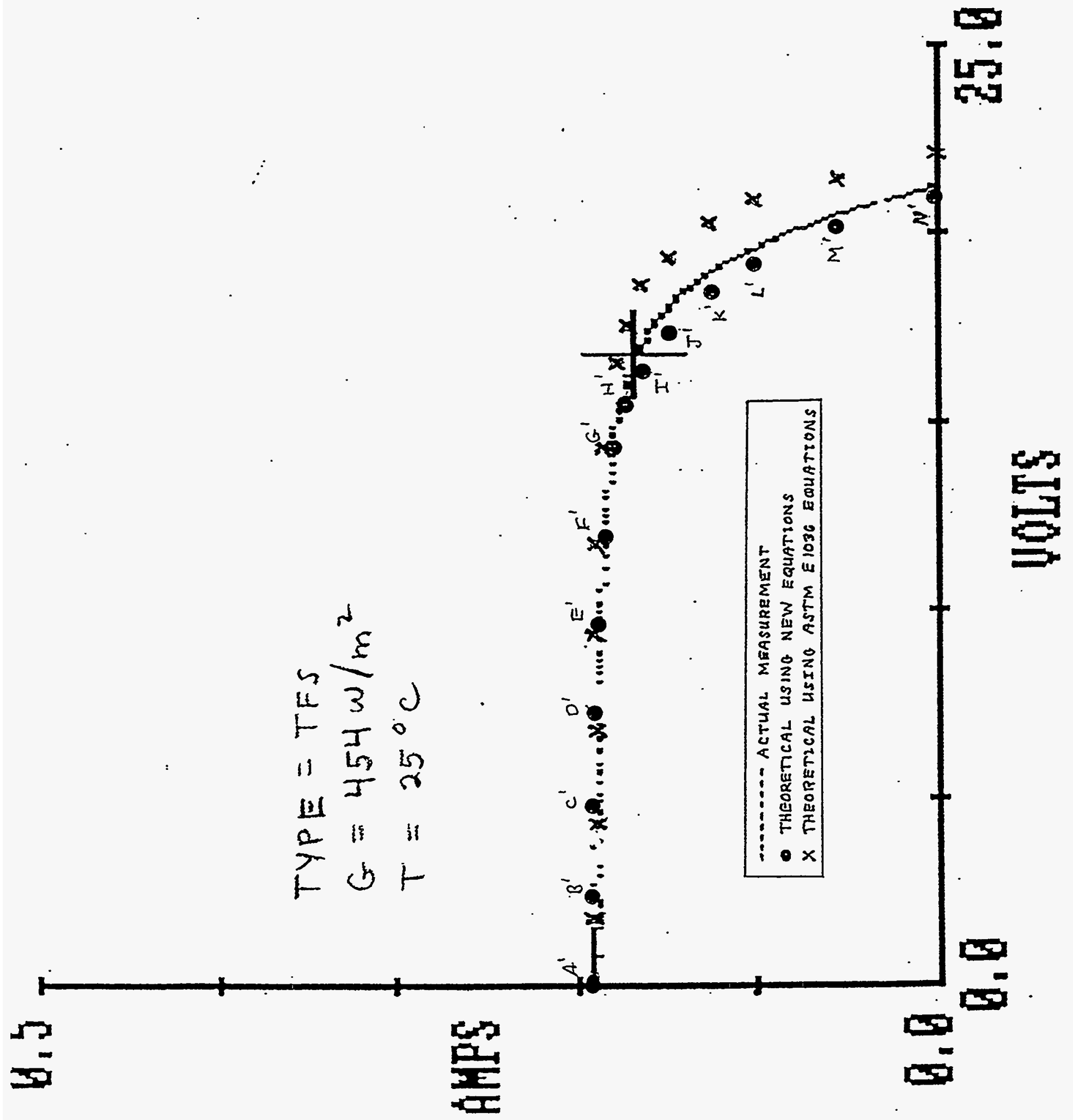




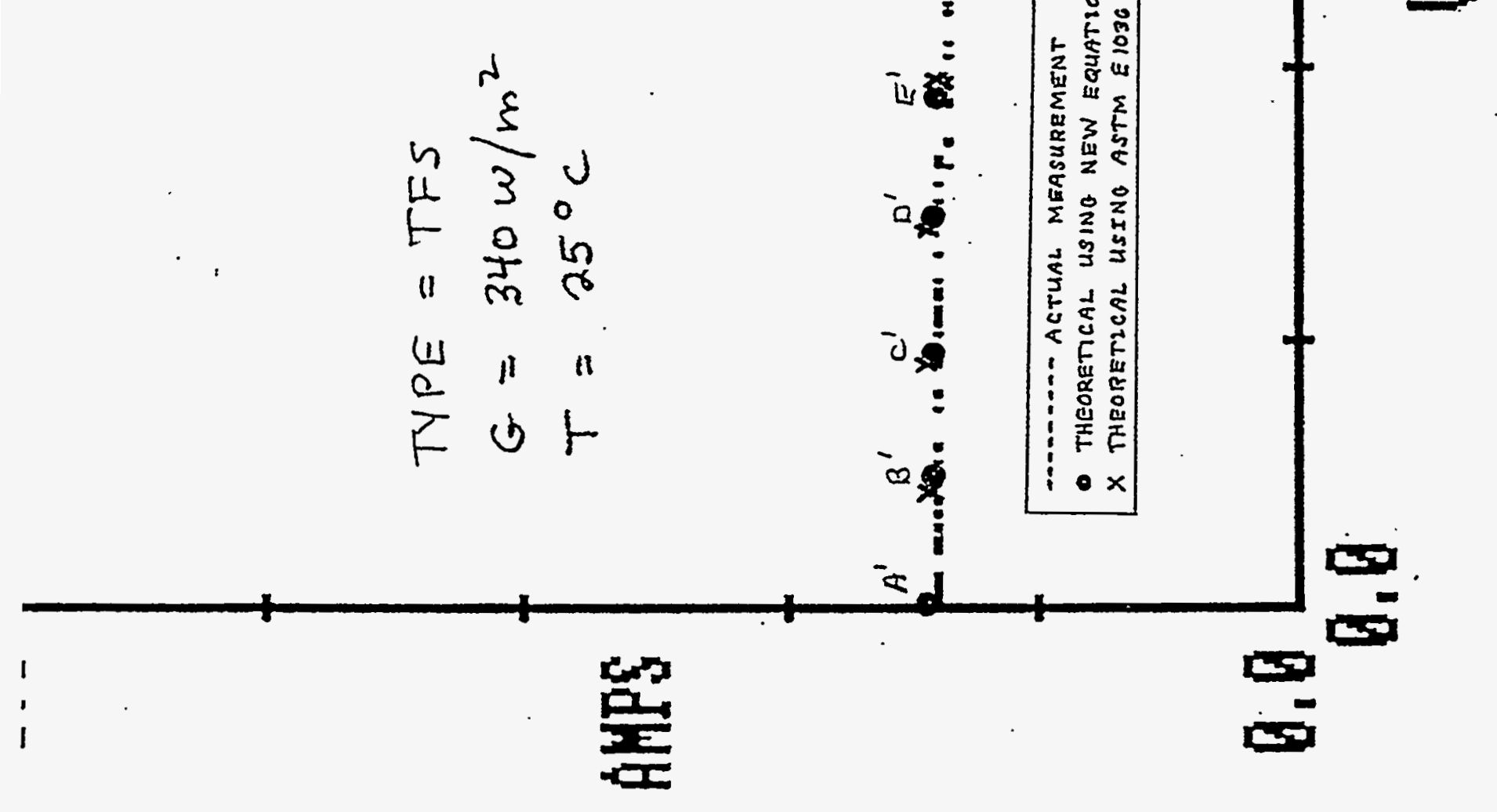




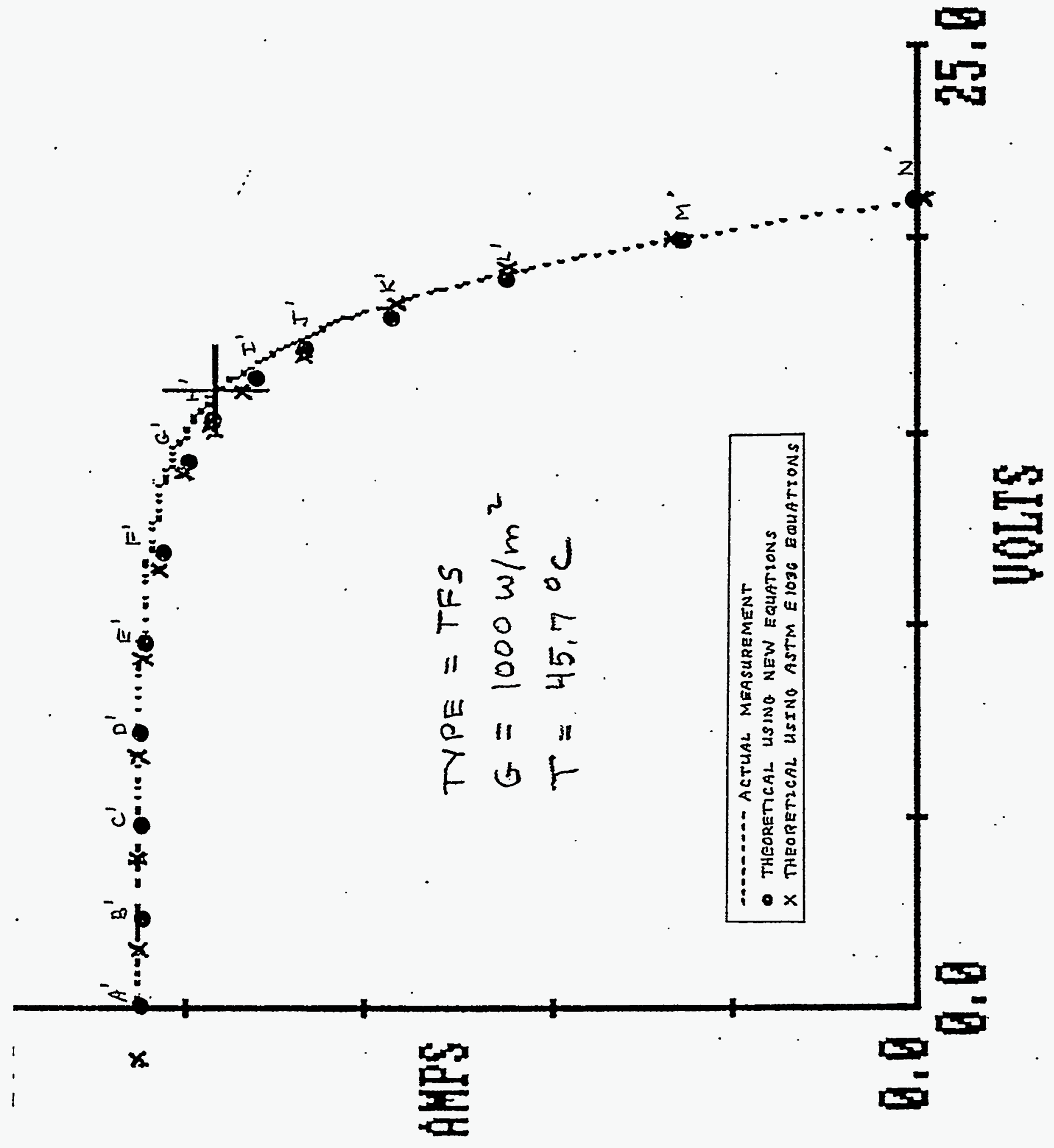




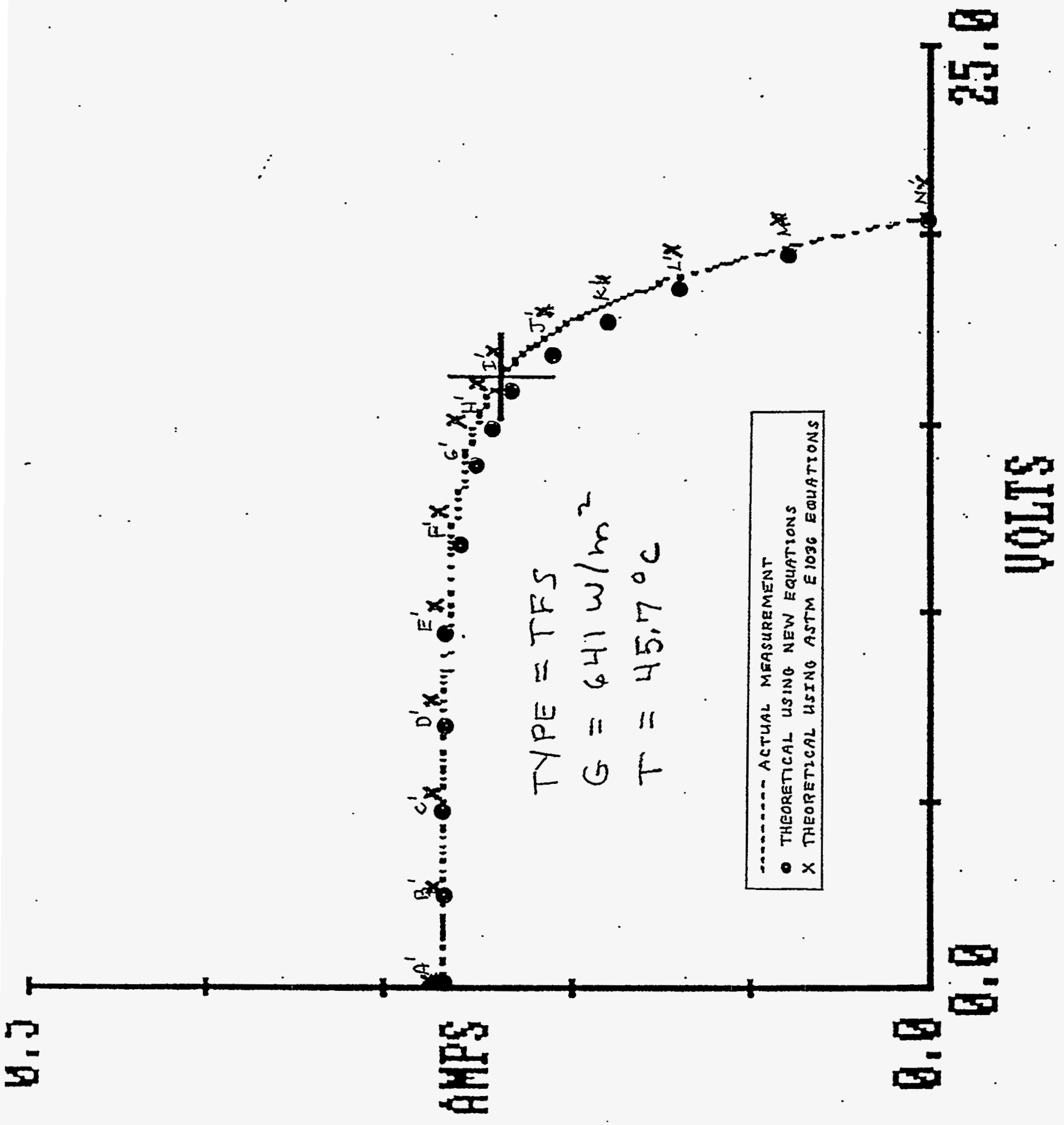




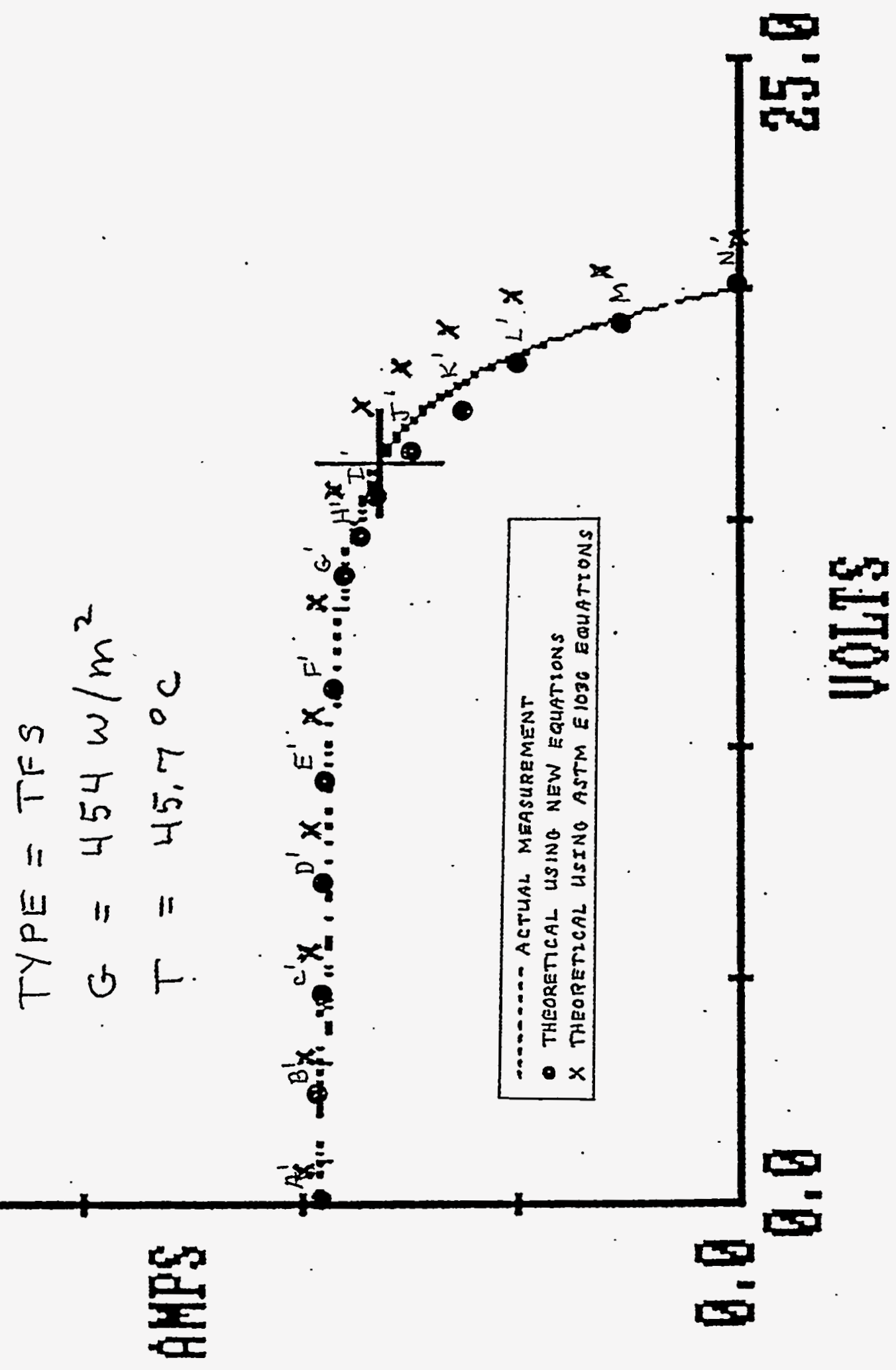




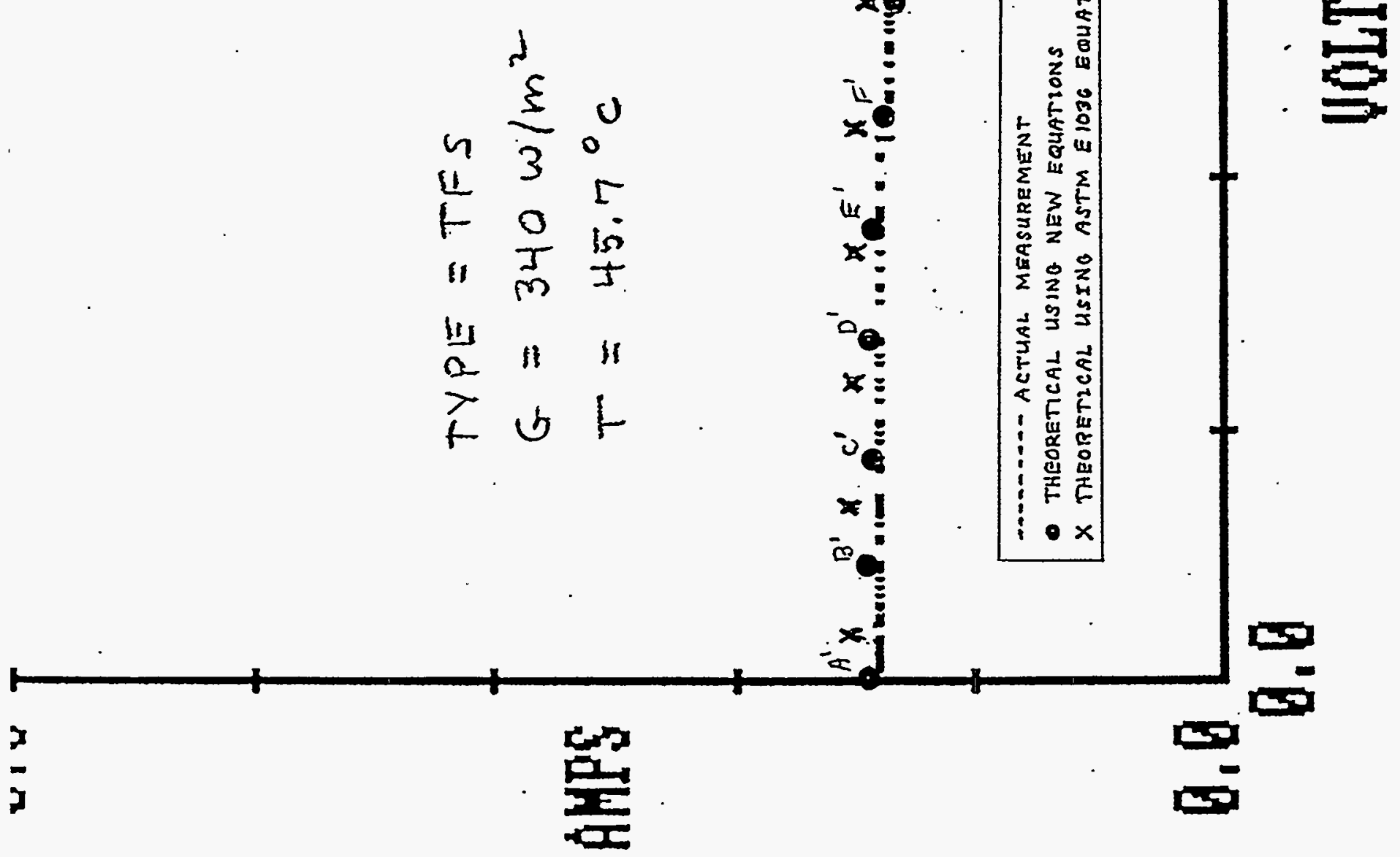




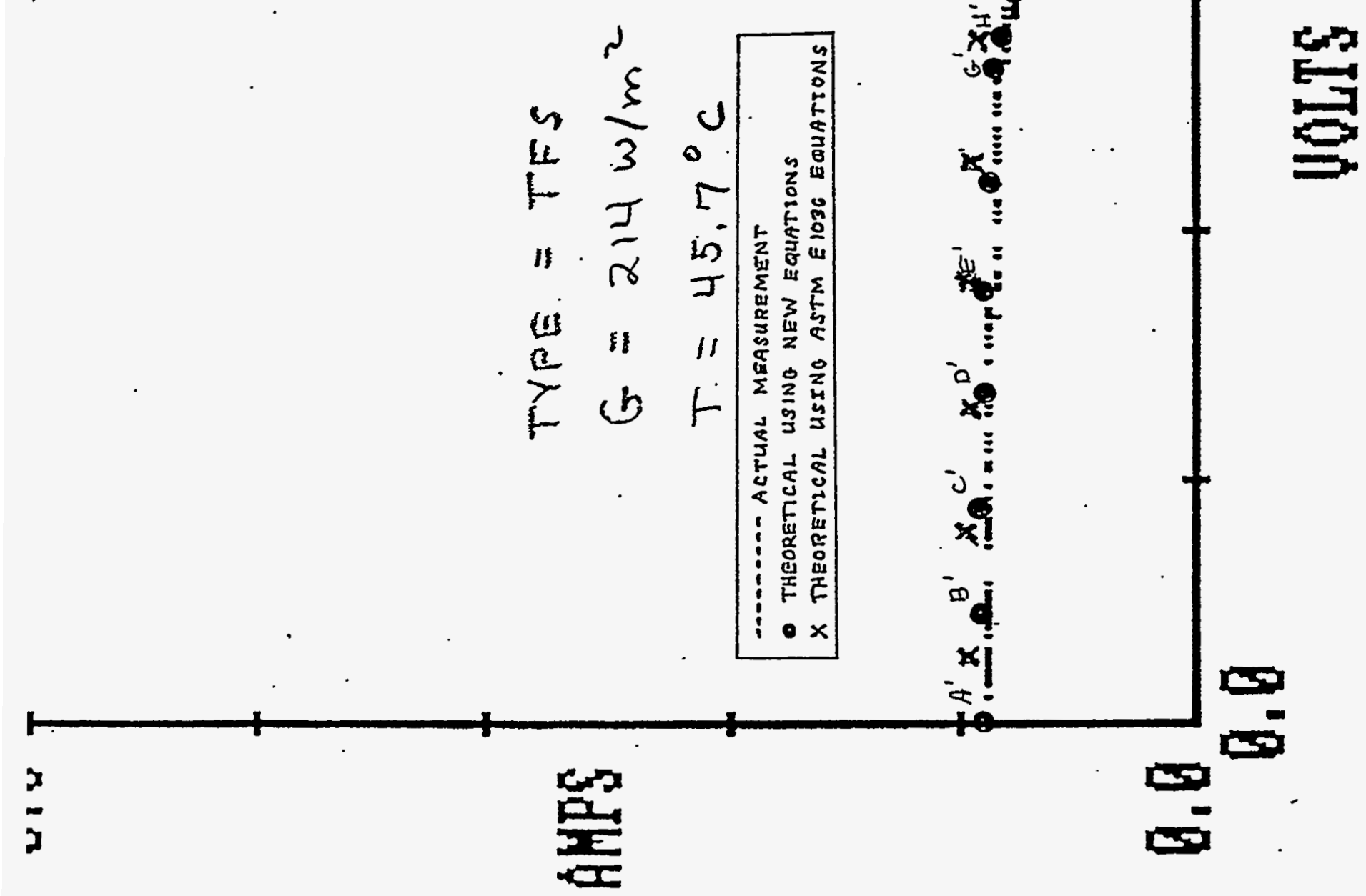




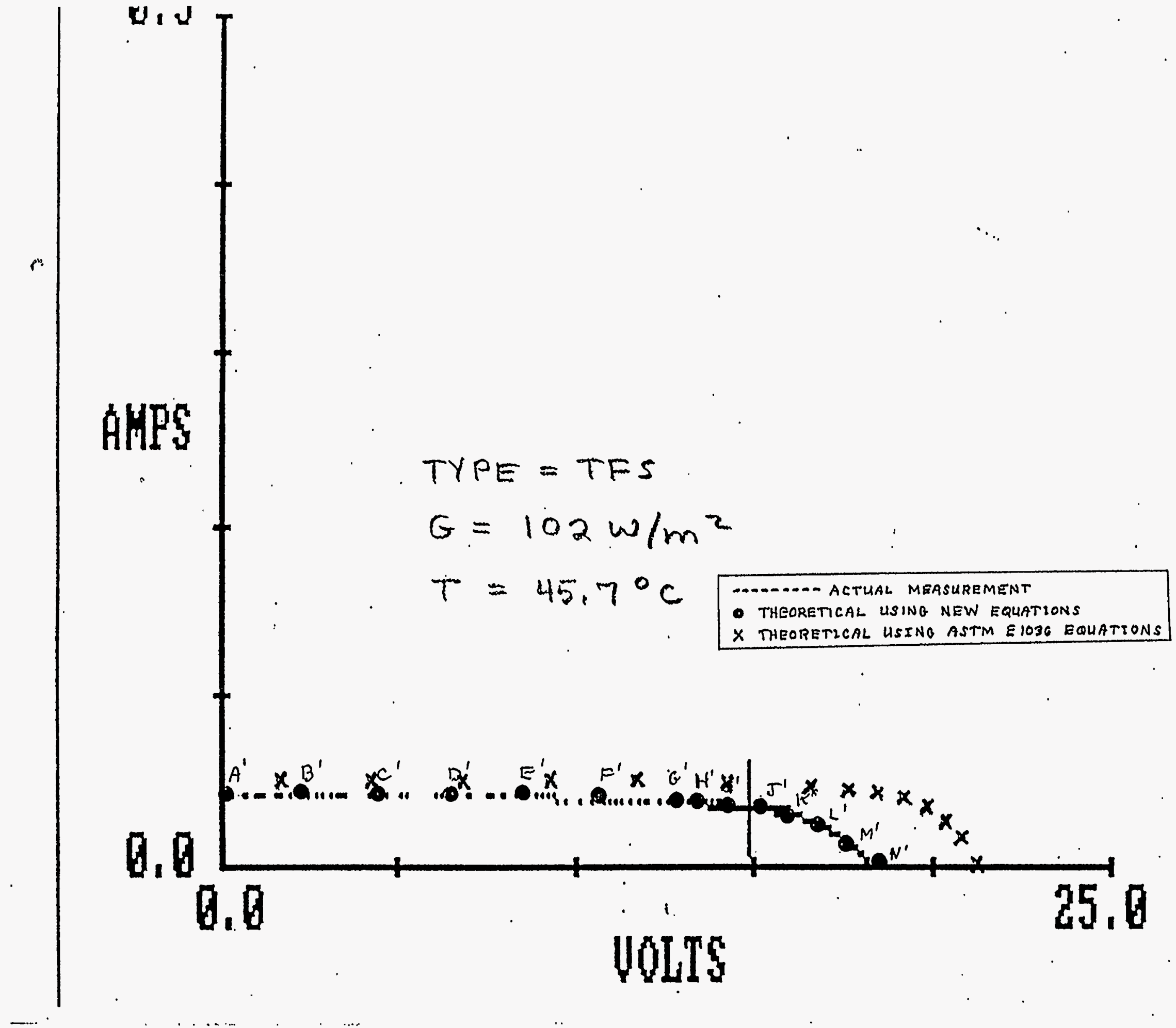




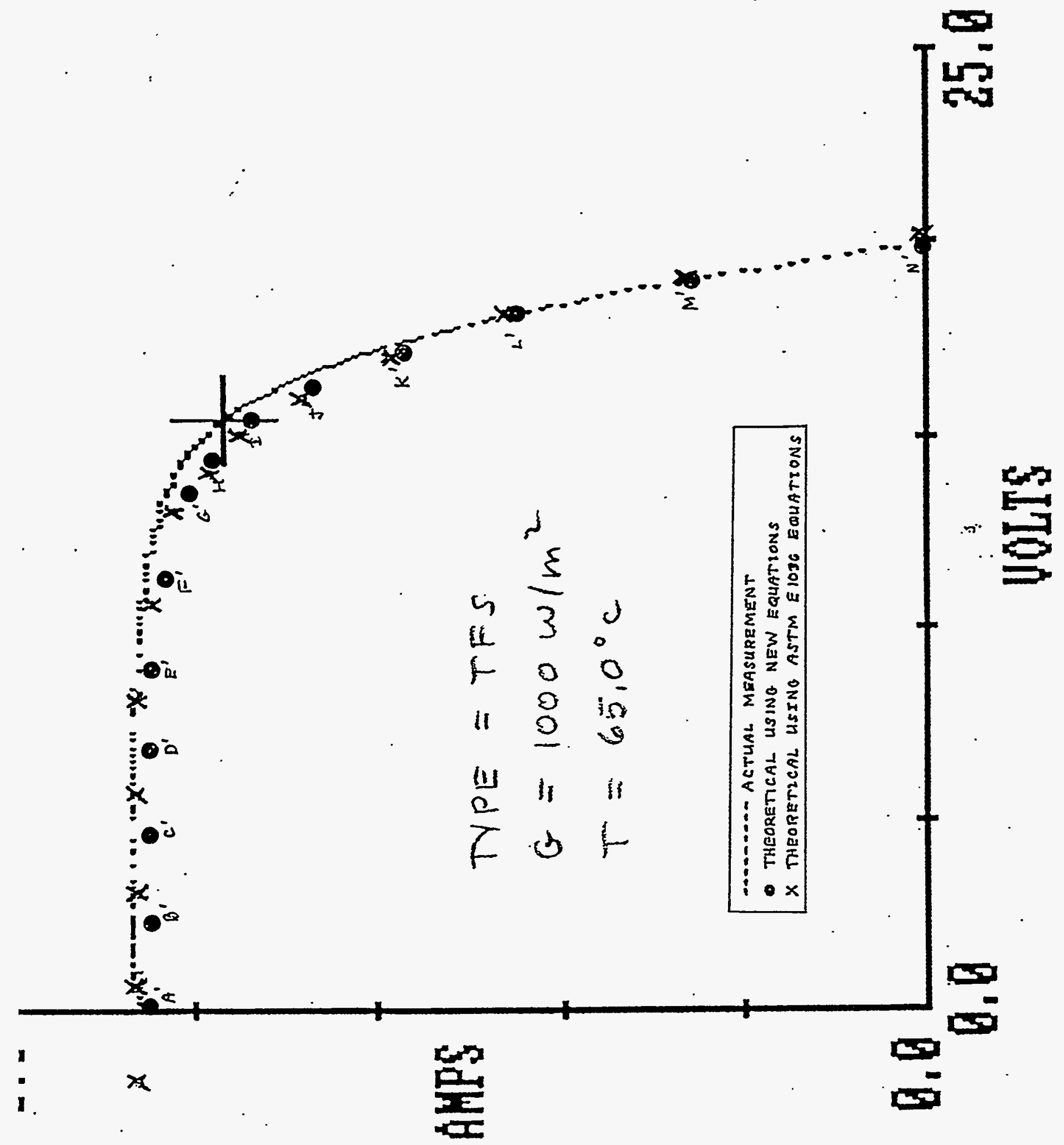




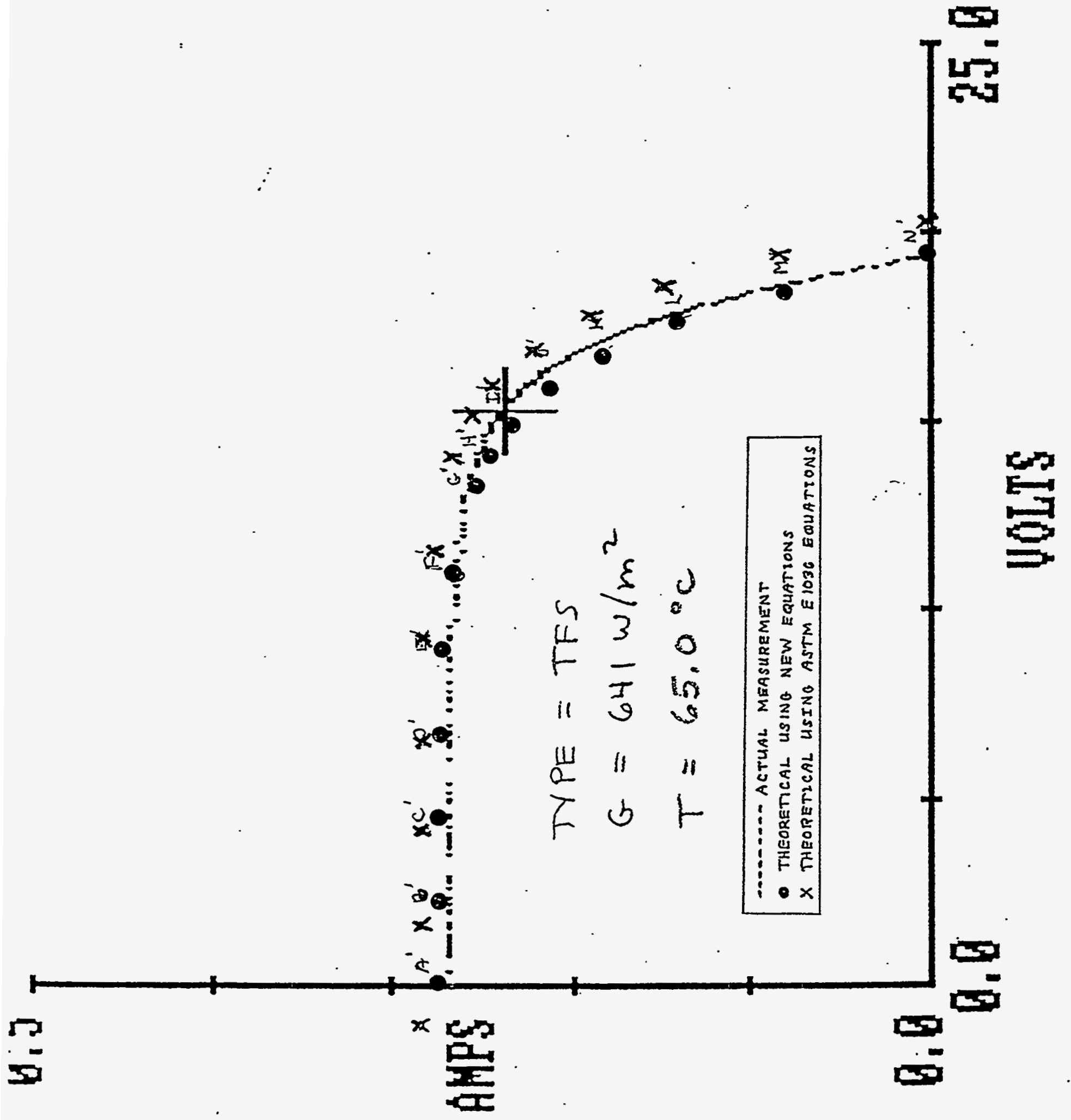




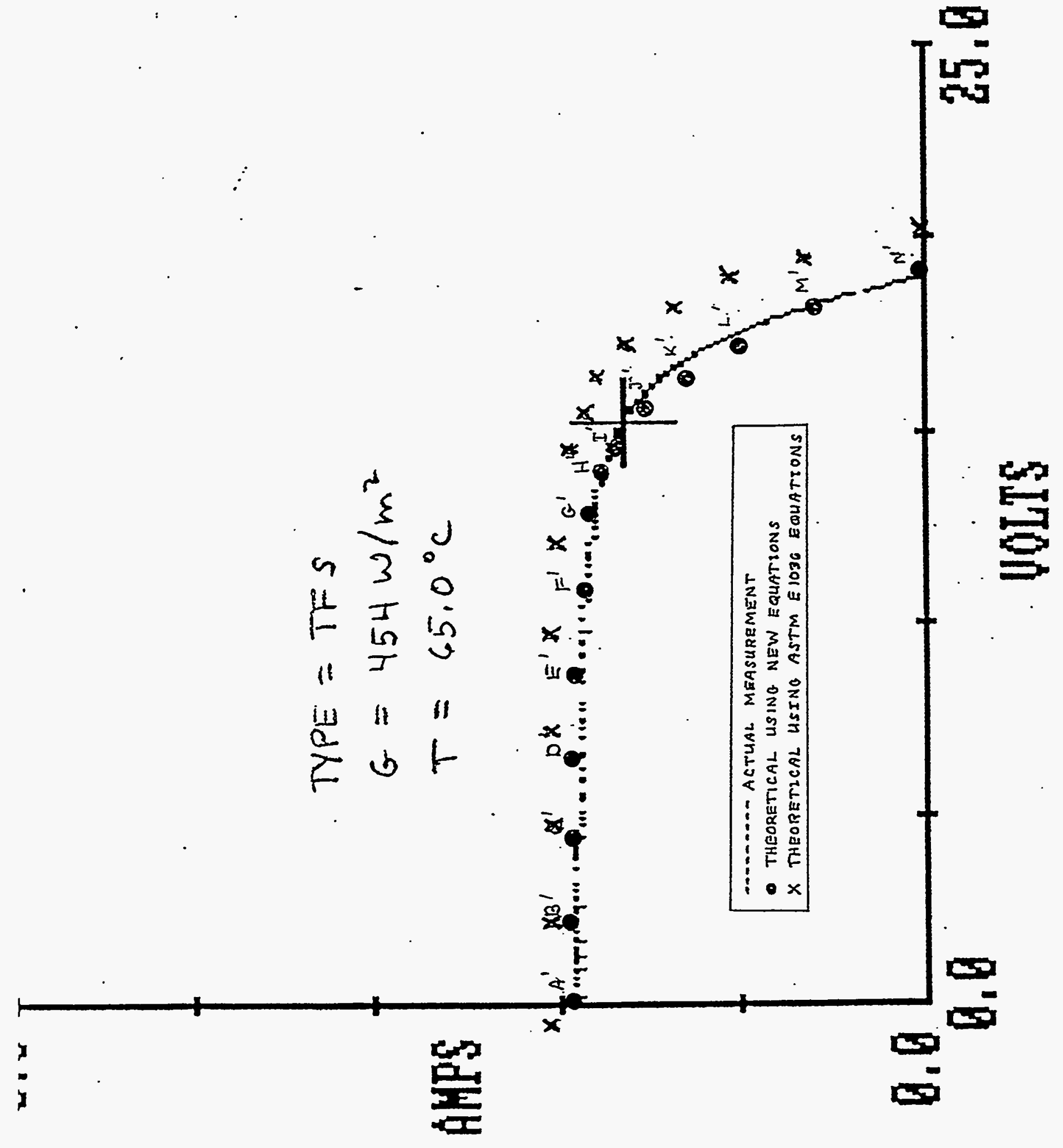





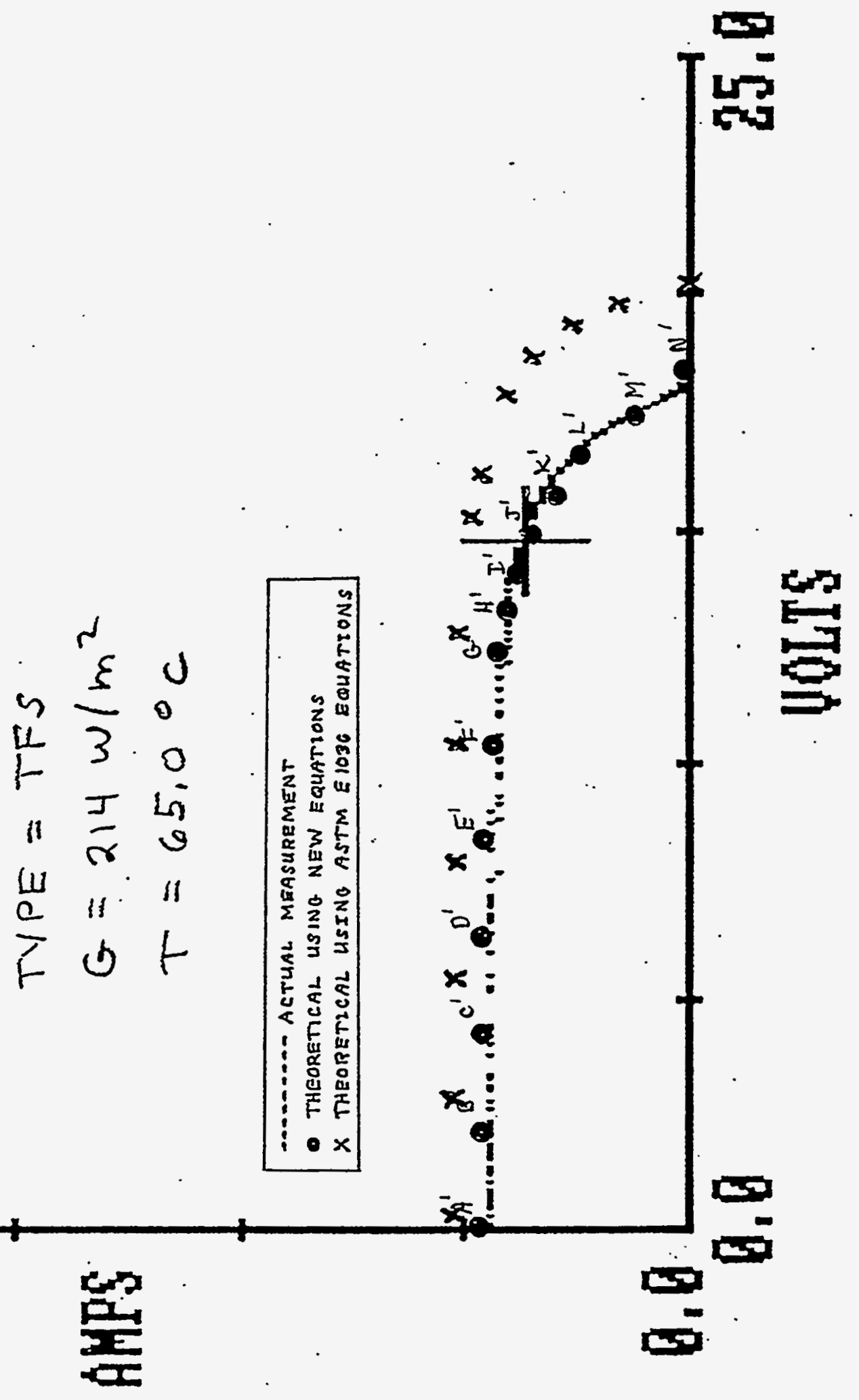




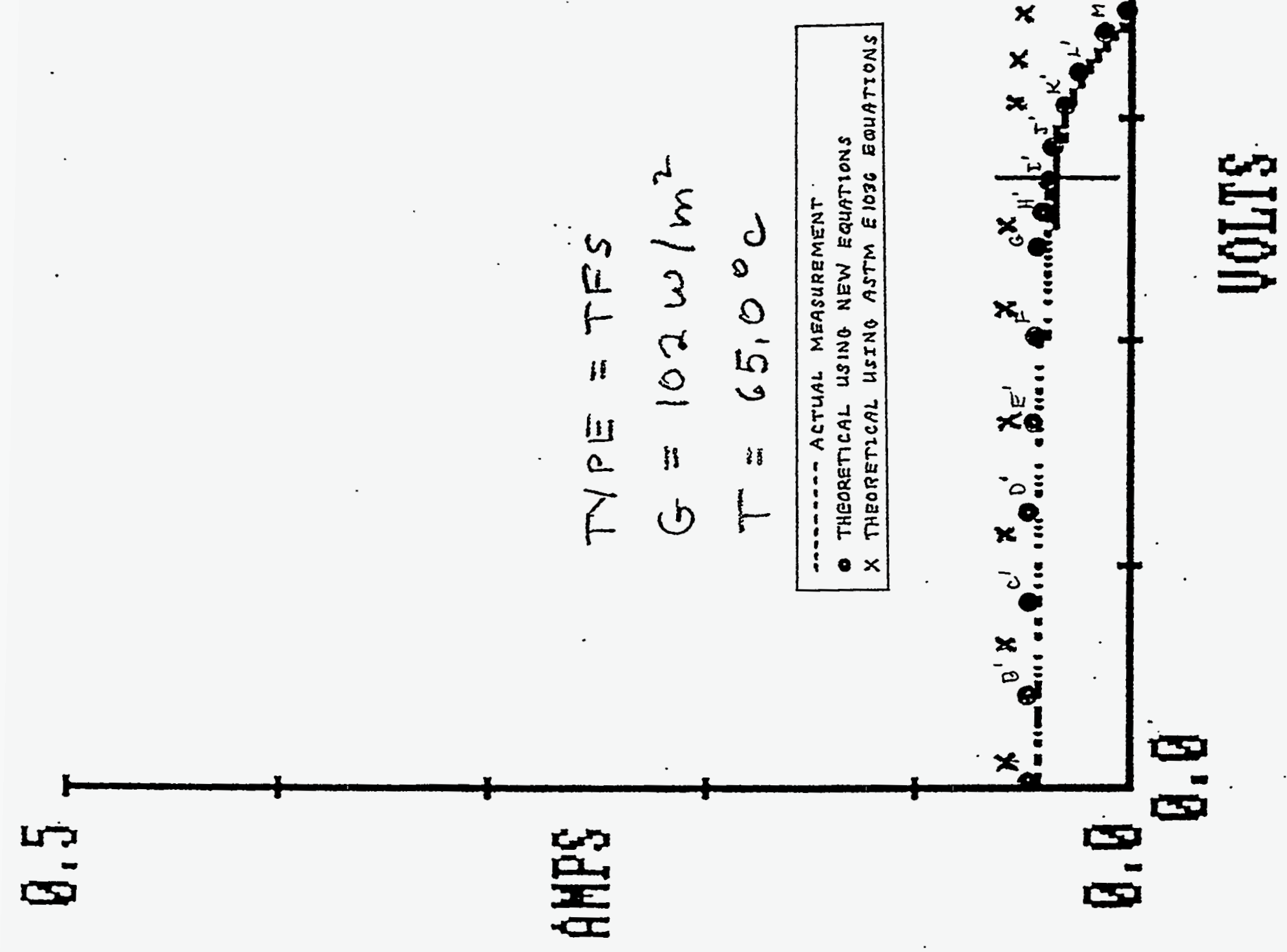




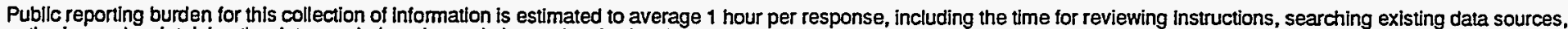

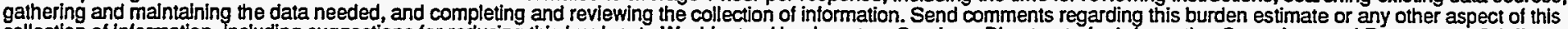

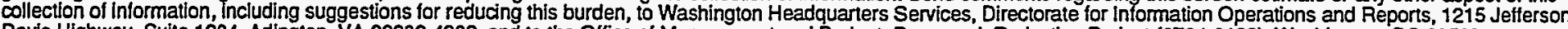
Davis Highway, Suite 1204, Arlington, VA 22202-4302, and to the Office of Management and Budget. Paperwork Reduction Project (0704-0188), Washington, DC 20503.
1. AGENCY USE ONLY (Leave blank)
2. REPORT DATE January 1996
3. REPORT TYPE AND DATES COVERED Final Subcontract Report

4. TITLE AND SUBTITLE

5. FUNDING NUMBERS

Photovoltaic Translation Equations: A New Approach

C: $T A D-4-14166-01$

6. AUTHOR(S)

TA: PV660103

A. J. Anderson

7. PERFORMING ORGANIZATION NAME(S) AND ADDRESS(ES)

Sunset Technology

3388 W. Oak Leaf Place

Highlands Ranch, CO 80126

9. SPONSORINGMONITORING AGENCY NAME(S) AND ADDRESS(ES)

National Renewable Energy Laboratory

1617 Cole Blvd.

Golden, CO 80401-3393

8. PERFORMING ORGANIZATION REPORT NUMBER

10. SPONSORINGMONITORING AGENCY REPORT NUMBER

TP-411-20279

DE96000507

11. SUPPLEMENTARY NOTES

NREL Technical Monitor: L. Mrig

12a. DISTRIBUTION/AVAILABILITY STATEMENT

12b. DISTRIBUTION CODE

UC-1260

\section{ABSTRACT (Maximum 200 words)}

New equations were developed for the purpose of evaluating the performance of photovoltaic cells, modules, panels, and arrays. These equations enable the performance values determined at one condition of temperature and irradiance to be translated to any other condition of temperature and irradiance. The equations were developed to satisfy the following goals: (1) The equations should more accurately translate the short-circuit current and the open-circuit voltage $\left(V_{o c}\right)$. In particular, the influence of irradiance on $V_{o c}$ should be more accurately treated. (2)The equations should more accurately and more simply translate the $1-V$ curve data point pairs, $l_{i}$ and $V_{i}$. ( 3 ) The equations should be based on the use of dimensionless coefficients such that $\alpha$ and $\beta$ have units of ${ }^{\circ} \mathrm{C}^{-1}$ and not, for example, amps $/{ }^{\circ} \mathrm{C}$ or volts $/{ }^{\circ} \mathrm{C}$. (4) An equations should be developed for translating the maximum power without involving the translation of $\mathrm{I}_{\text {se, }}$ $\mathrm{V}_{o c}$ or any $\mathrm{I}-\mathrm{V}$ data pairs. The data presented in this report show good agreement between the analytical predictions made with the new equations versus actual test measurements and superior performance when compared to the current translation equations.

\section{SUBJECT TERMS}

equations ; photovoltaics ; solar cells
15. NUMBER OF PAGES 135

16. PRICE CODE

20. LIMITATION OF ABSTRACT

UL

\author{
OF REPORT \\ Unclassified
}

18. SECURITY CLASSIFICATION OF THIS PAGE Unclassified
19. SECURITY CLASSIFICATION OF ABSTRACT Unclassified
Standard Form 298 (Rev. 2-89) Prescribed by ANSI Std. 239-18 


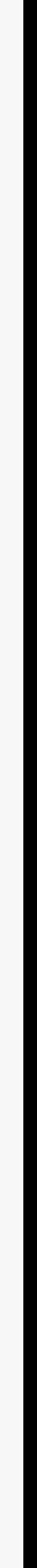




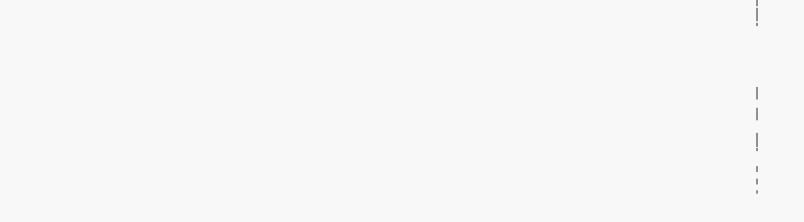

